\author{
Universidade de São Paulo \\ Instituto de Física
}

\title{
Aplicação da técnica de Luminescência Opticamente Estimulada em Fototerapia para determinar a energia entregue em meios iluminados com Laser ou LED nas faixas do vermelho e infravermelho
}

\author{
Raphael Henrique de Carvalho Alves
}

Orientador: Profa. Dra. Elisabeth Mateus Yoshimura

Dissertação de Mestrado apresentada ao Instituto de Física para a obtenção do título de Mestre em Ciências

Banca Examinadora:

Prof. Dr. Elisabeth Mateus Yoshimura (IFUSP)

Prof. Dr. Mikiya Muramatsu (IFUSP)

Prof. Dr. Martha Simões Ribeiro (IPEN) 


\section{FICHA CATALOGRÁFICA \\ Preparada pelo Serviço de Biblioteca e Informação do Instituto de Física da Universidade de São Paulo}

Alves, Raphael Henrique de Carvalho

Aplicação da técnica de luminescência opticamente estimulada em fototerapia para determinar a energia entregue em meios iluminados com laser ou LED nas faixas do vermelho e infravermelho. São Paulo, 2017.

Dissertação (Mestrado) - Universidade de São Paulo. Instituto de Física. Depto. de Física Nuclear

Orientador: Profa. Dra. Elisabeth Mateus Yoshimura

Área de Concentração: Física

Unitermos: 1. Luminescência; 2. Dosimetria luminescente;

3. Fototerapia; 4. Laser terapêutico.

USP/IF/SBI-002/2017 
"Já levou 500 socos na cara em uma noite só? Depois de um tempo começa a doer"

Rocky Balboa 
Aos meus alunos que me fazem enxergar e ter esperança todos os dias que este mundo é maravilhoso. 


\section{AGRADECIMENTOS}

A professora Beth que com muita paciência e dedicação me ajudou a construir este projeto e se mostrou um grande exemplo pessoal e profissional de cientista e professor.

A minha mãe e meus irmãos que durante todo este período, mesmo passando por diversos dificuldades, me apoiavam em todas as situações.

A minha avó Maria Amélia por todo o amor, carinho e dedicação e por deixar sua estória de vida como exemplo a ser seguido.

A meus tios, primos e familiares que sempre me apoiaram e confiaram me dando força para seguir em frente.

A Nancy, Chico e Martha e outros técnicos do Laboratório de Dosimetria das Radiações e Física Médica que me ensinaram e me ajudaram e, devido a isso, tiveram um papel importante na execução deste trabalho.

As professoras Ana Regina e Emico, que todos os dias me ensinam a leveza de viver e a humildade de ser um cientista.

Aos professores Nora e Vito que proporcionaram a minha entrada neste mundo científico.

A Aline, Arthur, Camila, Fabi, Felipe, Janaina, Jessica, Karlos, Kinho, Marçal, Marcela, Mary, Natalia, Ricardo, Roberta, Ulisses, Vagnão e Will que foram a minha segunda família durante todo este período e seguraram diversas barras comigo.

Ao Bruno, Felipe, Felisberto, Ícaro, Lelas, Leonardo, LM, Viktor e Aline por serem grandes parceiros no café, no instituto e em muitas discussões.

Ao professor Paulo e aos outros alunos e companheiros do Laboratório de Dosimetria das Radiações e Física Médica que todos os dias me ensinam e mostram a quantidade de coisas a serem aprendidas.

A Priscila que se tornou uma grande amiga e uma pessoa da qual nunca quero me separar.

A Carol pela importante participação no período deste trabalho.

A Gabi e à Katia por serem as mais belas parceiras que um físico pode ter.

Ao pessoal da Samba \& Cia por serem tão importantes e me proporcionar diversos momentos de alegria e descontração.

A todos os outros que, ao menos com um pouco de tempo, me acompanharam nessa trajetória me dando força e incentivo para sempre continuar indo em frente.

A CPG-IFUSP por todo o apoio e ajuda necessário para o término deste trabalho.

A CAPES e CNPq pelo apoio financeiro. 


\section{RESUMO}

Alguns ramos da Medicina vêm empregando lasers ou LEDs de baixa potência em diversas especialidades. Estes lasers e LEDs são classificados como luz de baixa potência (LBP) e são usados na área de Fototerapia com comprimentos de onda na faixa do vermelho e do infravermelho.

Por outro lado, a área de dosimetria utiliza dispositivos (dosímetros) capazes de estimar a energia depositada devido a exposição prévia à radiação ionizante usando luz visível como estímulo para obtenção de um sinal luminoso - esta técnica é a luminescência opticamente estimulada (OSL). O objetivo deste trabalho é avaliar a possibilidade de estimar a energia entregue por iluminação com laser e LED de baixas potências com comprimentos de onda na faixa do vermelho e infravermelho, utilizados na Fototerapia, empregando a dosimetria OSL.

Foram empregados dosímetros de óxido de alumínio, óxido de berílio e fluorita natural, irradiados previamente com radiação beta (dose absorvida de aproximadamente $50 \mathrm{mGy}$ ), e iluminados com laser de $658 \mathrm{~nm}$ ou LED de $870 \mathrm{~nm}$. Utilizamos o laser com potências de 10, 20, 50 e $100 \mathrm{~mW}$, na faixa de energias de 0,1 a 13,2 J, e os LEDs com potências de 14,5, 58,0 e 130,5 mW, com faixa de energia entre 0,2 e 23,5 J. Para a medida de OSL foi utilizado o leitor TL/OSL Ris $\varnothing$ (modelo TL/OSL-DA20) no modo de leitura CW-OSL e estimulo com LED de luz azul de $72 \mathrm{~mW}$. A análise das curvas de emissão OSL foi feita observando tendências na modificação do sinal inicial OSL (integrado no primeiro $1 \mathrm{~s}$ de leitura) e no sinal OSL total (integrado em $100 \mathrm{~s}$ ) normalizados por sinal OSL obtido para irradiação padronizada.

Os resultados obtidos mostraram que a iluminação com laser de $658 \mathrm{~nm}$ reduz 0 sinal OSL das amostras de óxido de alumínio para energias entre $\sim 0,1$ e $\sim 12 \mathrm{~J}$, e o sinal OSL de fluorita em uma faixa de energias mais baixa, entre 0,1 e $4 \mathrm{~J}$. Para a iluminação com LED de $870 \mathrm{~nm}$ somente as amostras de fluorita mostraram redução do sinal OSL, no intervalo de 0,1 e 15 J de energia luminosa incidente; essa mudança foi mais acentuada para o sinal inicial da curva OSL do que para o sinal integrado. As mudanças observadas são independentes das potências luminosas empregadas. As amostras de óxido de berílio não mostraram mudanças na emissão OSL para nenhum dos feixes de luz no intervalo de energia utilizados.

Além destes resultados também foi observado que a iluminação com diferentes energias luminosas incidentes nas amostras muda o formato das curvas de emissão OSL das amostras de fluorita: o tempo característico de decaimento das curvas de emissão cresce à medida que mais energia luminosa (infravermelho) é depositada nas amostras.

Os resultados mostraram que a técnica OSL poderia ser utilizada para a avaliar de energia luminosa incidente no óxido de alumínio, iluminado com laser de $658 \mathrm{~nm}$, e na fluorita natural, iluminada com LED de $870 \mathrm{~nm}$. Para a fluorita, a mudança nas curvas de emissão OSL das amostras também pode estar relacionada com a energia luminosa incidente nela, fato que deverá ser mais bem estudado em trabalhos posteriores. 


\section{ABSTRACT}

Some branches of Medicine are using low power lasers and LEDs in various specialties. These devices are classified as low-power or low-level lasers and LEDs and they are used in phototherapy in the red and infrared wavelength range.

On the other hand, in dosimetry some devices (dosimeters) are used to estimate the deposited energy due to a previous exposure to ionizing radiation through a visible light stimulus to get a light signal - this technique is the optically stimulated luminescence (OSL). The objective of this study is to evaluate the possibility of assessing the energy delivered by illumination with laser and LED in the red and infrared wavelength ranges, used in the phototherapy, using the OSL technique.

OSL dosimeters of aluminum oxide, beryllium oxide and natural fluorite were used. They were previously exposed to beta radiation (absorbed dose of about $50 \mathrm{mGy}$ ) and illuminated with $658 \mathrm{~nm}$ laser or $870 \mathrm{~nm}$ LED. The laser powers were 10, 20, 50 and $100 \mathrm{~mW}$, and the light energy was in the range 0.1 to $13.2 \mathrm{~J}$; and the chosen LED powers were $14.5,58.0,130.5 \mathrm{~mW}$, delivering energies in the range 0.2 to $23.5 \mathrm{~J}$. The OSL emission curves were measured with the TL/OSL Ris $\varnothing$ (TL/OSL-DA-20 model), CW-OSL mode, stimulating light provided by blue LEDs of $72 \mathrm{~mW}$. The analysis of the OSL curves was carried out through the observation of trends in the variations of initial OSL signal (integrated in the first $1 \mathrm{~s}$ ) and the whole OSL signal (integrated in $100 \mathrm{~s}$ ) normalized by an OSL signal due to a standard irradiation.

The results showed that the illumination with $658 \mathrm{~nm}$ laser reduces the OSL signal from aluminum oxide samples in the energy range between $\sim 0.1$ and $\sim 12 \mathrm{~J}$, and from fluorite in the energy range from $\sim 0.1$ to $\sim 4 \mathrm{~J}$. For the $870 \mathrm{~nm}$ LED illumination, only fluorite samples showed a reduction in the OSL signal in the range from $\sim 0.1$ to $15 \mathrm{~J}$ of incident light energy. This change was more pronounced for the initial OSL signal than for the integrated signal. The observed changes were independent of the light power used in the illumination. The OSL signal of beryllium oxide samples showed no changes for any of the light beams used.

It was also observed that illumination with different incident light energy changes the shape of fluorite OSL curves. The characteristic decay time of the emission curves grows as the light energy (infrared) deposited on the samples of fluorite increases.

The results showed that the OSL technique could be used to evaluate the light energy incident on aluminum oxide, illuminated with $658 \mathrm{~nm}$ laser, and on fluorite, illuminated with $870 \mathrm{~nm}$ LED. For fluorite samples, the change in the OSL emission curve can also be related to the incident light energy. This fact needs further studies for a better understanding. 


\section{LISTA DE FIGURAS}

Figura 1. Esquema que exemplifica os processos que ocorrem na quando a luz atravessa dois meios. Figura Adaptada (Huang, Chen, \& Hamblin, 2009) de (Niemz, 2004).....

Figura 2. Espectro de absorção de tecidos. Figura adaptada de (Huang, Chen, \& Hamblin, 2009).

Figura 3. Diagrama de níveis de energia para elétrons. As linhas horizontais representam estados de energia permitidos para os elétrons. As regiões em cinza representam a junção de estados permitidos. Na figura, a) representa os níveis permitidos para o elétron livre, b) os níveis para o elétron preso em um potencial do tipo oscilador harmônico, c) o elétron em um poço de potencial e d) o elétron ligado a um conjunto poços de potenciais. Adaptado de (Yukihara \& McKeever, 2011).

Figura 4. Representação dos estados na banda proibida causados por defeitos. Os estados com energia logo abaixo da BC são as armadilhas de elétrons. Os estados com energia logo acima da BV são as armadilhas de buracos. Os estados com energia intermediária são os centros de recombinação. Figura adaptada de (Yukihara \& McKeever, 2011) .......................................... 8 Figura 5. Esquema representando o fenômeno de luminescência estimulada. O processo de excitação leva as cargas elétricas as bandas deslocalizadas para armadilhas. Após um estímulo, as cargas retornam as bandas deslocalizadas e se recombinam nos CR liberando os fótons de luminescência. Figura adaptada de (Yukihara \& McKeever, 2011)

Figura 6. Exemplo de curva TL para os processos de primeira ordem. Os picos indicam a presença de armadilhas na amostra e só dependem da energia de ativação E e da constante s.

Figura 7. Exemplo de curvas OSL obtidas com o modo de estímulo CW-OSL. (a) exemplos curvas OSL obtidas com vários valores da concentração inicial de elétrons armadilhados apresentada como função de $n 0$ e o mesmo valor de $p O S L$. Neste caso, o valor inicial muda, mas o formato da curva (taxa de decaimento) se mantém o mesmo. (b) exemplos de curvas obtidas com mesmo valor $n 0$ para a concentração de elétrons armadilhados e diferentes valores de $p O S L$. Para estes casos o formato da curva muda, mas a área total permanece a mesma. 14

Figura 8. Exemplo de curva obtida no modo CW-OSL em comparação com o modo LM-OSL... 16 Figura 9. Esquema de estimulo da amostra na P-OSL. (a) estímulo ótico, ou pulso e (b) estado do obturador do sistema de deteç̧ão da luz de luminescência.

Figura 10. O sinal OSL na P-OSL com duração de pulso com $10 \%$ do tamanho da vida média da amostra. Para (a), (b), (c) e (d) a frequência do pulso foi aumentada e, em consequência, o

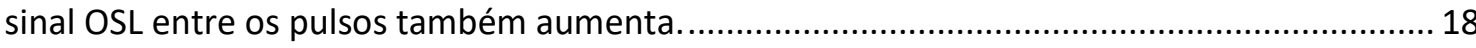

Figura 11. Foto do equipamento emissor laser MMO Twin Flex Laser.................................... 19 Figura 12. Leitor TL/OSL Ris $\emptyset$ do Grupo de Dosimetria das Radiações e Física Médica do IFUSP.

Figura 13. Espectro de transmissão dos filtros disponibilizados pelo leitor TL/OSL Ris $\varnothing$. Retirado de (Malthez, 2015).

Figura 14. Espectro de emissão dos LEDs e espectro de transmissão dos filtros disponíveis para utilização do equipamento Ris $\varnothing$ (Riso DTU, 2010).

Figura 15. Amostras utilizadas de óxido de alumínio, óxido de berílio e fluorita, respectivamente.

Figura 16. Espectro de emissão(a) e excitação(b) OSL do óxido de alumínio irradiado com 1 Gy. O espetro de emissão foi obtido com a iluminação da amostra a luz de excitação de 550nm e foi medido com o filtro Schott OG-515 a frente do tubo fotomultiplicador. 0 espectro de 
estimulação foi obtido através da iluminação da amostra por luz de diversos comprimentos de onda e leitura da luz de luminescência fixa em 380 nm. Reimpresso de Yukihara \&

McKeever(2011)

Figura 17. Foto do banco ótico montado para as leituras da curva de potência do equipamento

MMO Twin Flex Laser.

Figura 18. Exemplificação do método utilizado para estimar a influência do fading no sinal OSL das amostras. O tempo de espera é o tempo dado entre a iluminação e a leitura OSL dos dosímetros.

Figura 19. Curva OSL da amostra de Luxel. O sinal integrado OSL sem a influência da iluminação de fundo (área verde), a curva com o valor médio do fundo extrapolado durante todo o intervalo da curva OSL devido ao fundo e sinal integrado OSL sem a influência do mesmo (área cinza) são evidenciados.

Figura 20. Curva de variação da potência do equipamento MMO Twin Flex Laser par as potências de 10, 20, 50 e $100 \mathrm{~mW}$. No gráfico, as retas horizontais representam as potências de $10,20,50$ e $100 \mathrm{~mW}$.

Figura 21. Curva de variação da potência normalizada para o valor máximo da curva de potência do equipamento MMO Twin Flex Laser para as potências de 10, 20, 50 e 100mW. .. 33 Figura 22. Variação do sinal inicial OSL normalizado ao primeiro ponto para os experimentos de iluminação das amostras de óxido de alumínio com laser de $658 \mathrm{~nm}$ e potências de 10,20 , 50 e $100 \mathrm{~mW}$ em função da energia luminosa incidente nos dosímetros.

Figura 23: Variação do sinal inicial OSL relativo para os experimentos de iluminação das amostras de óxido de alumínio com laser de $658 \mathrm{~nm}$ e potências de 10, 20, 50 e 100mW em função da energia luminosa incidente nos dosímetros.

Figura 24 Variação do sinal inicial OSL relativo normalizado para os experimentos de iluminação das amostras de óxido de alumínio com laser de $658 \mathrm{~nm}$ e potências de 10, 20, 50 e $100 \mathrm{~mW}$ em função da energia luminosa incidente nos dosímetros.

Figura 25. Variação do sinal integrado OSL normalizado ao primeiro ponto das amostras de óxido de alumínio iluminadas por laser de $658 \mathrm{~nm}$ e potências de 10, 20, 50 e 100mW em função da energia luminosa incidente nas mesmas.

Figura 26 Variação do sinal integrado OSL relativo das amostras de óxido de alumínio iluminadas por laser de $658 \mathrm{~nm}$ e potências de 10, 20, 50 e 100mW em função da energia luminosa incidente nos dosímetros.

Figura 27 Variação do sinal integrado OSL relativo normalizado ao primeiro ponto das amostras de óxido de alumínio iluminadas por laser de $658 \mathrm{~nm}$ e potências de 10, 20, 50 e 100mW em função da energia luminosa incidente nos dosímetros.

Figura 28. Variação do sinal inicial OSL normalizado para o primeiro ponto dos experimentos com iluminação das amostras de óxido de alumínio com LED de 870nm e potências de $130,5 \mathrm{~mW}$ em função da energia luminosa incidente nos dosímetros.

Figura 29. Variação do sinal inicial OSL relativo para os experimentos de iluminação das amostras de óxido de alumínio com LED de $870 \mathrm{~nm}$ e potências de 130,5mW em função da energia luminosa incidente nos dosímetros.

Figura 30. Comparação da variação do sinal inicial OSL e do sinal relativo normalizados ambos ao respectivo primeiro ponto para os experimentos de iluminação das amostras de óxido de alumínio com LED de $870 \mathrm{~nm}$ e potências de $130,5 \mathrm{~mW}$ em função da energia luminosa incidente nos dosímetros.

Figura 31. Variação do sinal integrado OSL para os experimentos de iluminação das amostras de óxido de alumínio com LED de $870 \mathrm{~nm}$ e potências de $130,5 \mathrm{~mW}$ em função da energia luminosa incidente nos dosímetros. 
Figura 32. Variação do sinal integrado OSL relativo para os experimentos de iluminação das amostras de óxido de alumínio com LED de $870 \mathrm{~nm}$ e potências de 130,5mW em função da energia luminosa incidente nos dosímetros.

Figura 33. Comparação da variação do sinal integrado OSL e sinal relativo normalizado ambos ao respectivo primeiro ponto para os experimentos de iluminação das amostras de óxido de alumínio com LED de $870 \mathrm{~nm}$ e potências de $130,5 \mathrm{~mW}$ em função da energia luminosa incidente nos dosímetros.

Figura 34 Variação do sinal inicial OSL das amostras de óxido de berílio iluminadas por laser de $658 \mathrm{~nm}$ e potências de 10,20, 50 e $100 \mathrm{~mW}$ em função da energia luminosa incidente nas mesmas.

Figura 35. Variação do sinal inicial OSL relativo normalizado das amostras de óxido de berílio iluminadas por laser de $658 \mathrm{~nm}$ e potências de 10, 20, 50 e 100mW em função da energia luminosa incidente nos dosímetros.

Figura 36. Variação do sinal integrado OSL normalizado ao primeiro ponto das amostras de óxido de berílio iluminadas por laser de $658 \mathrm{~nm}$ e potência de 10, 20, 50 e $100 \mathrm{~mW}$ em função da energia luminosa incidente nas mesmas.

Figura 37. Variação do sinal integrado OSL relativo das amostras de óxido de berílio iluminadas por laser de $658 \mathrm{~nm}$ e potência de 10, 20, 50 e 100mW em função da energia luminosa incidente nas mesmas.

Figura 38. Variação do sinal inicial OSL normalizado para o primeiro ponto dos experimentos com iluminação das amostras de óxido de berílio com LED de $870 \mathrm{~nm}$ e potências de $130,5 \mathrm{~mW}$ em função da energia luminosa incidente nos dosímetros.

Figura 39. Variação do sinal inicial OSL relativo normalizado para o primeiro ponto dos experimentos com iluminação das amostras de óxido de berílio com LED de 870nm e potências de 130,5mW em função da energia luminosa incidente nos dosímetros.

Figura 40. Variação do sinal integrado OSL normalizado para o primeiro ponto dos experimentos com iluminação das amostras de óxido de berílio com LED de 870nm e potências de $130,5 \mathrm{~mW}$ em função da energia luminosa incidente nos dosímetros.

Figura 41. Variação do sinal integrado OSL relativo normalizado para o primeiro ponto dos experimentos com iluminação das amostras de óxido de berílio com LED de 870nm e potências de 130,5mW em função da energia luminosa incidente nos dosímetros.

Figura 42. Variação do sinal inicial OSL normal e relativo normalizado de amostras de fluorita em função do tempo de espera sem iluminar.

Figura 43. Variação do sinal inicial OSL de amostras de fluorita em função do tempo de espera sem iluminar. Uma reta $f(x)$ foi ajustada aos dados experimentais e os parâmetros ajustados foram colocados em destaque.

Figura 44. Variação do sinal inicial OSL relativo de amostras de fluorita em função do tempo de espera sem iluminar. Uma reta $f(x)$ foi ajustada aos dados experimentais e os parâmetros ajustados foram colocados em destaque.

Figura 45. Variação da fração de tempo de espera antes da segunda irradiação comparado com o tempo de espera antes da primeira irradiação em função da ordem de leitura OSL dos dosímetros.

Figura 46. Variação do sinal integrado OSL normal e relativo normalizado de amostras de fluorita em função do tempo de espera sem iluminar. .

Figura 47. Variação do sinal integrado OSL de amostras de fluorita em função do tempo de espera sem iluminar. Uma reta $f(x)$ foi ajustada aos dados experimentais e os parâmetros ajustados foram colocados em destaque. 
Figura 48. Variação do sinal integrado OSL relativo de amostras de fluorita em função do tempo de espera sem iluminar. Uma reta $f(x)$ foi ajustada aos dados experimentais es parâmetros ajustados foram colocados em destaque.

Figura 49. Variação do sinal inicial OSL normalizado para o primeiro ponto das amostras de fluorita iluminadas por laser de $658 \mathrm{~nm}$ e potências de 10, 20, 50 e $100 \mathrm{~mW}$ em função da energia luminosa incidente nas mesmas.

Figura 50. Variação do sinal inicial OSL relativo normalizado para o primeiro ponto das amostras de fluorita iluminadas por laser de $658 \mathrm{~nm}$ e potências de 10, 20, 50 e $100 \mathrm{~mW}$ em função da energia luminosa incidente nos dosímetros.

Figura 51. Variação do sinal integrado OSL normalizado par o primeiro ponto das amostras de fluorita iluminadas por laser de $658 \mathrm{~nm}$ e potência de 10, 20, 50 e $100 \mathrm{~mW}$ em função da energia luminosa incidente nas mesmas.

Figura 52. Variação do sinal integrado OSL relativo normalizado para o primeiro ponto das amostras de fluorita iluminadas por laser de $658 \mathrm{~nm}$ e potências de 10, 20, 50 e 100mW em função da energia luminosa incidente nos dosímetros.

Figura 53 .Variação do sinal inicial OSL das amostras de fluorita iluminadas por LED de 870nm e potências de 14,5; 58 e 130,5mW em função da energia luminosa incidente nas mesmas...... 54 Figura 54 Variação do sinal inicial OSL relativo das amostras de fluorita iluminadas por LED de $870 \mathrm{~nm}$ e potências de 14,5; 58 e 130,5mW em função da energia luminosa incidente nas mesmas.

Figura 55. Variação do sinal inicial OSL relativo normalizado ao primeiro ponto das amostras de fluorita iluminadas por LED de 870nm e potências de 14,5; 58 e 130,5mW em função da energia luminosa incidente nas mesmas.

Figura 56. Variação do sinal integrado OSL das amostras de fluorita iluminadas por LED de $870 \mathrm{~nm}$ e potências de 14,5; 58 e 130,5mW em função da energia luminosa incidente nas mesmas.

Figura 57. Variação do sinal integrado OSL relativo das amostras de fluorita iluminadas por LED de $870 \mathrm{~nm}$ e potências de 14,5; 58 e 130,5mW em função da energia luminosa incidente nas mesmas.

Figura 58. Variação do sinal integrado OSL relativo normalizado ao primeiro ponto das amostras de fluorita iluminadas por LED de $870 \mathrm{~nm}$ e potências de 14,$5 ; 58$ e 130,5mW em função da energia luminosa incidente nas mesmas.

Figura 59. Curvas OSL das amostras de óxido de alumínio iluminadas previamente por laser de $658 \mathrm{~nm}$ e potência de $10 \mathrm{~mW}$ com os tempos descritos na legenda.

Figura 60. Curvas OSL das amostras de óxido de alumínio iluminadas previamente por laser de $658 \mathrm{~nm}$ e potência de $20 \mathrm{~mW}$..

Figura 61. Curvas OSL das amostras de óxido de alumínio iluminadas previamente por laser de $658 \mathrm{~nm}$ e potência de $50 \mathrm{~mW}$.

Figura 62.. Curvas OSL das amostras de óxido de alumínio iluminadas previamente por laser de $658 \mathrm{~nm}$ e potência de $100 \mathrm{~mW}$. 59

Figura 63. Curvas OSL das amostras de fluorita iluminadas previamente por LED 870nm e potência de $14,5 \mathrm{~mW}$.

Figura 64. Curvas OSL das amostras de fluorita iluminadas previamente por LED 870nm e potência de $58 \mathrm{~mW}$.

Figura 65. Curvas OSL de amostras de fluorita iluminadas previamente por LED 870nm e potência de $130,5 \mathrm{~mW}$.

Figura 66. Curva OSL das amostras de óxido de alumínio iluminadas com mesma energia, mas potências e tempos de iluminação diferentes. 
Figura 67. Curva OSL das amostras de fluorita iluminadas com mesma energia, mas potências e tempos de iluminação diferentes 


\section{Sumário}

Agradecimentos

V

Resumo.

Erro! Indicador não definido.

Abstract

Erro! Indicador não definido.

Lista de Figuras .vi

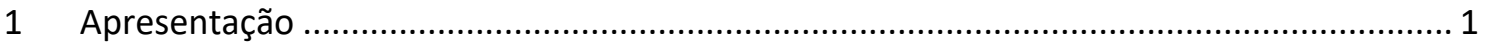

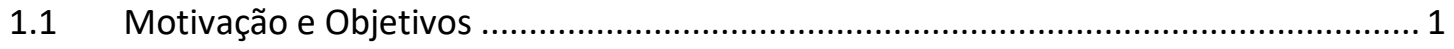

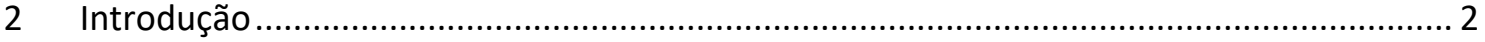

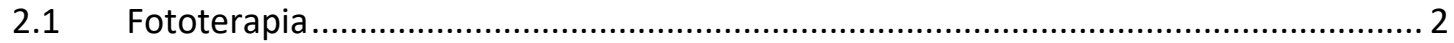

2.1.1 Histórico da Fototerapia.................................................................... 2

2.1.2 Interações da Luz com a Matéria ............................................................ 2

2.1.3 Terapia com Laser de Baixa Potência (TLBP) ......................................... 4

2.2 Dosimetria por Luminescência ................................................................... 6

2.2.1 Modelo de Bandas e Defeitos em Cristais.................................................. 6

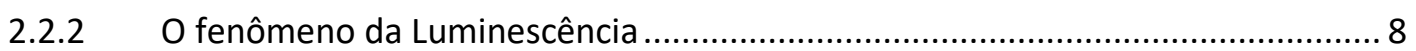

2.2.3 Termoluminescência $(\mathrm{TL})$...................................................................... 10

2.2.4 Luminescência Opticamente Estimulada (OSL) .......................................... 11

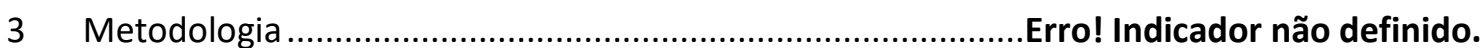

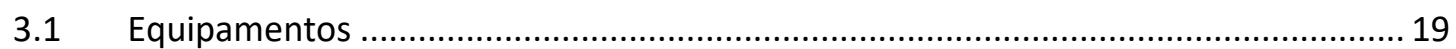

3.1.1 Aparelho para Fototerapia Twin Flex Evolution............................................ 19

3.1.2 Leitor TL/OSL Ris $\varnothing$ (modelo TL/OSL-DA-20) ................................................ 20

3.1.3 Medidor de potência Ophir LaserStar .................................................... 22

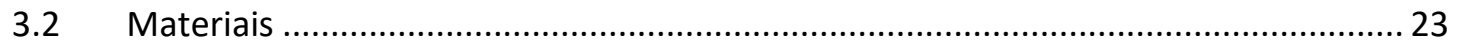

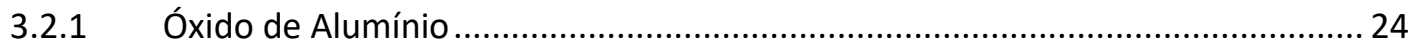

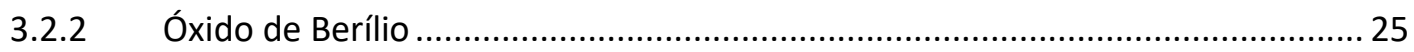

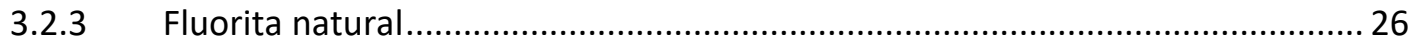

3.3 Metodologia empregada nos experimentos ................................................... 26

3.3.1 Estudo da variação da potência luminosa emitida pelo MMO Twin Flex em função do tempo ................................................................................................ 27

3.3.2 Estudo da variação do sinal OSL em função da iluminação das amostras......... 27

3.3.3 Estudo do Fading (Desvanecimento) de sinal OSL de amostras de Fluorita ....... 29

3.3.4 Metodologia de análise do sinal OSL nos experimentos............................... 30

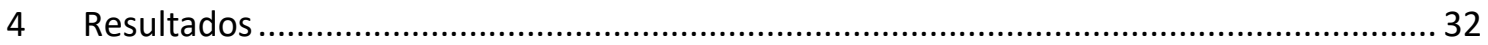


4.1 Estudo da variação da potência luminosa emitida pelo MMO Twin Flex em função do tempo 32

4.2 Estudo da Variação do Sinal OSL em função da Energia Luminosa incidente nos dosímetros

4.2.1 Estudo da influência da lluminação com laser vermelho (658nm) e LED infravermelho $(870 \mathrm{~nm})$ no Sinal OSL para dosímetros de Óxido de Alumínio 34

4.2.2 Estudo da influência da lluminação no Sinal OSL para dosímetros de Óxido de Berílio 41

4.2.3 Estudo da influência da Energia Luminosa em dosímetros de Fluorita $\left(\mathrm{CaF}_{2}\right) \ldots . .46$

4.2.4 Estudo das curvas OSL para as amostras de Óxido de Alumínio e Fluorita .........57

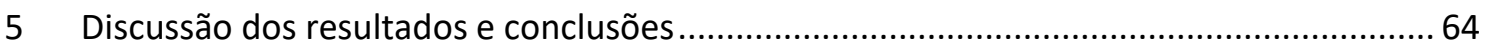

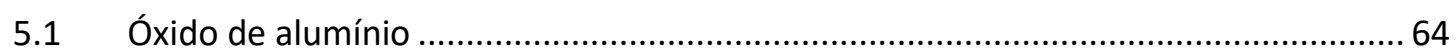

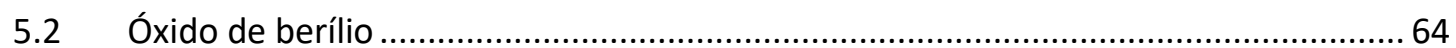

5.3 Fluorita ....................................................................... Indicador não definido.

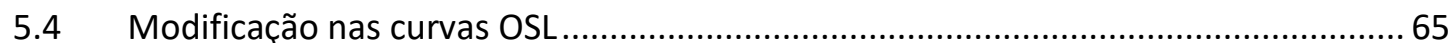

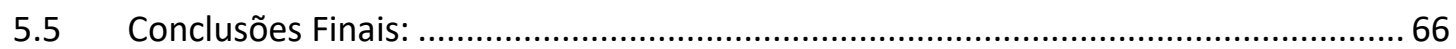

6 Obras Citadas

Erro! Indicador não definido. 


\section{APRESENTAÇÃO}

\subsection{Motivação e Objetivos}

Nos últimos anos, o desenvolvimento de novas tecnologias vem auxiliando em diversas áreas na Medicina. Dentre as tecnologias utilizadas na área médica, há o uso da luz de lasers e LEDs, dada sua interação com o tecido humano. Essa terapia com luz tem sido utilizada em diversas especialidades da Medicina.

Um dos tipos de lasers utilizados são os lasers de baixa potência (LBP) na área chamada, no aspecto mais geral, de Fototerapia. Os tratamentos com estes tipos de lasers têm a característica de não causarem efeitos colaterais devido à baixa potência deles. Estes lasers são utilizados com comprimentos de onda na faixa do vermelho e do infravermelho, que aumentam a penetração no tecido sem que ocorra um aumento de temperatura considerável na região iluminada.

O entendimento do mecanismo bioquímico que governa as interações moleculares com a luz incidente ainda não é inteiramente conhecido e é necessário que ocorram mais estudos sobre o mesmo. Um dos fatores que dificultam o esse entendimento é o grande número de variáveis físicas e biomoleculares que influenciam os resultados. Dentre as variáveis físicas que podem influenciar os resultados esperados são a densidade de potência da luz incidente, densidade de energia, tempo de irradiação, comprimento de onda da luz, etc.

O objetivo deste estudo é verificar a influência de iluminação de lasers e LEDs, com intervalos energias e comprimentos de onda na região empregada pela Fototerapia, em pequenos detectores. A influência será verificada de acordo com mudanças na emissão luminescente destes detectores através da técnica de Luminescência Opticamente Estimulada (OSL). Nossa expectativa é que as mudanças introduzidas permitam usar os detectores para avaliar a quantidade de luz entregue em um tratamento por Fototerapia. 


\section{INTRODUÇÃO}

\subsection{Fototerapia}

\subsubsection{Histórico da Fototerapia}

A Fototerapia teve seus primórdios nos anos 1960 com o professor Endre Mester que observou a influência da incidência de laser em feridas em estado de cicatrização. Em 1966 o professor Mester também observou que o laser He-Ne poderia estimular a cicatrização de feridas e o crescimento de pelos em ratos (Chavantes, 2009). Ele também fez experimentos para o tratamento de úlceras cutâneas difíceis de curar. Nos anos seguintes publicou uma série de estudos que auxiliaram o reconhecimento e uso da Fototerapia na atualidade. Apesar de atualmente não existir um consenso para a medidas dosimétricas do uso da Fototerapia, a mesma vem sendo utilizada em um grande número de campos da saúde (Chung, et al., 2012).

A Fototerapia é a terapia de tratamento de patologias iluminando as regiões do paciente com laser ou LED de baixa potência (até $1 \mathrm{~W}$ ). Ela atua nas células promovendo os processos anti-inflamatórios, cicatriciais, analgésicos e imunológicos, resultando na biomodulação. Isso ocorre devido a uma escolha ótima dos parâmetros da iluminação, como o comprimento de onda. Entre os objetivos dessa técnica estão: a redução da inflamação, edema e dores crônicas; promoção da cicatrização de feridas superficiais e profundas em tecidos normais e neurais além de auxiliar no tratamento de doenças e dores crônicas (Chavantes, 2009) (Chung, et al., 2012).

\subsubsection{Interações da Luz com a Matéria}

A luz é caracterizada de acordo com seu comportamento ondulatório ou corpuscular. Como uma onda ela apresenta os parâmetros físicos de amplitude (que caracteriza o brilho da luz), comprimento de onda (caracteriza a cor da luz) e direção do ângulo de vibração (chamado de polarização). Como corpúsculo, ela é caracterizada por um conjunto de pacotes de energia chamados fótons. A energia de cada pacote é determinada pelo comprimento de onda da luz (Chung, et al., 2012).

Na fototerapia se utilizam com mais frequência os lasers e LEDs como fontes de luz. Cada um apresenta uma característica quanto à luz que produz e isto deve ser levado em consideração no tratamento a ser proposto (Chung, et al., 2012).

O laser é o fenômeno de emissão de luz devido a um processo de emissão estimulada em um meio ativo e ampliação de intensidade óptica. Devido a isto, a luz emitida é caracterizada por ser monocromática e coerente, ou seja, a onda luminosa por ele emitida tem a mesma fase. Os feixes também são colimados e também podem ser polarizados (Chung, et al., 2012). 
Os LEDs são diodos que têm uma junção $p$-n onde ocorre a recombinação de elétrons e buracos resultando em luz emitida. Diferente do laser, a luz do LED não é coerente e também não é monocromática, embora possa ter uma largura de banda estreita. (Chung, et al., 2012).

Quando a luz incide na interface do tecido com o ar podem ocorrer os processos de reflexão, transmissão, difusão (espalhamento) ou absorção (Chavantes, 2009). Cada um deles depende de fatores da luz incidente e de fatores do tecido no qual a luz incide.

O fenômeno da reflexão é caracterizado pelo retorno da luz, em ângulo simétrico ao da entrada, ao meio de origem após ela incidir na interface de dois meios. A reflexão da luz depende do índice de refração de cada meio. Quanto mais diferentes são os índices de refração dos dois meios, maior é a probabilidade de ocorrer a reflexão (Chung, et al., 2012).

No caso de a luz atravessar a interface ainda podem ocorrer os fenômenos de espalhamento e absorção. Em ambos, os fótons de luz interagem com os átomos ou moléculas do meio, mas na absorção o fóton que interage com os átomos do meio é totalmente absorvido pelos mesmos enquanto que no espalhamento o fóton que interage é reemitido, em geral em uma direção diferente da inicial, podendo ou não apresentar uma mudança na energia do fóton. Em geral, a luz que penetra no tecido sofre diversos espalhamentos elásticos (sem mudança do comprimento de onda) até ser absorvida ou sair do meio. O fenômeno da absorção é o responsável pelos efeitos biológicos observados. Nesse caso, a energia do fóton que foi absorvida é utilizada nos processos celulares que são o alvo do tratamento com fototerapia. A intensidade de um feixe colimado de luz após a mesma atravessar uma distância $x$ no meio é função dos coeficientes de absorção $\left(\mu_{a}\right)$ e espalhamento $\left(\mu_{s}\right)$ segundo a equação

$$
I(x)=I_{0} e^{-\left(\mu_{a}+\mu_{s}\right) x}
$$

onde $I(x)$ é a intensidade da luz transmitida na mesma direção da luz incidente, depois que ela atravessou uma espessura $x$ no meio e $I_{0}$ é a intensidade incidente. Ao valor $\mu_{t}=\mu_{a}+\mu_{s}$ denominamos de coeficiente de atenuação total (Chung, et al., 2012). Os fótons restantes no feixe de intensidade $I(x)$ são os fótons que não interagiram no meio, caracterizando o processo de transmissão. A Figura 1 exemplifica os processos que ocorrem na interação da luz com um meio. 


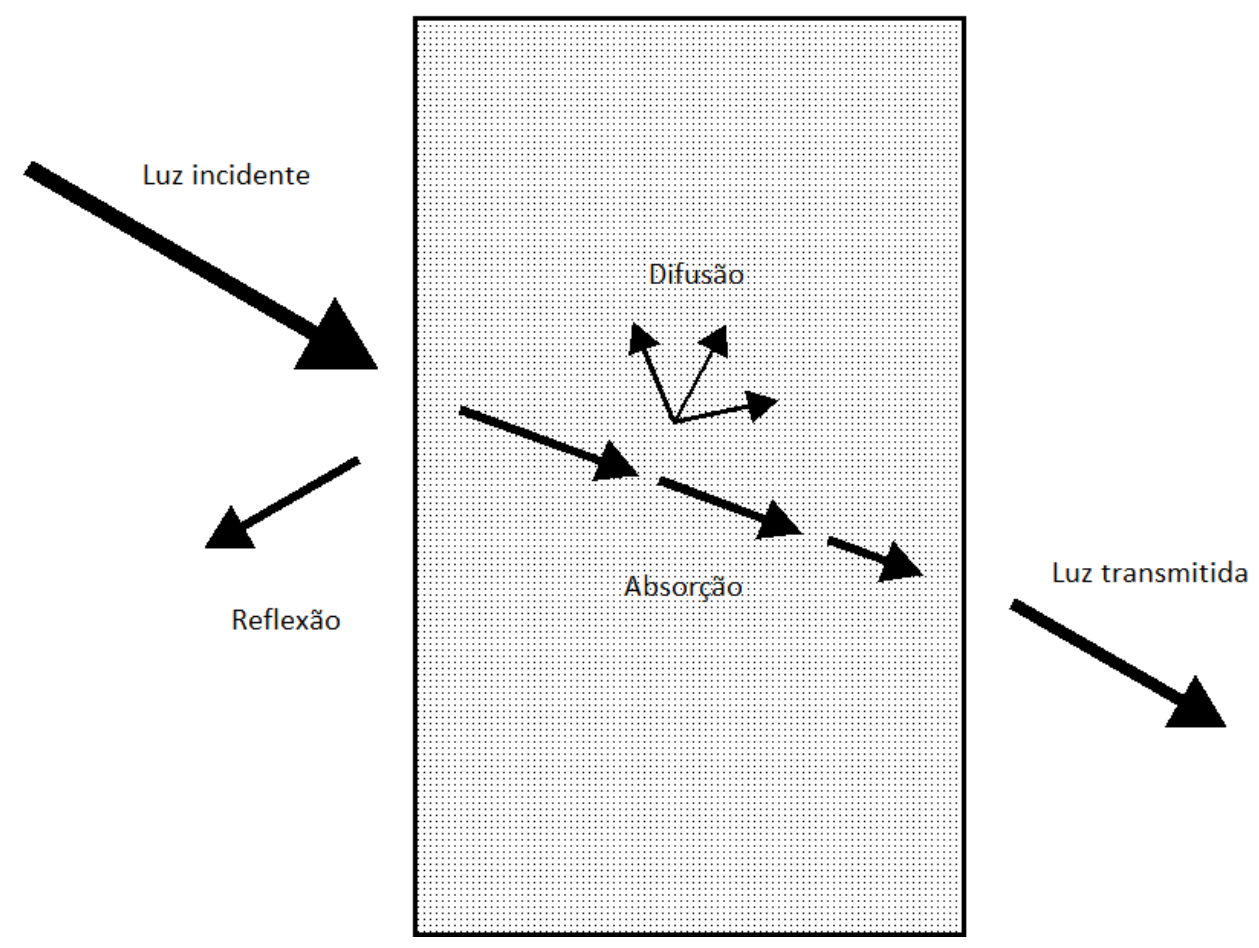

Figura 1. Esquema que exemplifica os processos que ocorrem na quando a luz atravessa dois meios. Figura Adaptada (Huang, Chen, \& Hamblin, 2009) de (Niemz, 2004)

\subsubsection{Terapia com Laser de Baixa Potência (TLBP)}

A utilização de laser nas áreas da saúde pode ser dividida segundo o seu efeito no tecido. Os grupos utilizados são os lasers de alta potência (LAP) ou laser cirúrgico e os lasers de baixa potência (LBP). O grupo dos LAP utilizam lasers de potência acima de $1 \mathrm{~W}$. Utilizam estes tipos de lasers quando se pretendem causar os efeitos fototérmico, fotomecânicoacústico, fotoablativo e fotoionizante (Chavantes, 2009). Neste estudo iremos nos ater aos lasers utilizados na TLBP (Terapia com Laser de Baixa Intensidade).

Os lasers do grupo LBP apresentam potências menores do que $1 \mathrm{~W}$. O que caracteriza o efeito deste grupo é que não ocorre destruição tecidual devido a um aumento significativo da temperatura do tecido em consequência da incidência do laser. Este fato faz com que a terapia com LBP apresente um efeito acumulativo da dose agindo como moduladora dos processos biológicos no tecido.

A TLBP trabalha com comprimentos de onda na "janela óptica" do vermelho ao infravermelho próximo (600-1400nm). Este é o intervalo onde ocorre uma menor absorção de luz pelos tecidos biológicos, proporcionando uma penetração maior da luz, como pode ser observado na Figura 2. 


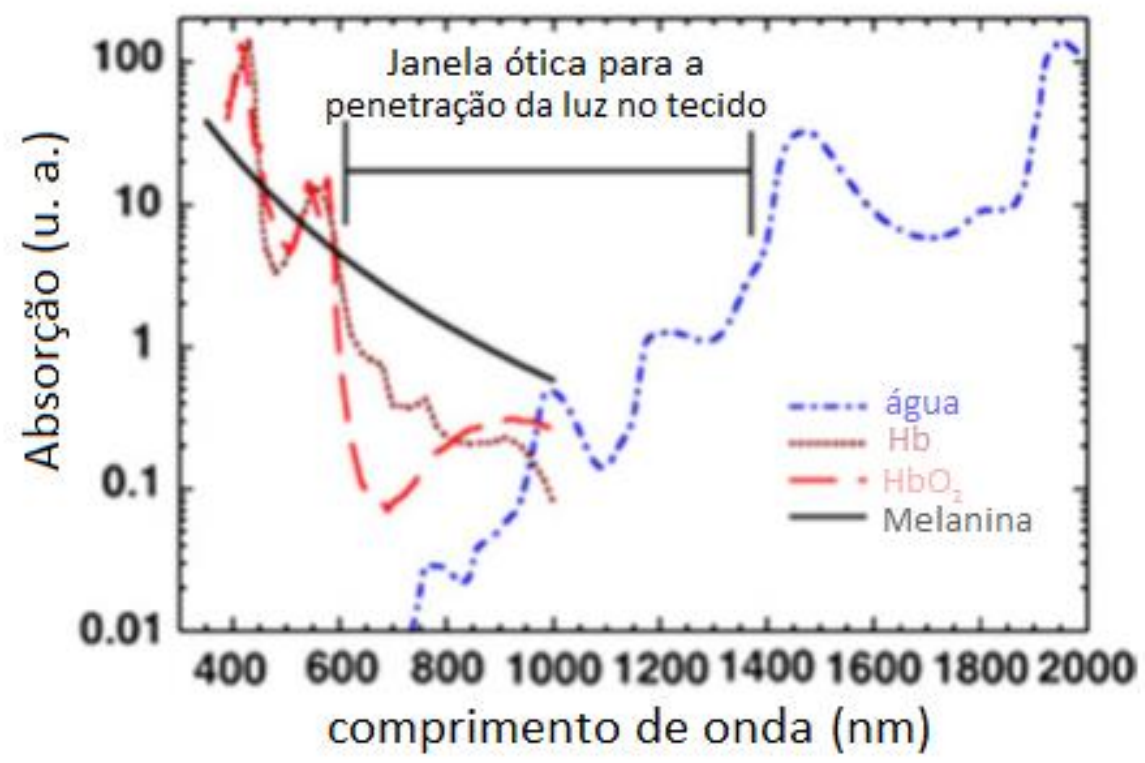

Figura 2. Espectro de absorção de luz por cromóforos dos tecidos humanos. Figura adaptada de (Huang, Chen, \& Hamblin, 2009).

A TLBP é usada atualmente basicamente para 3 propósitos: (i) promover a cicatrização de feridas e reparação de tecido. (ii) aliviar inflamação e edemas e (iii) reduzir a dor em geral.

A cicatrização de feridas foi uma das primeiras aplicações da TLBP com lasers de He-Ne. Acredita-se que o tratamento com TLBP atua nas 3 fases da cicatrização de feridas: (1) fase inflamatória, no qual as células do sistema imunológico migram para a região da ferida, (2) fase de proliferação, onde ocorre um aumento na produção de fibroblastos e macrófagos e (3) fase de remodelação no qual ocorre a deposição de colágeno no local da ferida e a matriz celular é reconstruída. Isso ocorre pois acredita-se que a TLBP promove a cicatrização de feridas devido à indução da liberação de citocinas, chemocinas e outros biomarcadores de resposta que diminuem o tempo para a ferida cicatrizar. Especula-se que estes resultados são devidos ao aumento da produção e ativação de fibroblastos e macrófagos melhorando a mobilidade de leucócitos, promovendo a formação de colágeno e indução de neovascularização. Apesar disso, existe uma falta de ensaios clínicos com parâmetros bem definidos para se determinar o impacto da TLBP na cicatrização de feridas. Ainda é necessário se realizar mais estudos para verificar a eficácia dela em diversos casos e para se obter o entendimento total da mecânica celular e bioquímica responsável neste processo.

Uma das dificuldades na área de dosimetria para a Fototerapia é o grande número de parâmetros correlacionados que são necessários para a utilização da técnica, e que nem sempre são reportados em estudos. Entre eles estão o comprimento de onda da luz, densidade de potência, densidade de energia, energia, tempo de irradiação, intervalo de tratamento. Existe uma carência de estudos que evidenciem a influência de cada uma destas variáveis na efetividade dos tratamentos devido ao considerável nível de complexidade na correlação dos parâmetros (Chung, et al., 2012). Além disso, existe o fenômeno da resposta bifásica da dose na Fototerapia. Isso corresponde a existência de limites superiores e inferiores para a energia absorvida na região a ser tratada para que ocorram os benéficos esperados por determinado 
tratamento. Um controle rigoroso das variáveis que influenciam o tratamento deve ser feito levando em consideração este fato (Huang et al., 2009).

\subsection{Dosimetria por Luminescência}

É possível se estimar a energia depositada em um meio exposto a radiação ionizante através de um dispositivo chamado dosímetro. Este dispositivo é usado para estimar a dose absorvida que um indivíduo ocupacionalmente exposto, ou um paciente, recebeu devido às condições de trabalho ou a um tratamento. Para isso, se utilizam certas características e propriedades que os materiais que compõem o dosímetro apresentam quando expostos à radiação. Uma forma de medir a dose absorvida que as pessoas receberam é através da luminescência que os dosímetros emitem em determinadas situações.

A luminescência é uma propriedade que os materiais apresentam de emitirem luz ao se desexcitarem. Esta luminescência pode ser devida a diversos fenômenos físicos, ou químicos, que podem ocorrer com o material. Dentre os tipos de luminescência que os materiais podem apresentar, neste estudo, enfatizaremos a termoluminescência, que consiste na propriedade que um material emitir luz quando estimulado termicamente, e a luminescência opticamente estimulada, que é a propriedade que um material tem de emitir luz quando estimulado por fótons de determinados comprimentos de onda.

O fenômeno de luminescência, em alguns casos, pode ser explicado considerando o modelo de bandas e níveis de energia com transições de elétrons e buracos entre estes níveis, descrito a seguir. Esse modelo é bem-sucedido para o estudo de isolantes e, especialmente, cristais.

\subsubsection{Modelo de Bandas e Defeitos em Cristais}

Segundo as regras da mecânica quântica, os elétrons ficam ligados ao átomo segundo um potencial, e podem ter diversos níveis discretos de energia. Estes níveis são os estados quantizados de energia permitidos ao elétron. No modelo de bandas e níveis de energia quando há o agrupamento de átomos em sólidos, como no caso da rede cristalina do material, os níveis de energia permitidos são definidos pela combinação dos potenciais de ligação dos elétrons aos diversos átomos, como é mostrado na Figura $3 \mathrm{~d}$ ). Nestes casos, o último nível de energia completamente preenchido de elétrons é chamado de banda de valência (BV) e o próximo é chamado banda de condução $(\mathrm{BC})$. A região do diagrama de bandas sem estados permitidos é chamada banda proibida e a diferença de energia entre o último nível de energia da $\mathrm{BC}$ e $\mathrm{O}$ primeiro nível de energia da BV é chamado de gap de energia (Kittel, 2006). 


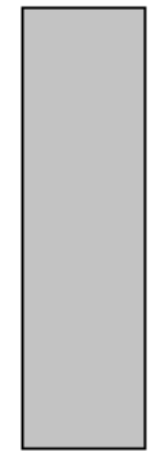

a)

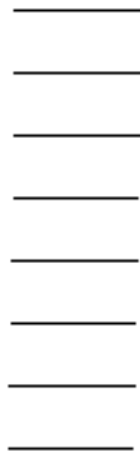

b)
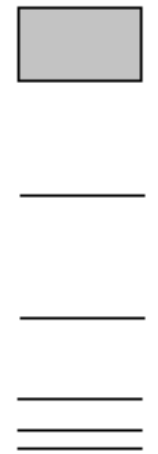

c)
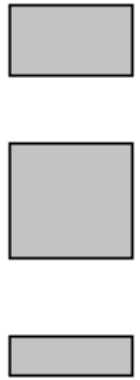

$\square$

d)

Figura 3. Diagrama de níveis de energia para elétrons. As linhas horizontais representam estados de energia permitidos para os elétrons. As regiões em cinza representam a junção de estados permitidos. Na figura, a) representa os níveis permitidos para o elétron livre, b) os níveis para o elétron preso em um potencial do tipo oscilador harmônico, c) o elétron em um poço de potencial e d) o elétron ligado a um conjunto poços de potencial. Adaptado de (Yukihara \& McKeever, 2011).

Os materiais são definidos como condutores e isolantes de acordo com o preenchimento das BV e BC e pelo valor do gap. Em um material que apresenta a BV com todos os estados permitidos preenchidos, separada da BC vazia por um gap amplo, a influência de um campo elétrico externo não consegue alterar o momento dos seus elétrons, caracterizando um material com baixa condutividade elétrica, conhecido como isolante. Nos materiais com as camadas parcialmente cheias, no caso da BV transferir um número pequeno dos seus elétrons à $\mathrm{BC}$, um campo elétrico externo pode influenciar mais facilmente no momento dos portadores de carga elétrica e, nesse caso, o material se comporta como um condutor, ou metal. O fato da BC estar cheia ou parcialmente cheia depende da dimensão do gap entre as bandas. Para um gap muito grande, dificilmente os elétrons da BV do material vão para a BC, caracterizando um material isolante. Para um gap pequeno, mais facilmente os elétrons da $B V$ vão à $B C$, caracterizando um material condutor, ou metal. Os semicondutores têm uma ou mais camadas quase cheia ou quase vazia (Kittel, 2006).

É possível introduzir em materiais isolantes níveis de energia na região da banda proibida. Estes níveis são introduzidos devido à presença de defeitos no material, principalmente o cristalino. Os defeitos são irregularidades na rede cristalina do material. Eles são, basicamente, violações da periodicidade na rede cristalina que introduzem um campo elétrico local no material. Eles podem ser devidos a omissão de átomos (vacâncias), a átomos extras (interstícios), a átomos diferentes no lugar dos átomos originais do material (impurezas), além de deslocamento de átomos na rede. Também podem ser introduzidos através de tratamento térmico, dopagem no processo de crescimento do cristal, recozimento, irradiações com partículas e fótons (Yukihara \& McKeever, 2011) (Kittel, 2006). 
Os defeitos podem ter um papel de "armadilha de elétrons" - termo empregado para caracterizar a atração que exercem sobre as cargas negativas - armadilha de buracos e centros de recombinação (CR) e esse papel depende da probabilidade do elétron escapar do defeito comparada com a probabilidade de um buraco ser capturado pelo defeito (Yukihara \& McKeever, 2011). O buraco é a ausência de um elétron na BV. Esta ausência de elétron é considerada uma partícula devido à mesma apresentar um comportamento análogo ao de um elétron de carga positiva. Os estados denominados armadilhas de elétrons são os que ficam logo abaixo da banda de condução e os estados denominados armadilhas de buracos ficam logo acima da banda de valência, no diagrama de bandas. Os estados intermediários às bandas de condução e de valência são os centros de recombinação. Um esquema representando o modelo descrito é mostrado na Figura 4.

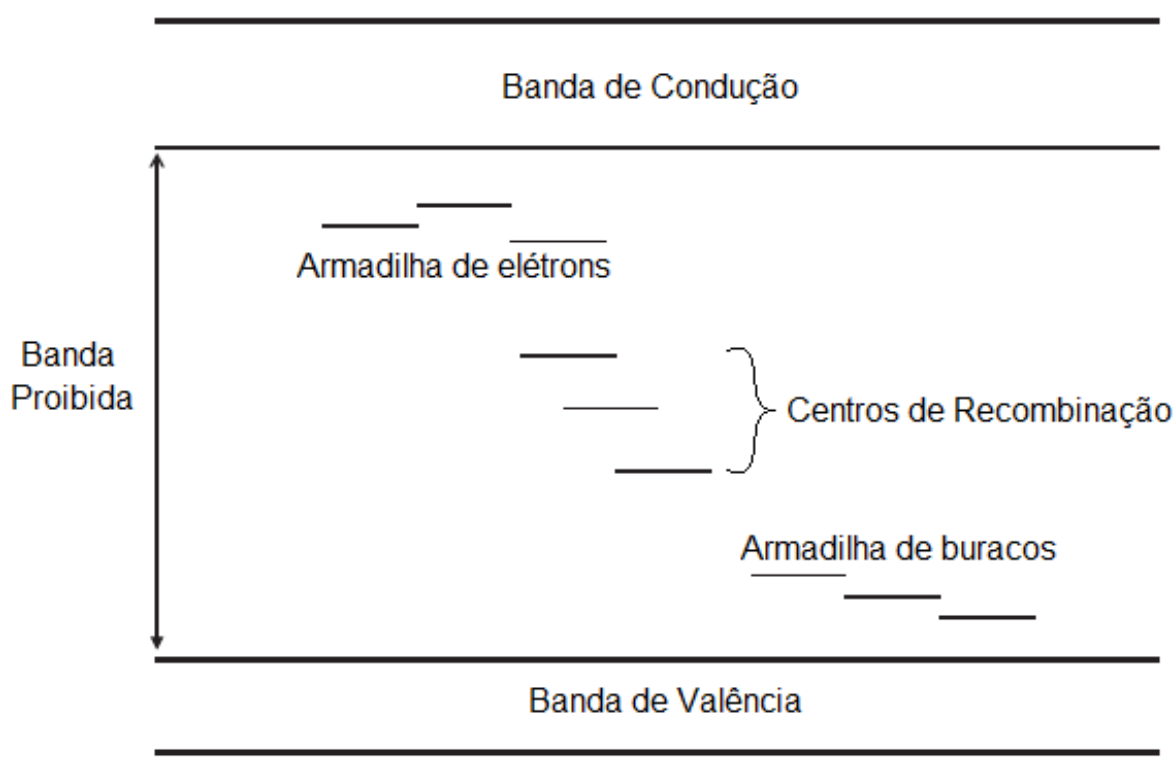

Figura 4. Representação dos estados na banda proibida causados por defeitos. Os estados com energia logo abaixo da $B C$ são as armadilhas de elétrons. Os estados com energia logo acima da BV são as armadilhas de buracos. Os estados com energia intermediária são os centros de recombinação. Figura adaptada de (Yukihara \& McKeever, 2011)

\subsubsection{O fenômeno da Luminescência}

O fenômeno da luminescência é devido a recombinação de elétrons, ou buracos, que foram promovidos às $\mathrm{BC}$, ou $\mathrm{BV}$, com seus respectivos pares de carga oposta. Ela ocorre após a excitação das cargas elétricas (elétrons ou buracos) a esses níveis ou bandas deslocalizadas (BV para buracos e BC para elétrons).

O processo de excitação ocorre quando a radiação ionizante incide no material e transfere energia suficiente para que um elétron saia da BV. Para que ocorra a transição do elétron, é necessário que o mesmo receba uma energia maior ou igual ao gap. Quando isto ocorre, é criado o par elétron-buraco no cristal no qual os buracos permanecem na BV e os elétrons fazem uma transição para os estados de energia da BC. 
Após a criação do par elétron-buraco, parte dos portadores de carga pode ficar presa nos estados ligados a defeitos do material. Este processo é chamado de armadilhamento. Exemplificando para elétrons, na BC: eles perdem energia e fazem uma transição a um estado na banda proibida, introduzido pelo defeito do material. Este estado é chamado estado metaestável pois o elétron pode ficar nele durante longos intervalos de tempo. Para os buracos, fenômeno é análogo. (Yukihara \& McKeever, 2011).

Com os portadores de cargas elétricas armadilhados nos estados metaestáveis, é possível estimular transições para a BC ou BV para que ocorra, em seguida, a recombinação deles nos CR do material. A recombinação é processo pelo qual a partícula na banda deslocalizada (BV ou BC) faz uma transição para o CR do material perdendo energia liberando fótons. Os fótons liberados na transição de estados de energia do CR são os fótons de luminescência estimulada do material. Os materiais que apresentam luminescência estimulada e são usados na área de dosimetria têm a propriedade de a quantidade de luz emitida por eles estar correlacionada com a dose absorvida devido à exposição à radiação ionizante.

O processo de recombinação ocorre após a estimulação do material que libera as cargas elétricas para as bandas deslocalizadas. A estimulação é processo pelo qual as cargas armadilhadas fazem transições aos estados das bandas deslocalizadas ganhando energia. Esta estimulação pode ser feita de diversas formas e, neste estudo, vamos detalhar os estímulos térmico e óptico, com as técnicas de Luminescência Termicamente Estimulada ou Termoluminescência (TL - Thermoluminescence) e Luminescência Opticamente Estimulada (OSL - Optically Stimulated Luminescence). Os processos de excitação, estímulo e luminescência são exemplificados na Figura 5.

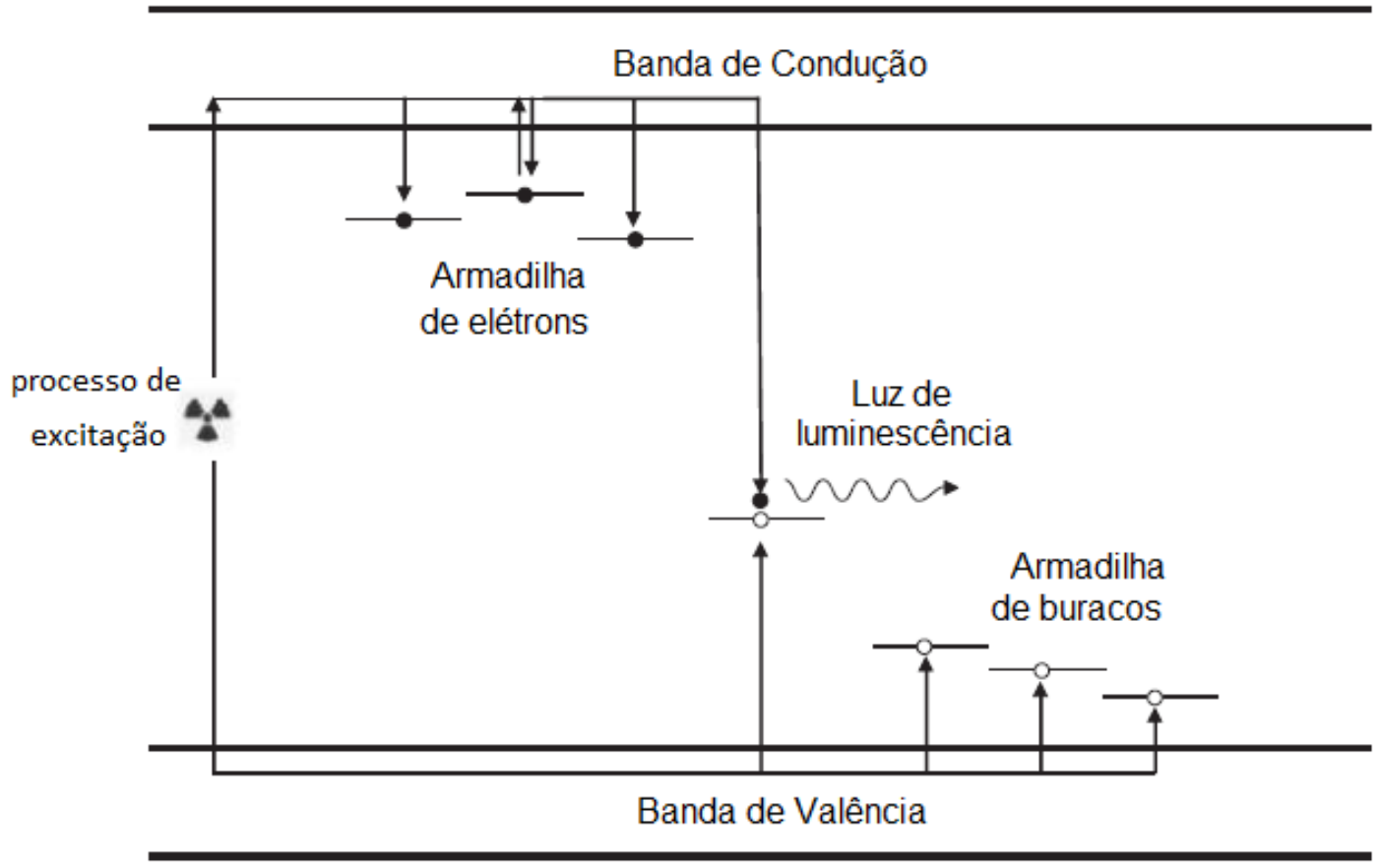

Figura 5. Esquema representando o fenômeno de luminescência estimulada. O processo de excitação leva as cargas elétricas as bandas deslocalizadas para armadilhas. Após um estímulo, as cargas retornam as bandas deslocalizadas e se recombinam nos CR liberando os fótons de luminescência. Figura adaptada de (Yukihara \& McKeever, 2011) 


\subsubsection{Termoluminescência ( $T L)$}

Na técnica de termoluminescência (TL) a luminescência é estimulada através do aquecimento da amostra. $\mathrm{Na}$ amostra pré-irradiada há elétrons e buracos armadilhados em estados metaestáveis da amostra e, através do aquecimento, as cargas armadilhadas recebem energia para fazer transições para as BC ou BV. Em seguida, estas cargas podem fazer uma transição para os centros de recombinação, onde se recombinam com um portador de sinal contrário, emitindo um fóton. Os fótons emitidos devido a transição dos elétrons e buracos aos centros de recombinação são os fótons de luminescência da amostra. é possível relacionar a temperatura da amostra com a probabilidade de desarmadilhamento do elétron em uma armadilha de energia $E$. Isto é dado segundo a equação

$$
p=s e^{-\frac{E}{k T}}
$$

onde $E$ é a energia de ativação para o processo de desarmadilhamento, $k$ é a constante de Boltzmann, $T$ é a temperatura da amostra e $s$ é uma constante chamada de fator de frequência (Yukihara \& McKeever, 2011).

A curva de sinal de termoluminescência em função da temperatura (chamada curva de emissão ou glow curve) obtida, para um modelo simples é exemplificada na Figura 6, para três valores de energia de ativação

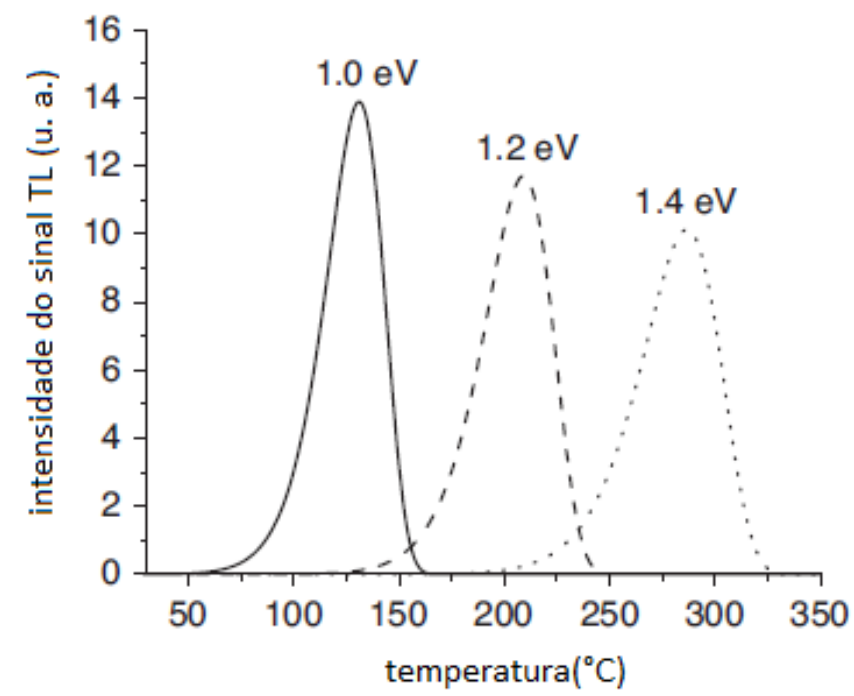

Figura 6. Exemplo de curva de emissão TL para algumas energias de ativação. Os picos indicam a presença de armadilhas na amostra e só dependem da energia de ativação E e da constante s (Yukihara \& McKeever, 2011). 


\subsubsection{Luminescência Opticamente Estimulada (OSL)}

$\mathrm{Na}$ técnica de luminescência opticamente estimulada (OSL) o estímulo se dá pela iluminação da amostra. Neste caso, os elétrons armadilhados são induzidos a fazer transições à $\mathrm{BC}$ devido a absorção dos fótons que iluminam a amostra. Estes fótons devem ter energia igual ou maior que a distância da armadilha à banda de condução. Em seguida, os elétrons na BC fazem transições aos CR onde se recombinam com os buracos emitindo fótons. Na transição dos elétrons da banda de condução para os centros de recombinação um fóton é emitido e o conjunto deles formam a luz de luminescência da amostra (Yukihara \& McKeever, 2011).

No modelo mais simples para o processo OSL a variação temporal na concentração de elétrons armadilhados $(n)$ durante a iluminação é proporcional ao número de elétrons armadilhados e à probabilidade por unidade de tempo de ocorrer a transição destes elétrons à $\mathrm{BC}\left(p_{O S L}\right)$, segundo a equação (3).

$$
\frac{d n}{d t}=-n p_{O S L}
$$

onde assumimos que não ocorre rearmadilhamento de elétrons nos defeitos. Resolvendo a equação (3), obtemos a equação

(4).

$$
n(t)=n_{0} e^{-p_{O S L} t}
$$

onde $n_{0}$ é a concentração inicial de elétrons armadilhados. Para uma fração constante de elétrons se recombinando, a intensidade do sinal OSL é proporcional à taxa de elétrons escapando das armadilhas. Com isso, obtemos a equação

$$
I_{O S L}(t) \propto\left|\frac{d n}{d t}\right|=n_{0} p_{O S L} e^{-p_{O S L} t^{t}}
$$

onde $I_{O S L}(t)$ é a intensidade do sinal OSL.

Nas interações dos defeitos com a radiação óptica é importante se considerar o comprimento de onda e a intensidade da radiação externa que estimula a luminescência. A probabilidade de transição óptica é dada pela equação (6). 


$$
p_{\text {OSL }}=\sigma \phi
$$

onde $\sigma$ é a seção de choque de fotoionização e $\phi$ é o fluxo incidente de fótons.

A seção de choque de fotoionização $(\sigma)$ é um importante fator no estímulo óptico das cargas armadilhadas nos estados metaestáveis do material. Ela determina a probabilidade de fotoionização por intervalo de tempo e por átomo. A seção de choque de fotoionização é estimada segundo diversas hipótese e, devido a isto, existem diversas expressões para a mesma. As mais usadas para representar a sua variação com a luz incidente na amostra são as de mostradas nas equações

(7) e (8) (Yukihara \& McKeever, 2011).

$$
\begin{gathered}
\sigma(h v) \propto \frac{\left(h v-E_{0}\right)^{3 / 2}}{(h v)^{3}} \\
\sigma(h v) \propto \frac{\left(h v-E_{0}\right)^{3 / 2}}{h v\left[h v+E_{0}\left(m_{0} / m-1\right)\right]^{2}}
\end{gathered}
$$

onde $h v$ é a energia do fóton incidente na amostra, $E_{0}$ é a energia limite para ocorrer a fotoionização do defeito do material, $m_{0}$ é a massa do elétron localizado nas vizinhanças do defeito e $m$ é a massa efetiva do elétron na banda de condução (Botter-Jensen, McKeever, \& Wintle, 2003).

Os parâmetros relevantes para o processo OSL são o comprimento de onda do fóton emitido na luminescência, a vida média do centro de luminescência e a eficiência quântica do processo de luminescência (Yukihara \& McKeever, 2011).

O conhecimento do comprimento de onda de emissão de luminescência do material é importante pois no uso da técnica OSL se faz necessário a utilização de um sistema apropriado de detecção de luz e um conjunto de filtros ópticos com a finalidade de diferenciar os fótons de luminescência dos fótons de estímulo de luminescência da amostra. Outro fato é que o conhecimento dos comprimentos de onda de emissão de luminescência do material também é relevante para a escolha do comprimento de onda de estímulo da luminescência do material. Este fato ocorre devido a existência de fenômenos que produzem emissão de fótons com comprimento de onda maior do que o comprimento de onda OSL, e que nem sempre são relacionados com a dose de radiação. Uma escolha adequada de filtros e sistema de deteç̧ão da luz de luminescência deve levar estes processos em consideração para que não se leve em conta, na OSL, a luminescência devido a outros efeitos (Yukihara \& McKeever, 2011).

A vida média do centro de luminescência é o parâmetro que indica a taxa de decaimento do sinal de luminescência da amostra. Este sinal de decaimento é devido ao centro de 
recombinação que, quando captura um buraco ou um elétron, fica excitado e decai segundo a expressão (9).

$$
N_{e}(t)=N_{e}(0) e^{-\frac{t}{\tau_{R}}}
$$

onde $N_{e}(t)$ é o número de centros de recombinação excitados no instante $t$ e $\tau_{R}$ é o tempo de vida média do centro de recombinação. Com uma escolha apropriada de intervalos de tempo é possível aumentar o número de centros de recombinação excitados e, assim, aumentar o sinal OSL produzido pela amostra. Este é o princípio da técnica P-OSL (Pulsed OSL). Os tempos de vida média são determinados segundo as regras da mecânica quântica para a transições para estados permitidos e proibidos dentro do cristal. Eles variam até $10^{-3} \mathrm{~s}$.

A eficiência quântica para o processo de luminescência é relacionada com o número de estados excitados nos centros de recombinação que retornam ao estado fundamental de forma radioativa, emitindo um fóton, comparado com o número dos estados que retornam não radioativamente. Um processo de retorno do estado excitado do defeito para o estado fundamental é a emissão de um fônon, onde a vibração da rede do cristal faz com que um defeito em seu estado excitado consiga fazer uma transição para o estado fundamental (processo conhecido como emissão de fônon). A eficiência quântica é dada segundo a expressão

(10).

$$
\eta=\frac{\Gamma_{R}}{\Gamma_{R}+\Gamma_{N R}}=\frac{\tau_{R}^{-1}}{\tau_{R}^{-1}+\tau_{N R}^{-1}}
$$

onde $\eta$ é eficiência quântica do processo de luminescência, $\Gamma_{R}=\tau_{R}^{-1}$ é a taxa de transição radioativa, $\Gamma_{N R}=\tau_{N R}^{-1}$ é a taxa de transição não radioativa, $\tau_{R}$ é a vida média nos processos radiativos e $\tau_{N R}$ é a vida média nos processos não radiativos.

\subsubsection{Modos de estimulação}

Existem diversos modos de estímulo da OSL em amostras. Estes modos visam obter uma curva de resposta do sinal OSL com informações mais detalhadas sobre os defeitos da amostra que auxiliam uma interpretação dos resultados obtidos. O que diferencia estes modos é a modulação da luz de estímulo de luminescência e o momento da leitura da luminescência em função do momento de estimulação da amostra. Dentre os possíveis modos de estimulação da OSL citaremos três: o modo de onda contínua (CW-OSL), o modo de potência modulada (LMOSL) e o modo pulsado (P-OSL). 


\subsubsection{Modo de Estímulo Contínuo de OSL (CW-OSL)}

No modo de estímulo contínuo da OSL (CW-OSL) a amostra é iluminada por um intervalo de tempo com luz de intensidade constante. A medição da luminescência é feita simultaneamente ao estímulo. Este método é o mais utilizado com a técnica OSL para a dosimetria e datação, e é o que empregamos neste trabalho (Yukihara \& McKeever, 2011).

Dependendo do modo de estímulo, a curva do sinal OSL apresenta um formato. Para o estímulo em modo CW-OSL o sinal OSL apresenta o formato mostrado na Figura 7. No modelo mais simples (equação (5)), a razão de decaimento da curva OSL no modo CW-OSL não depende da dose absorvida pela amostra. Ela depende somente dos parâmetros $\sigma$ e $\phi$. A área total da curva OSL é dada pela equação (11), e só depende de $n_{0}$. O formato da curva muda de acordo com os parâmetros $\sigma$ e $\phi$.

$$
\int_{0}^{\infty} I_{O S L}(t) d t \propto \int_{0}^{\infty} n_{0} \sigma \phi e^{-\sigma \phi t} d t=n_{0}
$$
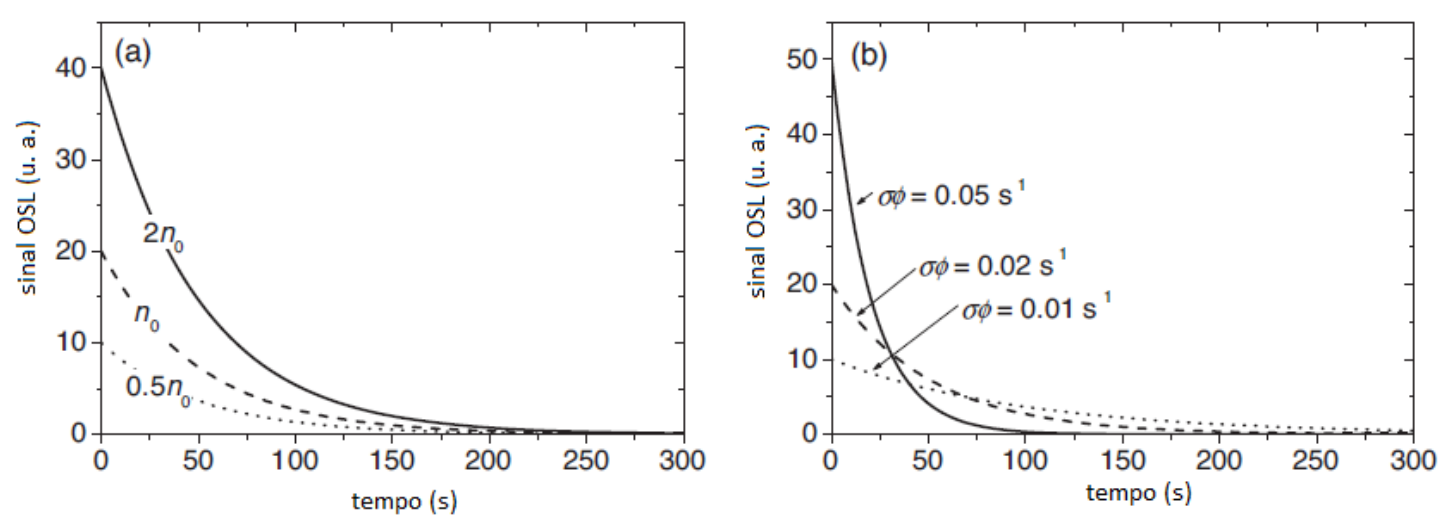

Figura 7. Exemplo de curvas OSL obtidas com o modo de estímulo CW-OSL. (a) exemplos curvas OSL obtidas com vários valores da concentração inicial de elétrons armadilhados apresentada como função de $n_{0}$ e o mesmo valor de $p_{O S L}$. Neste caso, o valor inicial muda, mas o formato da curva (taxa de decaimento) se mantém o mesmo. (b) exemplos de curvas obtidas com mesmo valor $n_{0}$ para a concentração de elétrons armadilhados e diferentes valores de $p_{O S L}$. Para estes casos o formato da curva muda, mas a área total permanece a mesma.

As curvas OSL modo CW apresentam implicações práticas. Uma delas é que a área sob a curva está relacionada com a dose absorvida pela amostra para qualquer intervalo de tempo. Levando isso em conta, é possível se retirar parte da curva OSL, que não altere significantemente a área total, fazendo uma leitura OSL em um pequeno intervalo de tempo. Nesse caso, tanto o sinal retirado quanto o restante da curva ainda estão relacionados com a dose absorvida pela amostra. Dessa forma, se o sinal OSL apresentar precisão e estabilidade suficiente, a curva OSL pode ser lida em um pequeno intervalo de tempo que não altere significantemente a área total, 
ou sinal integrado, do restante da curva OSL e o restante dela pode ser armazenada para o caso de uma releitura (Yukihara \& McKeever, 2011). Neste estudo realizamos a leitura do sinal por tempo suficiente para esgotá-lo, e usamos a análise do sinal inicial OSL (sinal OSL integrado até $1 \mathrm{~s}$ ), e do sinal integrado (o sinal OSL integrado para todo o tempo de leitura).

Outro fator é que o sinal inicial OSL é dependente da intensidade $\phi$, ou da potência da luz de estímulo. Devido a isto, para se obter resultados reprodutíveis é necessário se monitorar o sinal da fonte de estimulação (Yukihara \& McKeever, 2011).

Como foi dito anteriormente, estes fatores são a respeito da curva OSL no modo CW-OSL foram vistos segundo um modelo mais simples, dito pela equação (5). Para os materiais reais devem ser considerados efeitos além dos descritos (Yukihara \& McKeever, 2011).

Uma escolha essencial para a otimização da CW-OSL é que o comprimento de onda da luz de estímulo seja diferente do comprimento de onda da luz de luminescência $\left(\lambda_{\text {estímulo }} \neq \lambda_{\text {OSL }}\right)$ com a finalidade de que o sinal detectado não esteja contaminado pelos fótons da luz de estímulo na amostra (Yukihara \& McKeever, 2011). Além disso, também é necessário que se selecione para a detecção um comprimento de onda que seja menor do que o comprimento de onda de estímulo da OSL. Isso é necessário para evitar a medição de sinais devidos a outros fenômenos que não a luminescência da amostra relacionada com a dose absorvida da radiação. Estes cuidados podem ser providenciados com uma adequada escolha do conjunto de filtros óticos que selecionam o intervalo detectado pelo tubo fotomultiplicador que detecta o sinal OSL (Yukihara \& McKeever, 2011).

\subsubsection{Modo de Estimulo com Modulação Linear de OSL (LM-OSL)}

Um modo de estímulo não tão predominante na dosimetria é o modo de estimulação linear da OSL (LM-OSL). Neste modo, a intensidade da luz de estímulo aumenta de forma linear em função do tempo de incidência na amostra. Devido a isto, as curvas OSL obtidas neste modo de estimulação apresentam um crescimento inicial seguido de um declínio devido ao esvaziamento da concentração de cargas armadilhadas. Logo, as curvas no modo de estímulo LM-OSL apresentam picos ao invés de um decaimento exponencial que é visto na CW-OSL.

Uma das vantagens da LM-OSL quando comparada com a CW-OSL é que na primeira a influência de armadilhas diferentes, com seções de choque de fotoionização diferentes, no sinal de luminescência pode ser identificada. A desvantagem é que para esta técnica um sistema de modulação de intensidade é necessário e isso pode acrescentar complicações as medidas OSL (Yukihara \& McKeever, 2011). 


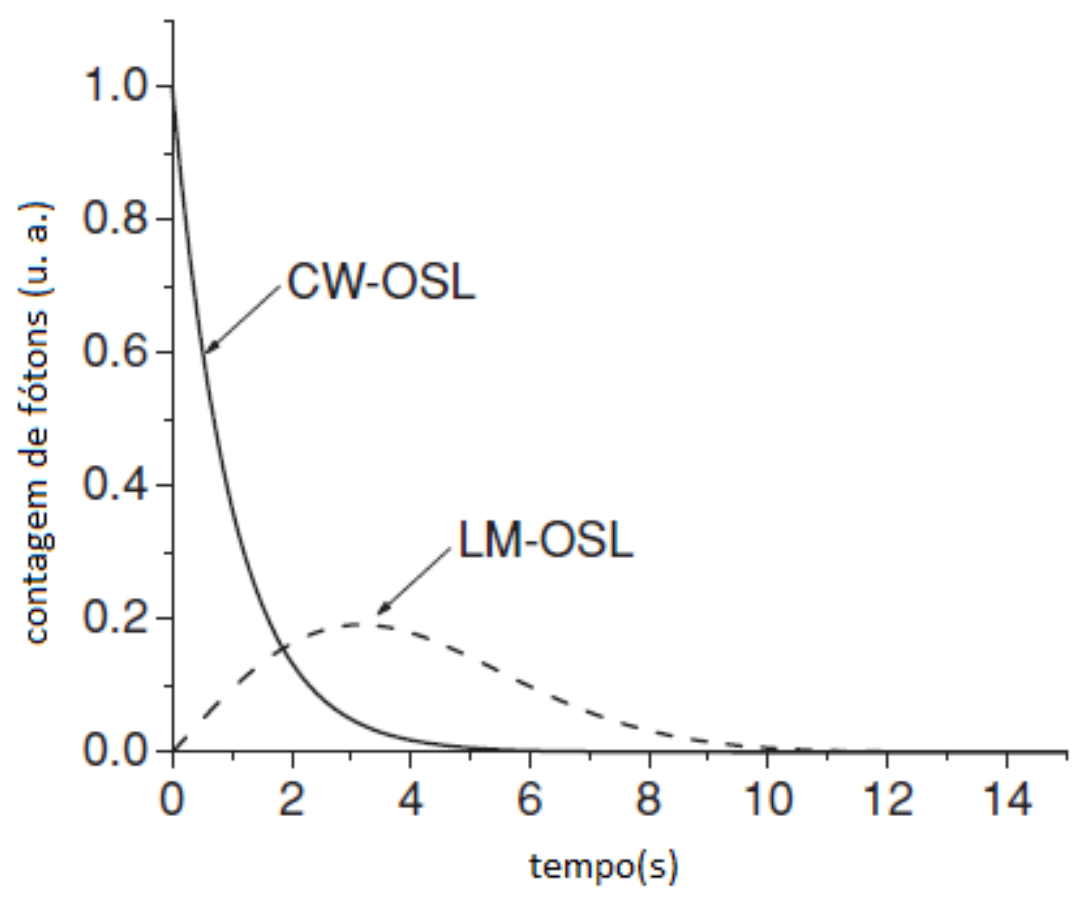

Figura 8. Exemplo de curva obtida no modo CW-OSL em comparação com o modo LM-OSL.

2.2.4.4 Modo de Estímulo Pulsado (P-OSL)

Um dos problemas da CW-OSL e da LM-OSL é a necessidade uso de filtros óticos para as medidas com a finalidade de diferenciar o sinal de estímulo do sinal de luminescência e como proteção do sistema de detecção de luz. Em algumas situações, pode ser vantajoso usar uma fonte de luz de estimulação pulsada e se fazer as leituras somente nos momentos em que o sistema não esteja iluminando a amostra. Adicionalmente à fonte de luz pulsada é necessário ter um sistema de detecção com um obturador para que se garanta a não leitura da luz espalhada devido à estimulação da OSL da amostra. Este tipo de medida é o modo de estímulo pulsado da OSL (P-OSL) (Yukihara \& McKeever, 2011). A Figura 9 esquematiza a P-OSL. 


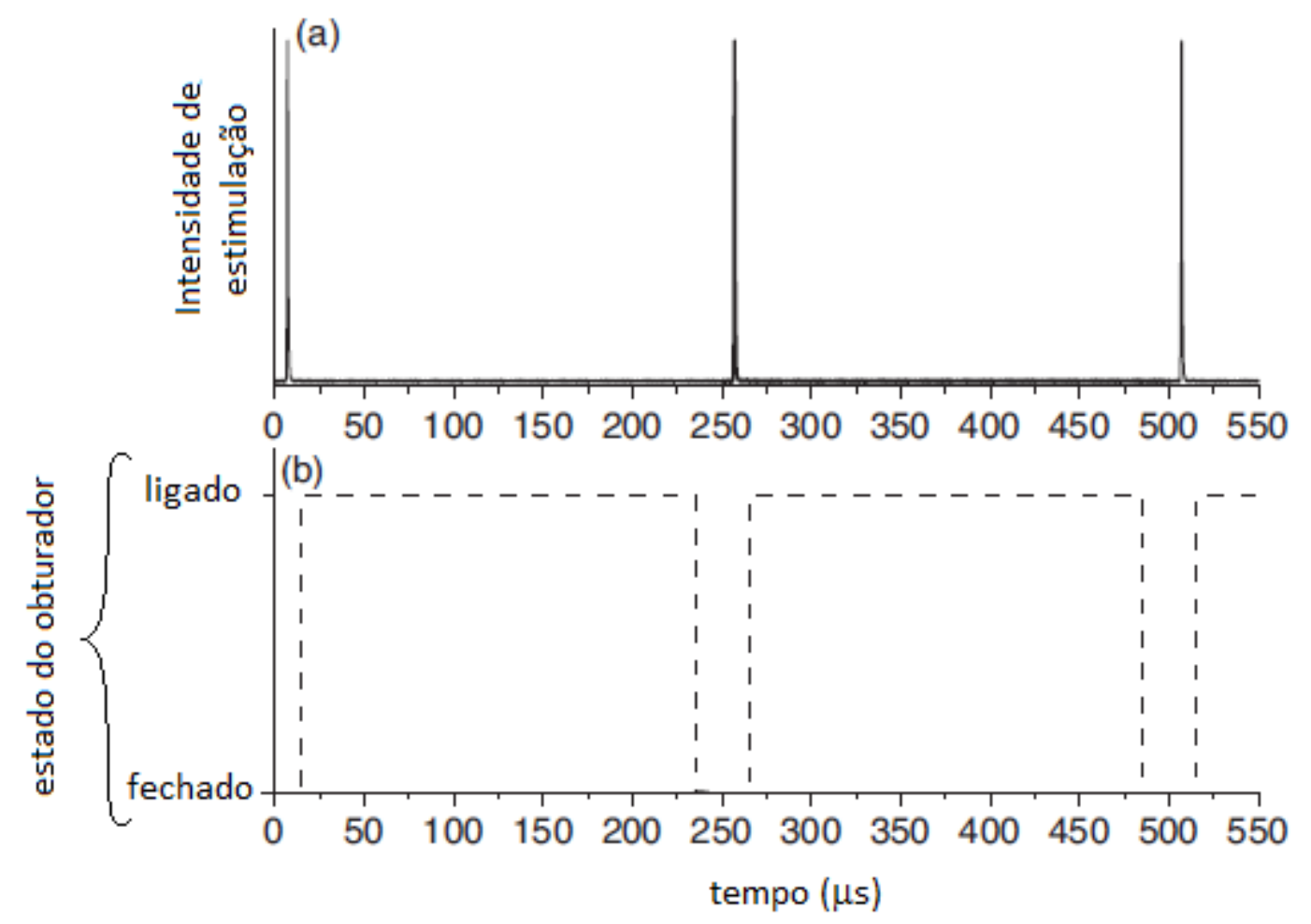

Figura 9. Esquema de estimulo da amostra na P-OSL. (a) estímulo ótico, ou pulso e (b) estado do obturador do sistema de deteç̧ão da luz de luminescência.

Uma característica importante das medidas de P-OSL é a dependência com o tempo de vida média dos centros de luminescência da amostra. $O$ tempo de vida média tem que ser tal que o tempo de duração do pulso possa estimular a amostra de forma que o sinal OSL não decaia significativamente neste período. Além disso, com um ajuste adequado da frequência do pulso de estímulo, pode-se aumentar a fração do sinal OSL obtido entre os pulsos, aumentando assim o sinal lido no sistema de deteç̧ão (Yukihara \& McKeever, 2011). Isto fica exemplificado na Figura 10. 
(a) $1 \mathrm{~Hz}$

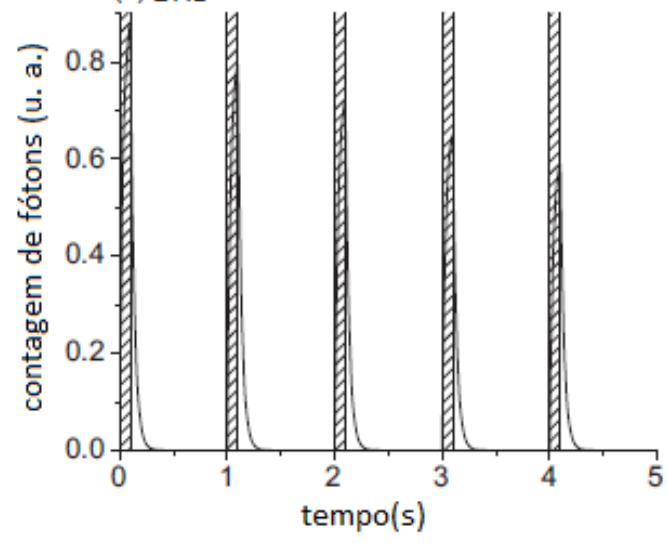

(c) $100 \mathrm{~Hz}$

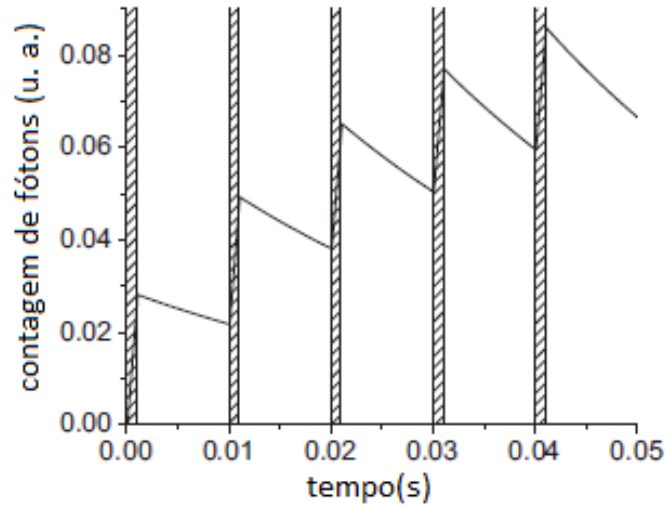

(b) $10 \mathrm{~Hz}$

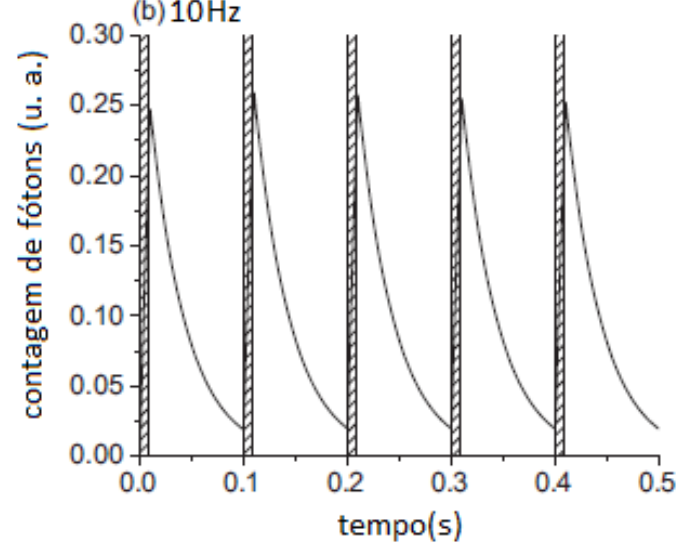

(d) $1000 \mathrm{~Hz}$

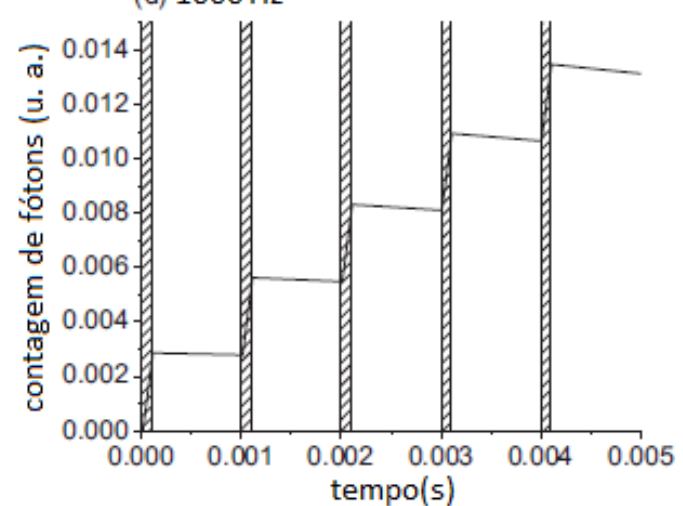

Figura 10. O sinal OSL na P-OSL com duração de pulso com $10 \%$ do tamanho da vida média da amostra. Para (a), (b), (c) e (d) a frequência do pulso foi aumentada e, em consequência, o sinal OSL entre os pulsos também aumenta. 


\section{MATERIAIS E MÉTODOS}

\subsection{Equipamentos}

\subsubsection{Aparelho para Fototerapia Twin Flex Evolution}

O equipamento Twin Flex Evolution (Figura 11) consiste de um aplicador laser utilizado nas áreas de Odontologia, Fisioterapia e Medicina. O modelo utilizado no Laboratório do Grupo de Dosimetria das Radiações e Física Médica consiste de um gabinete de controle e duas canetas utilizadas para a aplicação de laser de comprimentos de onda de $658 \mathrm{~nm}$ e $808 \mathrm{~nm}$. Com as especificações mostradas na Tabela 1.

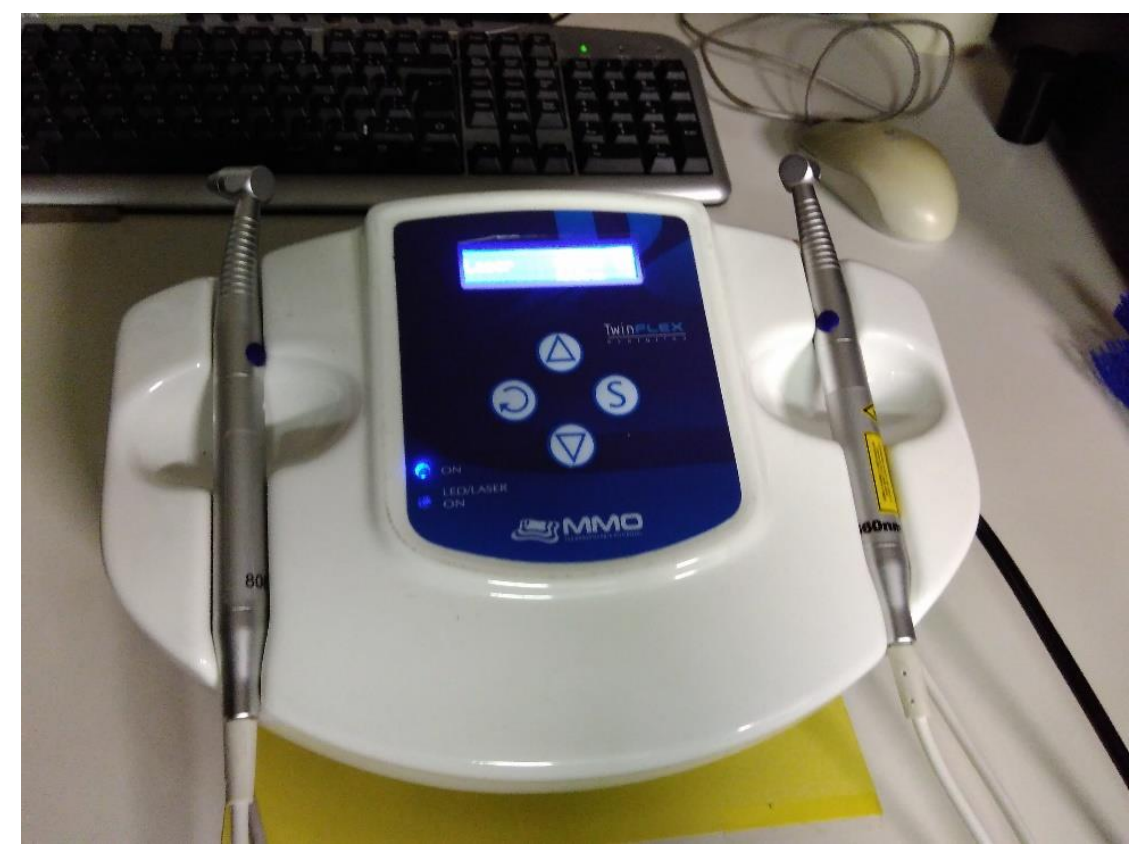

Figura 11. Foto do equipamento emissor laser MMO Twin Flex Laser.

Tabela 1. Parâmetros da caneta do emissor laser MMO Twin Flex Laser.

\begin{tabular}{|c|c|c|}
\hline \multicolumn{2}{|c|}{ área do feixe laser de saída no bico da caneta $\left(\mathrm{mm}^{2}\right)$} & 4 \\
\hline comprimento de onda $(\mathrm{nm})$ & potência máxima de saída $(\mathrm{mW})$ & divergência do feixe $(\mathrm{rad})$ \\
\hline 658 & $100(20)$ & 0,148 \\
\hline 808 & $150(30)$ & 0,14 \\
\hline
\end{tabular}


Para os dois comprimentos de onda a iluminação pode ser configurada com diversas potências (intervalo de 10 a $100 \mathrm{~mW}$ ) e por diversos intervalos de tempo (10 a $180 \mathrm{~s}$ ). Através da combinação destes parâmetros é possível se estabelecer a melhor maneira de realizar uma determinada iluminação.

Nos estudos aqui relatados, utilizamos a caneta com emissão do laser vermelho de $658 \mathrm{~nm}$ com as potências de 10, 20, 50 e $100 \mathrm{~mW}$ por intervalos de tempo iguais a 10, 20, 50, 90, 120 e $180 \mathrm{~s}$ para as todas as amostras utilizadas.

\subsubsection{Leitor TL/OSL Ris $\varnothing$ (modelo TL/OSL-DA-20)}

Na execução deste estudo foi utilizado o equipamento leitor TL/OSL Ris $\varnothing$ - fabricado por Ris $\varnothing$ DTU National Laboratory for Sustainable Energy, Dinamarca - conhecido como Ris $\varnothing$. Ele foi utilizado para as leituras do sinal OSL das amostras. Este equipamento consiste da junção de 3 sistemas: de deteç̧ão de luz (i), de estimulação de luminescência (ii) e de irradiação por fontes radioativas (iii). Em todos os experimentos utilizamos os três sistemas presentes no Ris $\emptyset$. A seguir fica explicitado como funciona cada um dos sistemas e a foto do equipamento no instalado no Laboratório de Dosimetria da USP está na Figura 12.

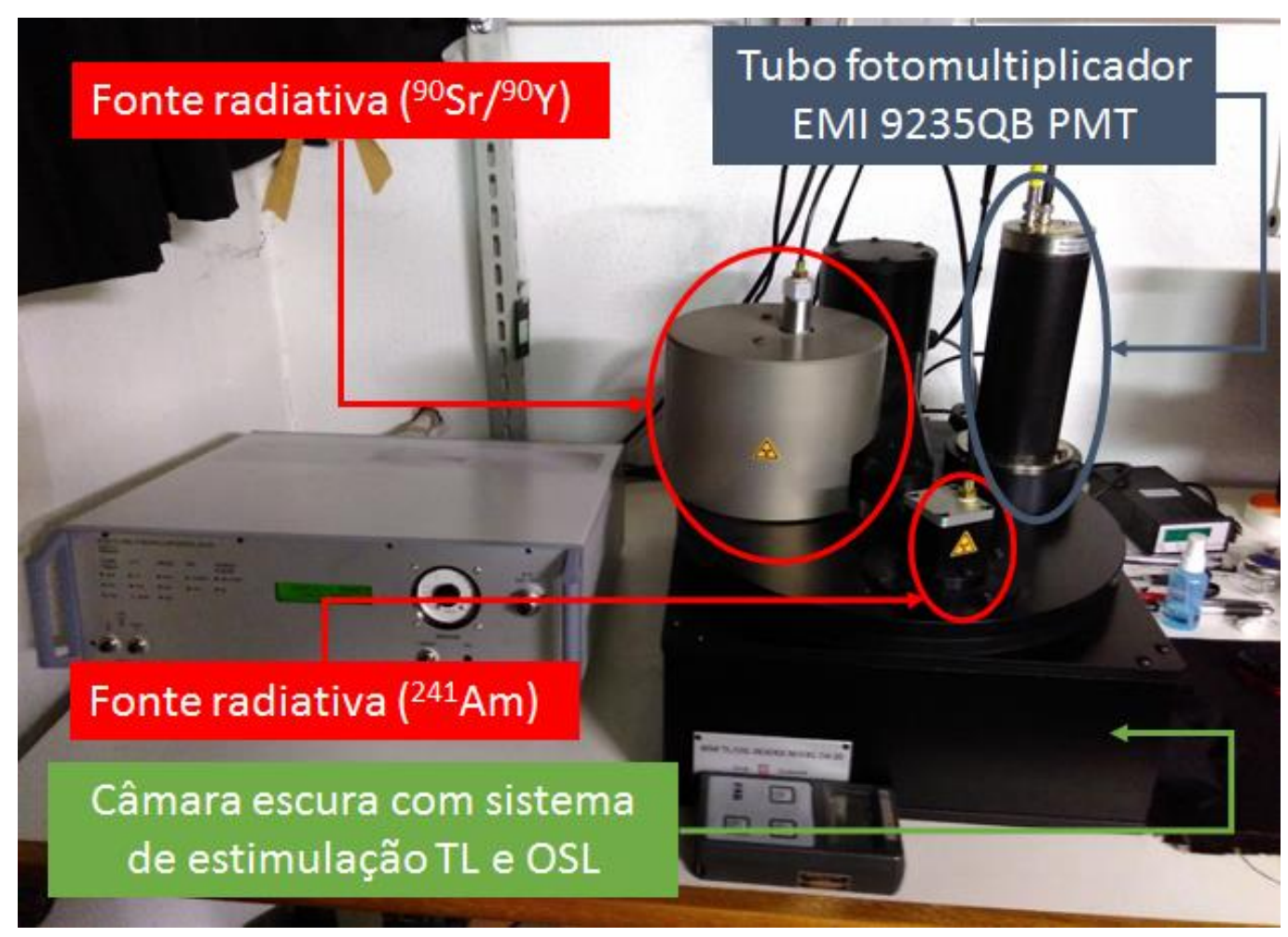

Figura 12. Leitor TL/OSL Risø do Grupo de Dosimetria das Radiações e Física Médica do IFUSP. 
i. Sistema de detecção de luz.

O sistema de deteç̧ão de luz é constituído por de um tubo fotomultiplicador (PMT) para a detecção da luz e um conjunto de filtros óticos que protegem o tubo fotomultiplicador da luz de estímulo e definem o intervalo de detecção da luz emitida pelas amostras no processo de luminescência.

O tubo fotomultiplicador é do modelo EMI 9235QB PMT, bialcalino, com máxima eficiência de deteç̧ão para luz nos comprimentos entre 200 e $400 \mathrm{~nm}$.

Os filtros de detecção são utilizados com a finalidade de discriminar a luz de estimulação da luz de luminescência da amostra. $O$ equipamento traz consigo um conjunto com os filtros Hoya U-340 (espessura de 7,5 mm e diâmetro de $45 \mathrm{~mm}$ ), Schott BG-39 (espessura de $2 \mathrm{~mm}$ e diâmetro de $45 \mathrm{~mm}$ ) Corning 7-59 (espessura de $4 \mathrm{~mm}$ e diâmetro de $45 \mathrm{~mm}$ ). A Figura 13 mostra o intervalo de transmissão dos filtros. Neste projeto as medidas foram realizadas utilizando o filtro de detecção Hoya U-340, com colimador óptico de $10 \mathrm{~mm}$.
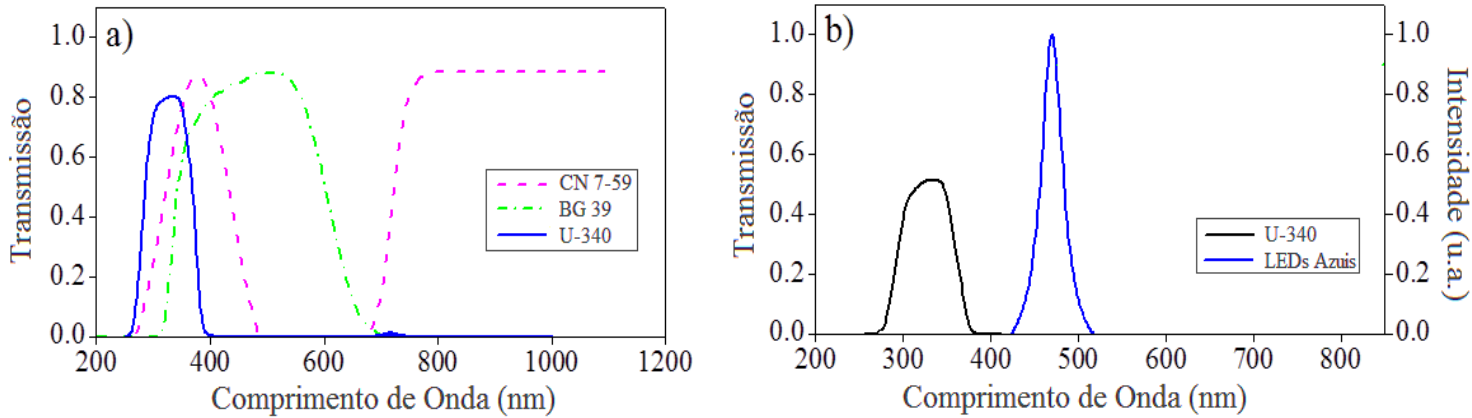

Figura 13. Espectro de transmissão dos filtros disponibilizados pelo leitor TL/OSL Risø. Retirado de (Malthez, 2015).

ii. Sistema de estimulação de luminescência

O equipamento Risø é capaz de realizar estímulo de luminescência utilizando o sistema de estimulação térmica e o sistema de estimulação óptica.

O sistema de estimulação térmica consiste de uma fita metálica, onde o porta-amostra fica posicionado, conectada a um gerador de ondas senoidais operando a $20 \mathrm{kHz}$. Este sistema é capaz de aquecer as amostras até a temperatura de $500^{\circ} \mathrm{C}$ a taxas constantes de aquecimento de 0,1 a $10 \mathrm{~K} / \mathrm{s}$ (Riso DTU, 2010).

O sistema de estimulação óptica pode ser feito com dois tipos de luz: LEDs na faixa do azul $(470 \mathrm{~nm})$ e do infravermelho $(870 \mathrm{~nm})$ com a possibilidade de variação da intensidade em função do tempo de estimulação. O estímulo para leitura OSL é realizado usando um conjunto de 28 LEDs de luz azul (NICHIA tipo NSPB-500AS, com pico em $470 \mathrm{~nm}$ e largura a meia altura de $20 \mathrm{~nm}$ ) com potência de até $80 \mathrm{~mW}$ na posição da amostra, ou 21 LEDs de luz infravermelha (Vishay TSFF 5210, com pico em 870 nm e largura a meia altura de $40 \mathrm{~nm}$ ) com potência de 
aproximadamente $145 \mathrm{~mW}$ na posição da amostra (Riso DTU, 2010). O espectro de emissão dos LEDs é mostrado na Figura 14.

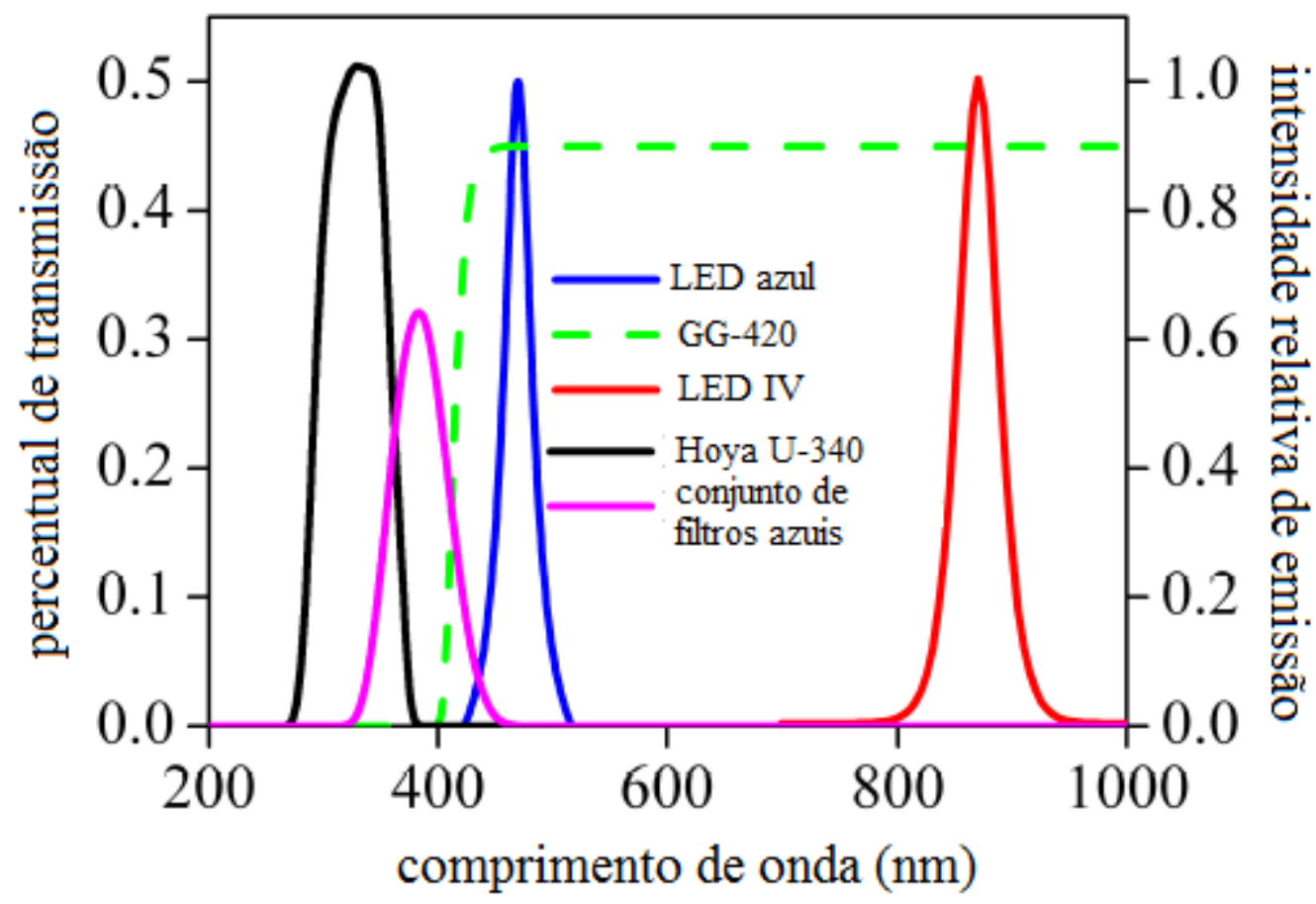

Figura 14. Espectro de emissão dos LEDs e espectro de transmissão dos filtros disponíveis para utilização do equipamento Risø (Riso DTU, 2010).

Nos experimentos realizados neste projeto, utilizamos o sistema de estimulação óptica com intensidade constante (CW) com os LEDs na faixa do azul, para a leitura do sinal OSL das amostras. Também empregamos os LEDs de infravermelho para iluminação delas, simulando iluminação em fototerapia.

iii. Fontes radioativas

O leitor TL/OSL Risø é equipado com 2 fontes de radiação: uma beta emissora $\left({ }^{90} \mathrm{Sr} /{ }^{90} \mathrm{Y}\right)$, e uma alfa emissora $\left({ }^{241} \mathrm{Am}\right)$. Nos experimentos feitos neste trabalho só foi utilizada a fonte de radiação beta para irradiar amostras por diferentes intervalos de tempo. Ela produz uma taxa de dose absorvida de aproximadamente $10 \mathrm{mGy} / \mathrm{s}$ na posição da amostra.

\subsubsection{Medidor de potência Ophir LaserStar}


O equipamento Ophir LaserStar é um medidor de potência e energia luminosas. Para a realização deste estudo foram feitas medidas com o fotodiodo PD300 que, quando iluminado, cria uma corrente que é proporcional à potência da luz incidente nele e dependente do comprimento de onda. Este deve ser conhecido e selecionado no equipamento antes da execução das medidas.

O fotodiodo PD300 também vem acompanhado de um filtro atenuador que amplia as possibilidades de medidas de potência luminosa. A tabela mostra as especificações do fotodiodo utilizado nas medidas.

Tabela 2. Especificações do detector PD300 do medidor de potências Ophir LaserStar com e sem filtro atenuador

\begin{tabular}{|c|c|c|}
\hline modo & sem filtro & com filtro \\
\hline $\begin{array}{c}\text { intervalo de comprimento } \\
\text { de onda (nm) }\end{array}$ & $350-1100$ & $430-1100$ \\
\hline intervalo de potência & $500 \mathrm{pW}$ a $30 \mathrm{~mW}$ & $200 \mu \mathrm{W}$ a $300 \mathrm{~mW}$ \\
\hline
\end{tabular}

Neste estudo, as medidas realizadas foram feitas com potências nominais de 10 a $100 \mathrm{~mW}$ e os comprimentos de onda da luz vermelha $(658 \mathrm{~nm})$ do equipamento MMO Twin Flex com o detector PD300 coberto pelo filtro atenuador. Neste intervalo o equipamento garante uma precisão nas medidas de até $\pm 5 \%$ na potência medida.

\subsection{Materiais}

Os materiais usados em medidas OSL apresentam a características de serem sensíveis a luz. Essa característica acarreta a necessidade de se manter os dosímetros protegidos da luz ambiente para que o sinal armazenado neles não seja influenciado por ela. Essa sensibilidade a luz também é útil para se realizar o processo de bleaching que estingue o sinal remanescente nas amostras as preparando para outras medidas.

O processo de bleaching é o processo que apaga o sinal OSL remanescente nas amostras. Neste trabalho ele foi realizado através da iluminação das amostras com luz intensa, branca, pelo período de tempo necessário para que o sinal OSL se esgote. Estudos anteriores, realizados no laboratório de dosimetria da USP, mostraram que para o óxido de alumínio e para o óxido de berílio um intervalo de $2 \mathrm{~h}$ era suficiente para se extinguir o sinal remanescente nas amostras e não induzia efeitos indesejados como a fototransferência ou a fotoionização

Além de usar o bleaching para a extinguir o sinal remanescente, também podem ser feitos tratamentos térmicos com a mesma finalidade. Estes tratamentos térmicos também foram analisados em estudos no laboratório e, para as amostras de fluorita, ele foi feito mantendo as mesmas em um forno de $400{ }^{\circ} \mathrm{C}$ pelo intervalo de tempo de 20 minutos. 
Entre os materiais estudos neste trabalho estão óxido de alumínio $\left(\mathrm{Al}_{2} \mathrm{O}_{3}: \mathrm{C}\right)$, o óxido de berílio $(\mathrm{BeO})$ e a fluorita natural $\left(\mathrm{CaF}_{2}\right)$, mostrados na Figura 15

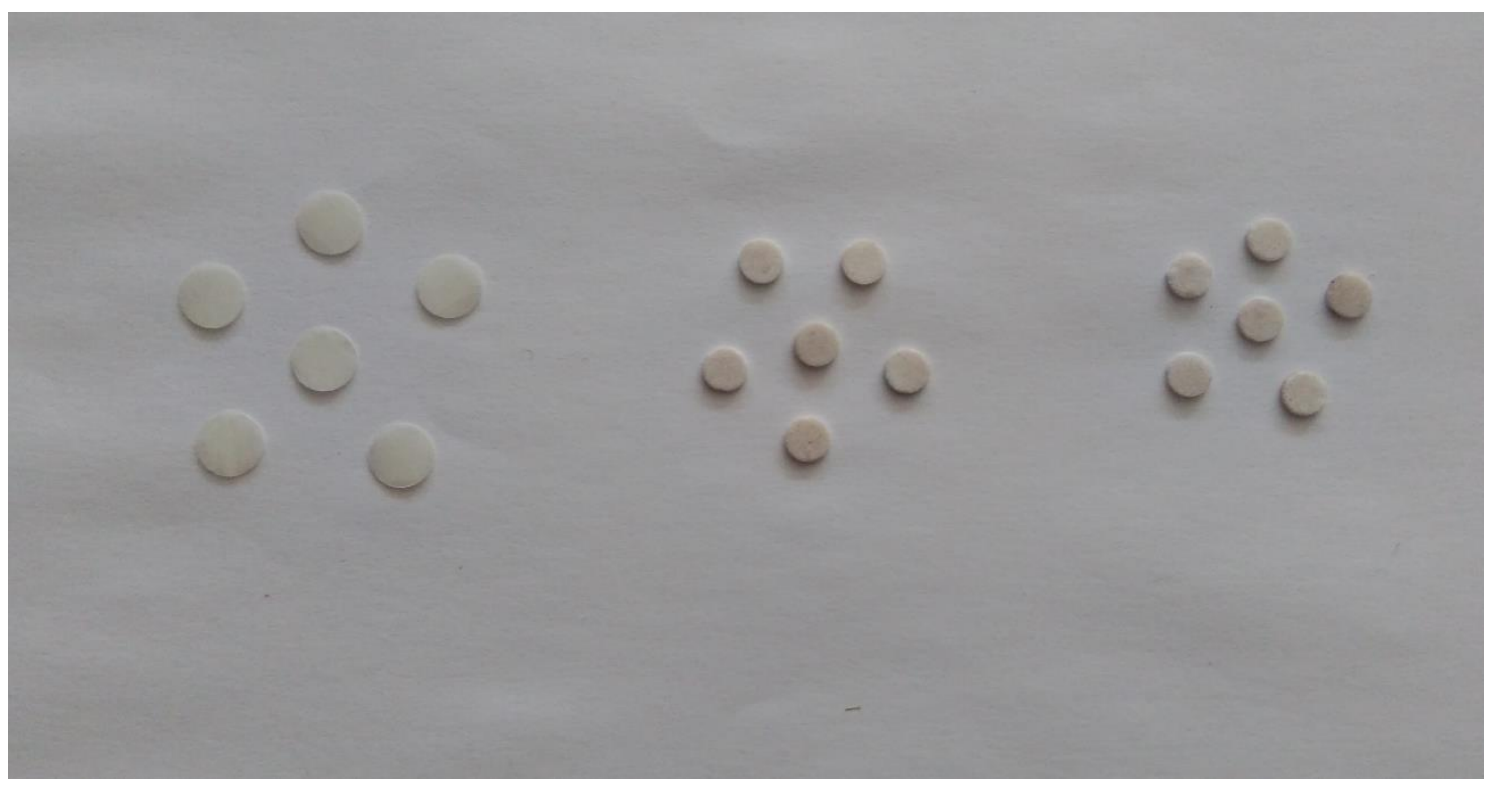

Figura 15. Amostras utilizadas de óxido de alumínio, óxido de berilio e fluorita, respectivamente.

\subsection{1 Óxido de Alumínio}

Estudamos o óxido de alumínio dopado com carbono $\left(\mathrm{Al}_{2} \mathrm{O}_{3}: \mathrm{C}\right)$. Este material serve como base para os sistemas dosimétricos Luxel e InLight da empresa Landauer ${ }^{\circledR}$ e era inicialmente usado com a técnica TL (Akselrod,1993 e McKeever, 1996) no entanto, suas características o tornaram um promissor material para o seu uso com a técnica OSL em diversas aplicações de dosimetria médica (Yukihara \& McKeever, 2011, p. 222).

O óxido de alumínio apresenta uma resposta que depende do comprimento de onda da luz incidente nele, como mostra a Figura 16. Dentre os defeitos do óxido de alumínio, os que são responsáveis pelo principal pico de emissão, que se encontra na posição de aproximadamente 415 nm (Yukihara \& McKeever, 2011, p. 78) se relacionam com vacâncias na rede cristalina. Este pico é na verdade uma banda larga e é possível se observar parte dela com o uso do filtro HoyaU340, utilizado nos experimentos realizados neste estudo. 

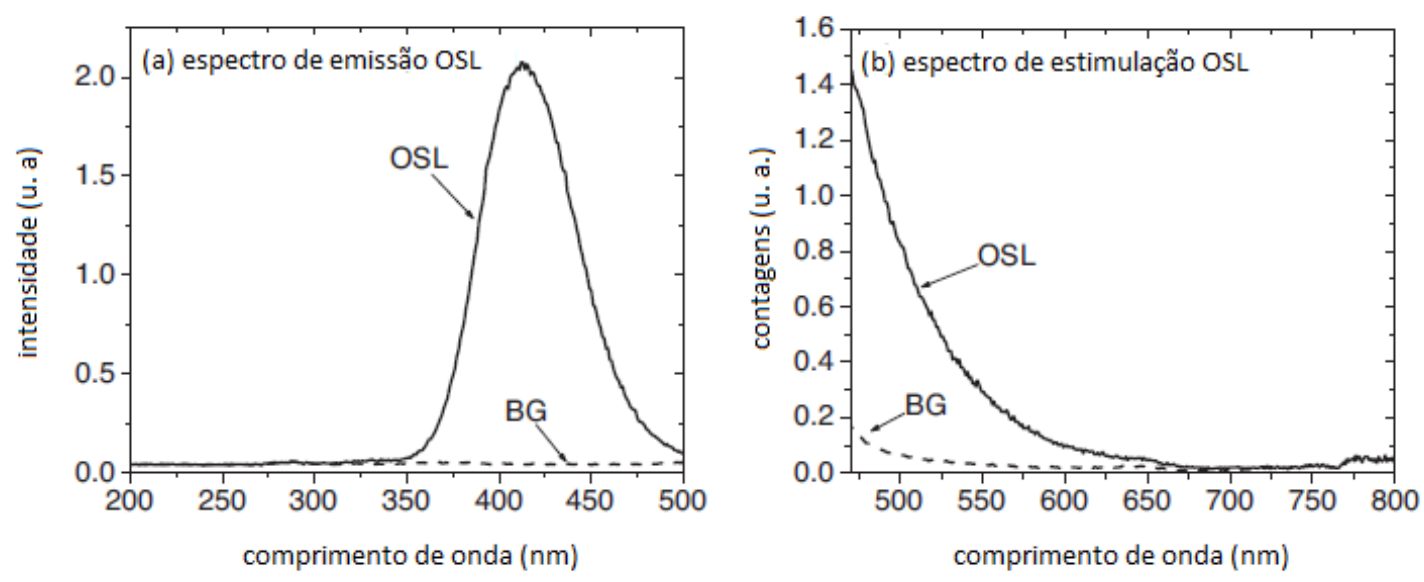

Figura 16. Espectro de emissão(a) e excitação(b) OSL do óxido de alumínio irradiado com 1 Gy. O espectro de emissão foi obtido com a iluminação da amostra a luz de excitação de $550 \mathrm{~nm}$ e foi medido com o filtro Schott OG-515 a frente do tubo fotomultiplicador. O espectro de estimulação foi obtido através da iluminação da amostra por luz de diversos comprimentos de onda e leitura da luz de luminescência fixa em $380 \mathrm{~nm}$. Reimpresso de Yukihara \& McKeever(2011).

O óxido de alumínio também apresenta uma resposta OSL linear em um amplo intervalo de doses, que inclui as energias utilizadas na área da dosimetria pessoal. Para altas doses, o sinal OSL tende a fugir da linearidade (Yukihara \& McKeever, 2011, pp. 132-133).

Nos experimentos relatados neste estudo as amostras de óxido de alumínio eram obtidas da fita Luxel, constituída de uma camada fina de pó de óxido de alumínio entre duas folhas de plástico, cortada em formato de discos de $7 \mathrm{~mm}$ de diâmetro e $0,3 \mathrm{~mm}$ de espessura.

\subsection{2 Óxido de Berílio}

O material BeO, utilizado neste trabalho, conhecido como ThermaloxTM 995, fornecido pela empresa Brush Wellman, é empregado em sistemas comerciais como um isolante elétrico.

Entre as características para a utilização do óxido de berílio como dosímetro OSL está o seu espectro de emissão e dependência linear com a dose. $O$ espectro de emissão dele é complexo e existem estudos que mostram picos de emissão em 335 nm e em 310 e 370 nm (Bulur \& Göksu, 1998) e (Yukihara E. , 2011). Ele também apresenta a característica de seu número atômico efetivo ser próximo ao do tecido humano $\left(Z_{\mathrm{BeO}}=7,31\right.$ e $\left.Z_{\mathrm{H} 2 \mathrm{O}}=7,51\right)$ e ter alta sensibilidade, além do custo relativamente baixo. Estes fatores o tornam um promissor material para ser usado na dosimetria (Bulur \& Göksu, 1998) (Bulur \& Yeltik, 2010); (Bos, 2001).

O óxido de berílio apresenta uma alta sensibilidade a radiação ionizante. Além disso, a resposta do sinal OSL é linear com a dose incidente entre $5 \mu$ Gy a 50 Gy.

Existem estudos que mostram os resultados do efeito de recozimentos diferentes na sensibilidade do óxido de berílio e estes não são muito relevantes, ou seja, as medidas com este material têm a características de serem reprodutíveis (Sommer \& Henniger, 2006). 
Para a limpeza do sinal OSL residual no óxido de berílio somente o processo de bleaching pode não ser suficiente em alguns casos. De qualquer forma, resultados mostram que o processo de bleaching retira a maior parte do sinal OSL residual.

Um fenômeno conhecido em amostras usadas em OSL é a diminuição do sinal OSL se há uma espera, mesmo no escuro, entre a irradiação e a leitura OSL. Este fenômeno recebe o nome de fading, e, em geral, a diminuição do sinal é função do tempo de espera. As amostras de óxido de berílio apresentam um fading de $5 \%$ do sinal OSL na primeira hora na temperatura ambiente (Sommer \& Henniger, 2006); (Bulur \& Göksu, 1998)). Após isto, o sinal se estabiliza.

Nos experimentos relatados neste estudo as amostras eram cilindros de 5,05 $\mathrm{mm}$ de diâmetro e 1,1 $\mathrm{mm}$ de espessura.

\subsubsection{Fluorita natural}

A fluorita $\left(\mathrm{CaF}_{2}\right)$ é um conhecido material com bastante sensibilidade a radiação gama utilizado como dosímetro TL. Ela é utilizada para a dosimetria ambiental na Índia há três décadas com dosímetria TL (Chougaonkar \& Bhatt, 2004). No Brasil, o Laboratório de Dosimetria das Radiações e Física Médica emprega fluorita natural para monitoração individual (indivíduos ocupacionalmente expostos) há três décadas, também com termoluminescência (Okuno, e al., 2015).

Com o desenvolvimento da técnica OSL e dos LEDs surgiram possibilidades do uso destas tecnologias em amostras para os estudos de datação. As medidas OSL com fluorita começaram em aplicações de datação geológica usando luz verde e infravermelho (McKeever S. M., 2001). Posteriormente, estudos apontaram a fluorita como um promissor material a ser utilizado para a área dosimétrica com a técnica OSL (Chougaonkar \& Bhatt, 2004) e (Yoshimura \& Yukihara, 2006). Um dos problemas relatados com amostras de fluorita é o seu fading que é relevante para medidas OSL. Apesar disso, este problema pode ser contornado com o tratamento térmico das amostras (Yoshimura \& Yukihara, 2006).

A fluorita natural apresenta diversas composições dependendo do local da procedência da mesma. Essa composição pode acarretar em uma resposta diferente a radiação (Bibiano, J. A., 2015). Nos experimentos relatados neste estudo as amostras eram pequenos discos de fluorita com metasilicato de sódio $\left(\mathrm{Na}_{2} \mathrm{SiO}_{3}\right)$, e dimensões de $5,1 \mathrm{~mm}$ de diâmetro e $1 \mathrm{~mm}$ de espessura.

\subsection{Metodologia empregada nos experimentos}

Para observar a influência da iluminação com luz vermelha e infravermelha no sinal OSL desses dosímetros foram feitos os seguintes estudos: variação da potência do emissor laser em função do tempo, variação do sinal OSL em função da iluminação das amostras, e fading em amostras de fluorita. Cada um destes estudos será detalhado nas seções seguintes. 


\subsubsection{Estudo da variação da potência luminosa emitida pelo MMO Twin Flex em função do tempo}

Com a finalidade de se determinar a energia luminosa incidente nas amostras com mais precisão, foi feito um experimento com o medidor de potência LaserStar e o emissor MMO Twin Flex Laser para o laser vermelho (658nm). O experimento consistia em posicionar o medidor de potência e a ponteira emissora de laser vermelho em um banco ótico e medir a potência emitida pelo equipamento MMO Twin Flex Laser em função do tempo para as potências nominais de 10, 20, 50 e $100 \mathrm{~mW}$. O arranjo experimental é mostrado na Figura 17.

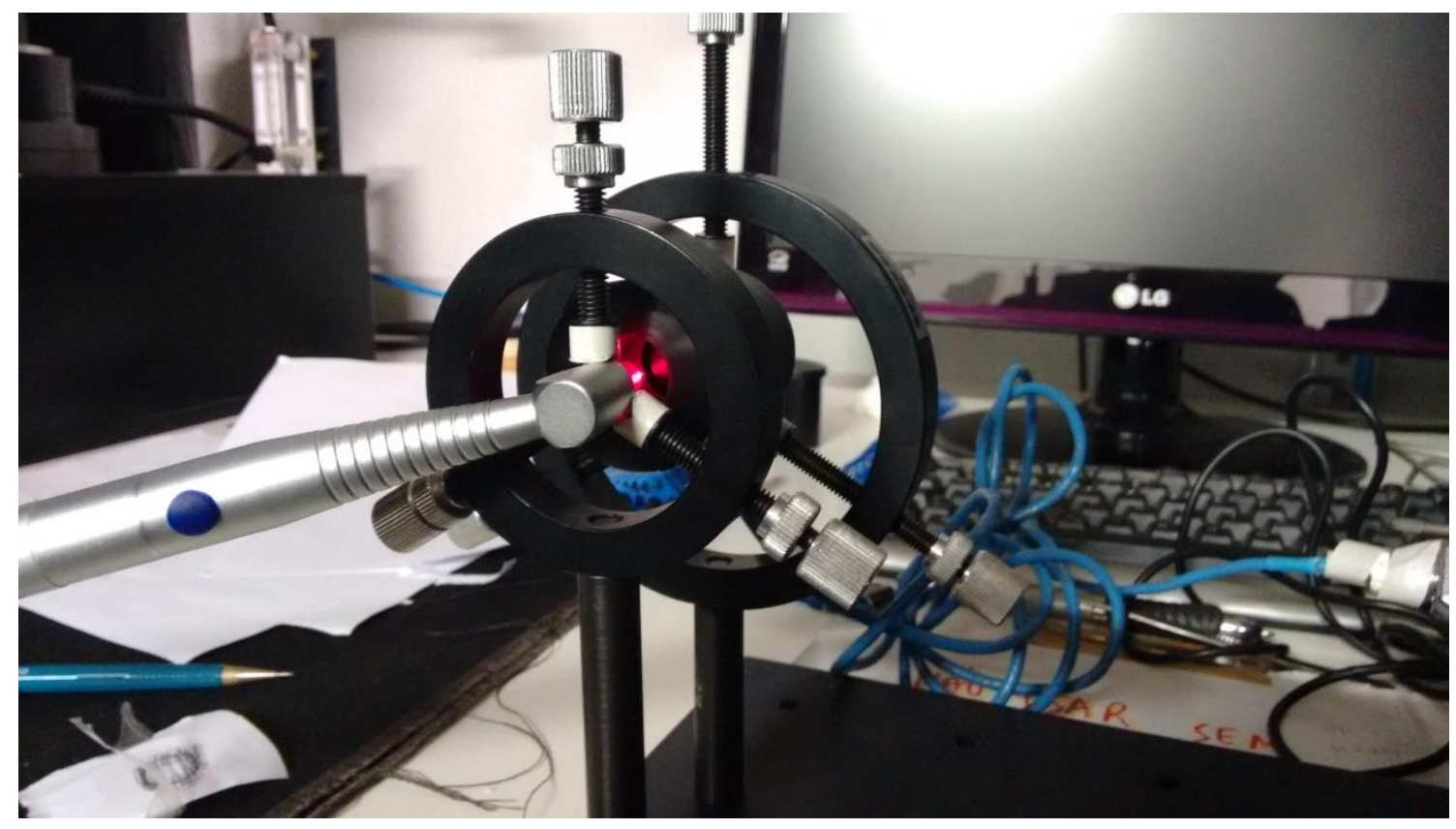

Figura 17. Foto do banco ótico montado para as leituras da curva de potência do equipamento MMO Twin Flex Laser.

Os intervalos de tempo de 10, 20, 50, 90, 120 e 180 s foram usados para a emissão, e o medidor de potência fazia medidas a intervalos de tempo fixados para cada leitura. Nas leituras com intervalo de tempo de 10 e $20 \mathrm{~s}$ foram feitas medidas da potência a cada $5 \mathrm{~s}$ e para o restante a potência foi lida a cada $10 \mathrm{~s}$.

Este experimento foi feito 3 vezes para cada intervalo de tempo selecionado $(10,20,50$, 90,120 e 180 s) e para cada potência utilizada no emissor laser (10, 20, 50 e $100 \mathrm{~mW}$ ). Com estes resultados, calculamos a energia devido a cada exposição através da integral numérica dos resultados como em função do tempo.

\subsubsection{Estudo da variação do sinal OSL em função da iluminação das amostras.}


Esse experimento, parte central deste estudo, visa estabelecer uma metodologia para avaliar a energia depositada nessas iluminações (com luz vermelha ou infravermelha) através da queda do sinal OSL das amostras iluminadas. Com este objetivo foram feitos estes experimentos que avaliam o sinal OSL após a iluminação de dosímetros OSL (previamente irradiados com radiação beta) com luz vermelha ou infravermelha. Eles foram realizados segundo as etapas: Limpeza de sinal residual, Irradiação das amostras, Iluminação, Leitura do sinal OSL e Irradiação e Leitura para o cálculo do sinal OSL relativo, etapas essas explicitadas a seguir.

A limpeza do sinal residual: foi feito um processo de condicionamento das amostras com a finalidade de eliminar o de sinal OSL residual das amostras (dosímetros). Este processo é diferente para cada tipo de amostra. No caso do óxido de alumínio e óxido de berílio, ele foi feito expondo o conjunto de amostras a luz branca (quatro lâmpadas Digilight ATEC com $55 \mathrm{~W}$ de potência) durante, no mínimo, $3 \mathrm{~h}$ (bleaching). Para as amostras de fluorita, este processo foi feito com tratamento térmico a $400{ }^{\circ} \mathrm{C}$ durante 20 minutos.

Irradiação das amostras: as amostras de cada material eram levadas ao equipamento TL/OSL Ris $\varnothing$ para serem irradiadas pela fonte $\beta\left({ }^{90} \mathrm{Sr} /{ }^{90} \mathrm{Y}\right.$ ), por $5 \mathrm{~s}$ (que corresponde a uma dose absorvida de, aproximadamente, $50 \mathrm{mGy}$ ).

Iluminação: as amostras eram retiradas do equipamento TL/OSL Ris $\varnothing$ e divididas em conjuntos de 4 dosímetros. Cada conjunto era iluminado pelo laser vermelho $(658 \mathrm{~nm})$ do equipamento MMO Twin Flex Laser por intervalos de tempo de 0, 10, 20, 50, 90, 120 e $180 \mathrm{~s}$. Este processo era feito em um local com baixa luminosidade com a finalidade de se diminuir a influência da iluminação ambiente no sinal das amostras. Para iluminação com infravermelho $(870 \mathrm{~nm})$ utilizamos os LEDs do equipamento do TL/OSL Ris $\varnothing$ pelos mesmos intervalos de tempo e as amostras não foram retiradas do equipamento.

Leitura de sinal OSL: as amostras eram levadas novamente ao equipamento TL/OSL Ris $\varnothing$ onde seriam realizadas leituras OSL. As leituras das curvas OSL foram realizadas com os LEDs azuis com $90 \%$ de potência durante o intervalo de tempo de 100 s utilizando o filtro Hoya U-340 e um colimador de $10 \mathrm{~mm}$ de diâmetro.

Irradiação e leitura para o cálculo do sinal relativo: as amostras ainda no equipamento TL/OSL Ris $\varnothing$, sem serem retiradas após a leitura de sinal OSL, eram novamente expostas à fonte $\beta$, por um intervalo de tempo de $2 \mathrm{~s}$ (que equivale a uma dose de $20 \mathrm{mGy}$ ). Uma nova leitura do sinal OSL das amostras era feita, com os mesmos parâmetros de leitura da etapa anterior

Com os sinais OSL de cada dosímetro das etapas da leitura de sinal OSL e Irradiação e leitura para o cálculo do sinal relativo, foi feito o cálculo como descrito na equação

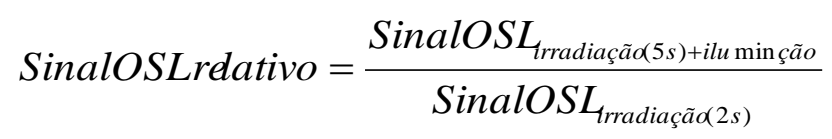

A proposta de análise do sinal OSL relativo é que o mesmo apresenta uma incerteza menor quando comparada com a incerteza do sinal OSL de um conjunto de dosímetros. A divisão dos sinais OSL das duas etapas tende a diminuir a variação do sinal OSL devido a características de 
cada dosímetro, como quantidade de massa. Com os dados coletados para cada conjunto de dosímetros iluminados pelo mesmo intervalo de tempo foi feita a análise estatística com a média e o desvio padrão dos resultados. A Figura 18 exemplifica as etapas experimentais, após a limpeza do sinal OSL, mencionadas.
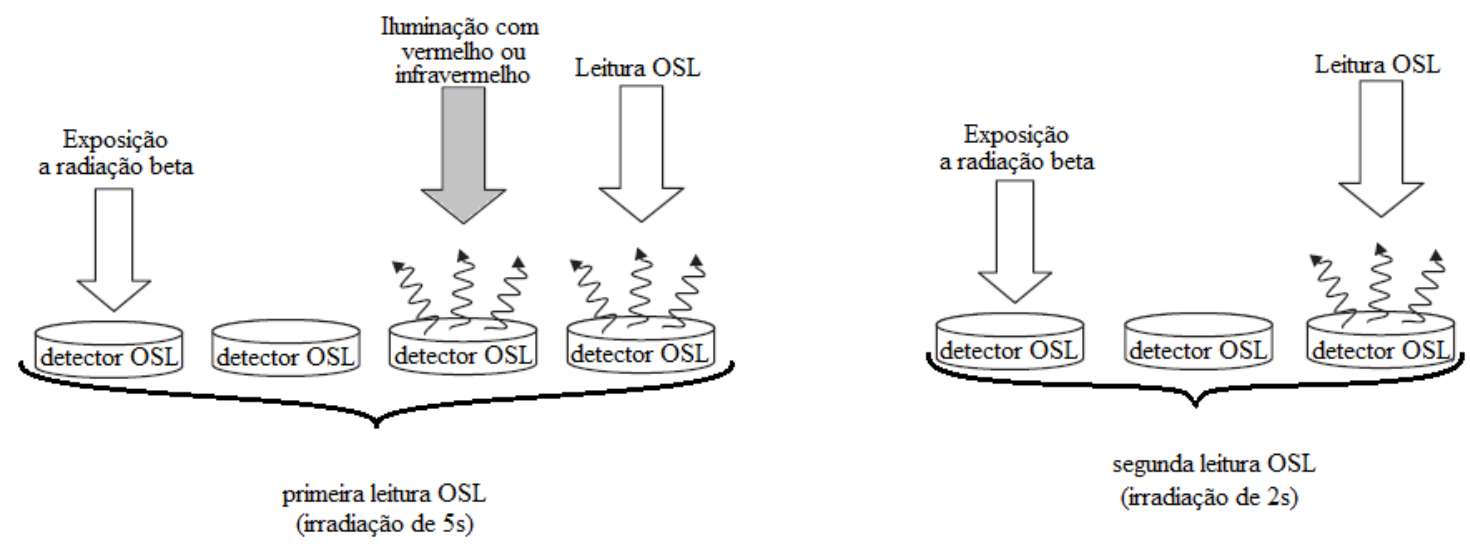

Figura 18. Esquema que demonstra as etapas experimentais para a análise da variação do sinal OSL

\subsubsection{Estudo do fading (Desvanecimento) de sinal OSL de amostras de Fluorita}

Entre as amostras estudadas, a fluorita apresenta fading que pode influenciar nas medidas realizadas. Devido a isto, foi feito um experimento para mensurar esta influência do fading da fluorita. Este experimento foi feito de maneira análoga aos experimentos que observam a influência da iluminação com laser vermelho ou infravermelho, descrito anteriormente. No entanto, nos momentos em que a amostra seria iluminada com luz vermelha ou infravermelha, foi feita uma espera no escuro, pelos mesmos intervalos de tempo $(0,10,20,50,90,120$ e $180 \mathrm{~s})$. Com isso, estimamos a variação no sinal OSL no escuro que corresponde ao fading. Comparando estes resultados com os do estudo anterior é possível estimar a variação do sinal OSL influenciado somente pela luminescência. $O$ método descrito é mostrado esquematicamente na Figura 19. 


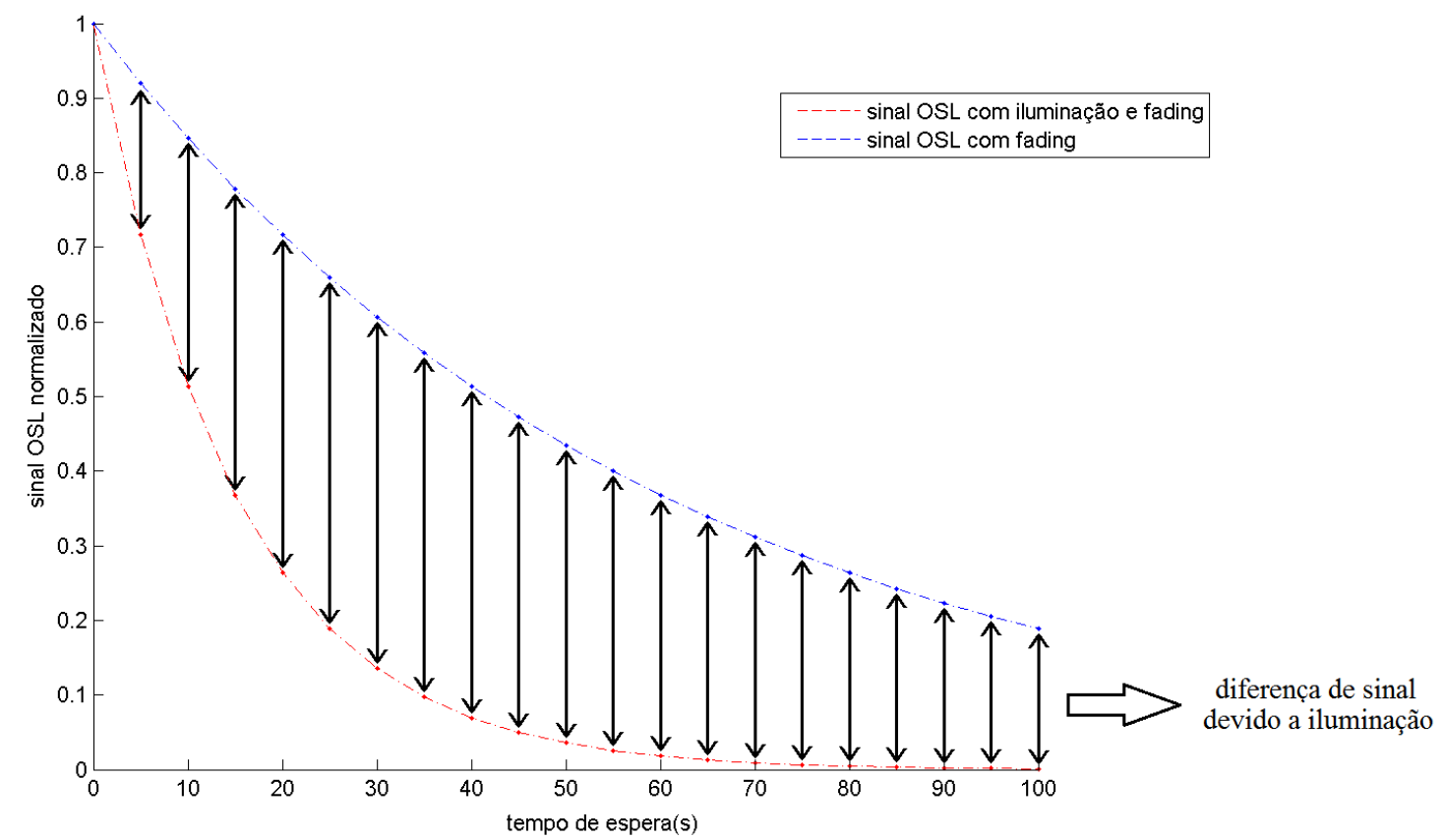

Figura 19. Exemplificação do método utilizado para estimar a influência do fading no sinal OSL das amostras. O tempo de espera é o tempo dado entre a iluminação e a leitura OSL dos dosímetros.

Contabilizando a diferença de sinal OSL entre os dosímetros mantidos no escuro e aqueles que foram iluminados (vermelho ou infravermelho), evidenciada na Figura 19, calculamos o quanto a curva OSL decai devido à iluminação, para cada tempo ao qual a amostra foi iluminada. Este resultado fica evidenciado na equação (13).

$$
\operatorname{SinalOSL}_{\text {lum }}(t)=1-\left[\operatorname{SinalOSL}_{\text {fading }}(t)-\operatorname{SinalOSL}_{\text {lum }+ \text { fading }}(t)\right]
$$

onde SinalOSL $L_{\text {ilum }}$ é o sinal OSL normalizado corrigido pela influência do fading da amostra, SinalOSLilum+fading é o sinal OSL normalizado com a influência da iluminação e do fading juntos, SinalOSL $L_{\text {fading }}$ é o sinal OSL normalizado devido somente ao fading das amostras, sem iluminação, e $t_{0}$ é o instante inicial de leitura. A equação (13) foi utilizada para estimar como seria a curva de variação do sinal OSL devido à iluminação da amostra, corrigindo o efeito do fading.

\subsubsection{Metodologia de análise do sinal OSL nos experimentos}

A análise dos dados obtidos com as leituras do sinal OSL das amostras nos experimentos foi realizada usando o sinal inicial e o sinal integrado OSL: sinal inicial OSL é a contagem do sinal OSL pelo intervalo de tempo de $1 \mathrm{~s}$ após o começo da estimulação. O sinal integrado OSL é a 
contagem obtida durante o intervalo de tempo total da estimulação (100 s). O cálculo do sinal relativo, já descrito anteriormente (equação (12)) foi feito para ambos os sinais.

Para as medidas do sinal integrado OSL retiramos do sinal OSL a contribuição de sinal de fundo de cada leitura. O sinal de fundo é a quantidade de luz detectada pelo tubo fotomultiplicador que é devido a outras fontes que não a luminescência da amostra. Para isso, estimamos o sinal OSL devido ao fundo por meio dos instantes finais de leitura das curvas OSL, pois já houve o esgotamento do sinal. Estimamos o sinal do fundo como a média dos últimos $10 \mathrm{~s}$ das curvas OSL para cada dosímetro. Após isto, extrapolamos este sinal para todo o intervalo de tempo de medida e a contagem devido ao fundo foi estimada com a área desta curva extrapolada. Para eliminar a influência do fundo no sinal OSL fizemos a subtração dos sinais integrados, como ilustrado na Figura 20. Para o sinal inicial OSL o fundo não era relevante nas medidas e a subtração não foi feita.

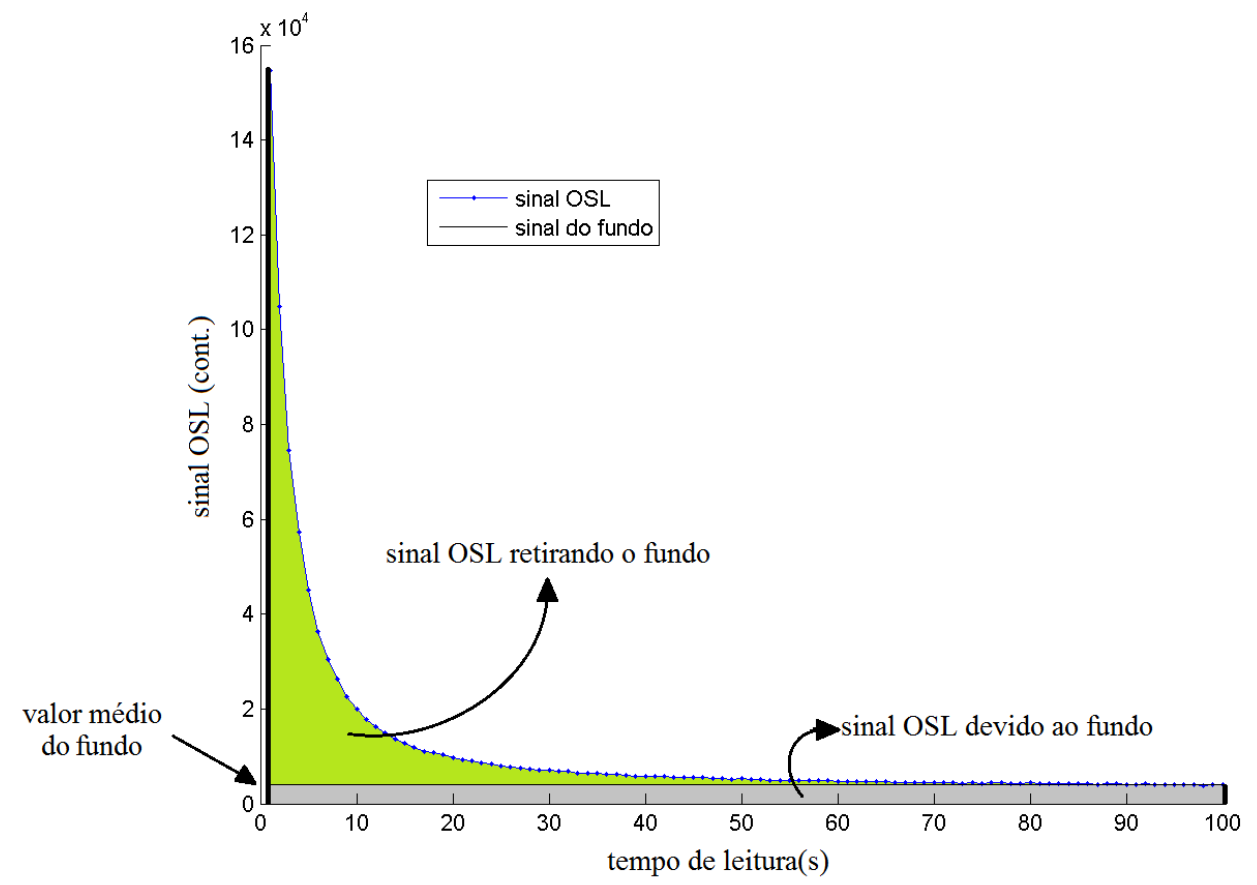

Figura 20. Curva OSL da amostra de Luxel. O sinal integrado OSL sem a influência da iluminação de fundo (área verde), a curva com o valor médio do fundo extrapolado durante todo o intervalo da curva OSL devido ao fundo e sinal integrado OSL sem a influência do mesmo (área cinza) são evidenciados.

Após esta etapa, para verificar a variação do sinal OSL em função do tempo de iluminação e a energia incidente nas amostras, foram feitas análises estatísticas (cálculo de média e desvio padrão) com o conjunto de dados obtidos em cada iluminação para cada iluminação com potência diferente. Com os resultados obtidos foram feitos gráficos que mostravam o valor de sinal remanescente nas amostras em função da energia luminosa de cada iluminação. 


\section{RESULTADOS}

4.1 Estudo da variação da potência luminosa emitida pelo MMO Twin Flex em função do tempo

Com a finalidade de se ter maior acurácia nas medidas de energia, a verificação da constância da potência do equipamento MMO Twin Flex Laser. Neste experimento, a ponteira do emissor MMO Twin Flex Laser era fixada ao medidor de potência Ophir LaserStar através de um banco óptico e o primeiro emitia o laser vermelho $(658 \mathrm{~nm})$ durante os intervalos de tempo de 10, 20, 50, 90, 120 e $180 \mathrm{~s}$. Os valores de potência obtidos ao longo do tempo são mostrados na Figura 21, e os valores relativos à potência máxima medida estão na Figura 22

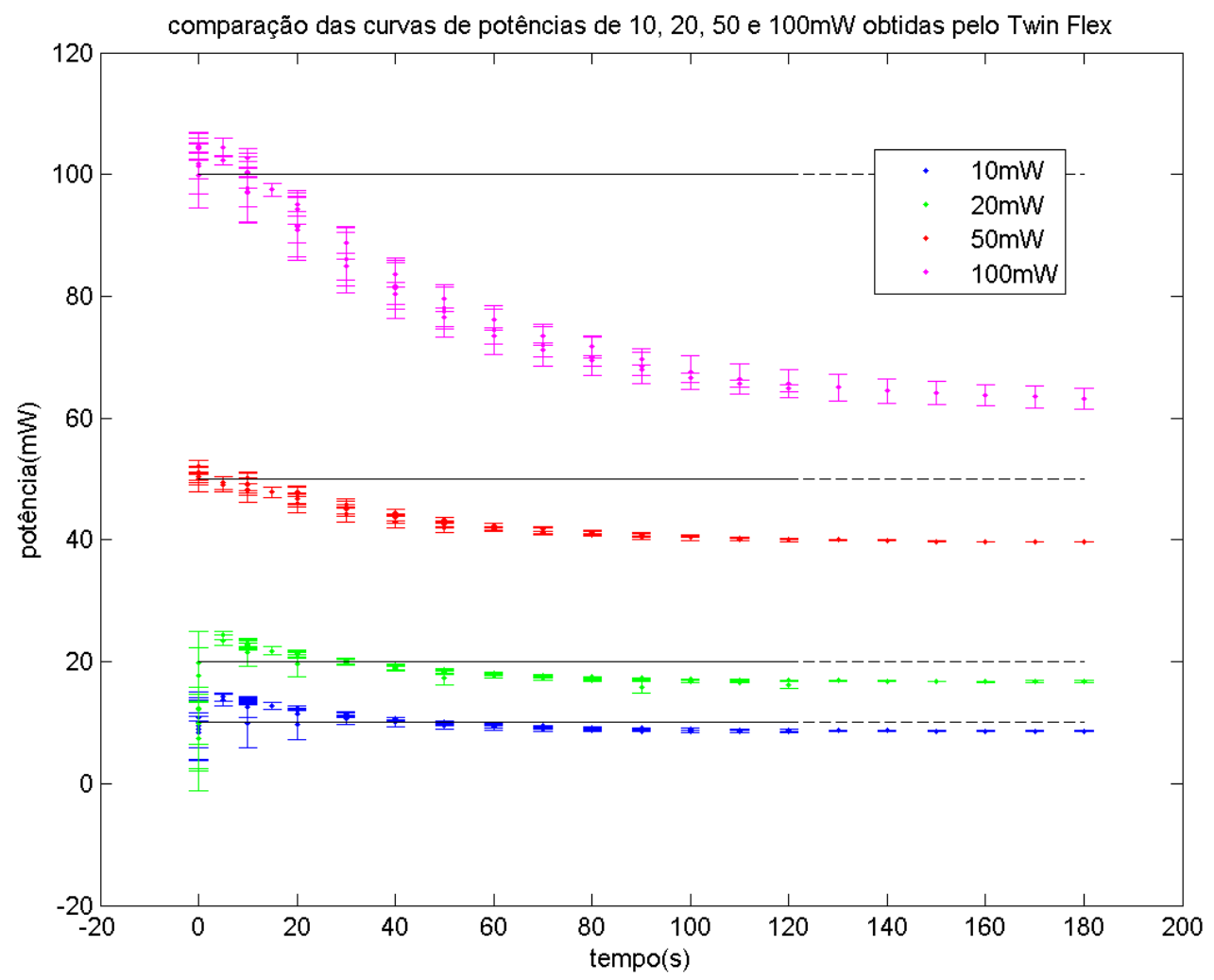

Figura 21. Variação da potência do equipamento MMO Twin Flex Laser par as potências de 10, 20, 50 e $100 \mathrm{~mW}$ no tempo. No gráfico, as retas horizontais representam as potências nominais de 10, 20, 50 e 100mW. 


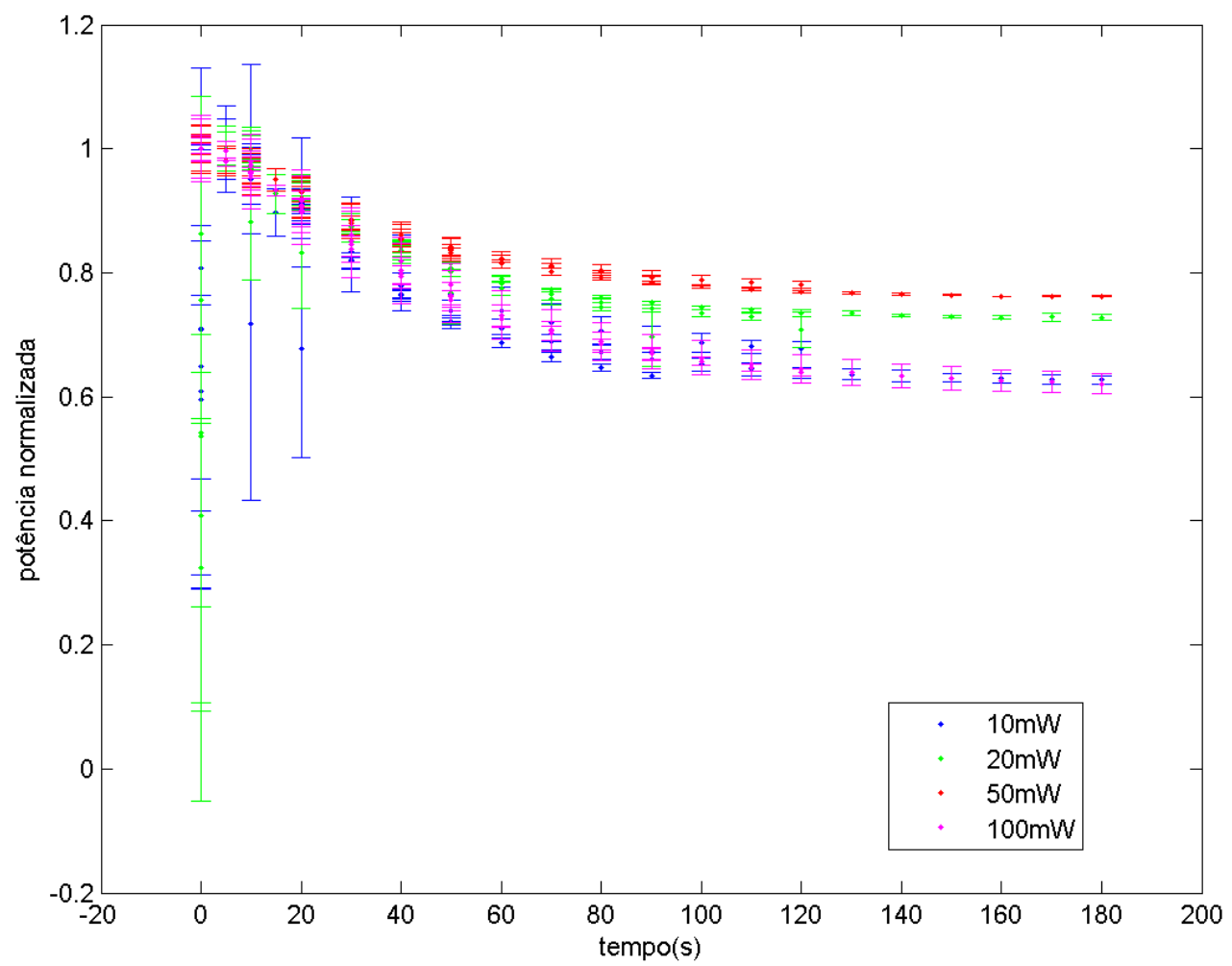

Figura 22. Variação da potência normalizada para o valor máximo da curva de potência do equipamento MMO Twin Flex Laser para as potências de 10, 20, 50 e $100 \mathrm{~mW}$.

Com estes resultados constatamos que a potência do emissor MMO Twin Flex Laser varia com o tempo de iluminação e que o comportamento no tempo não é o mesmo para todas as potências nominais. Observamos um crescimento rápido das potências nos instantes iniciais, acima da potência nominal, e depois decréscimo para valores menores do que a potência esperada. Isso poderia alterar a energia com a qual as amostras eram iluminadas.

Logo, para calcular a energia luminosa a que cada amostra foi exposta, foi feito o cálculo da integral numérica no tempo dos valores de potência medidos. Os resultados encontrados são mostrados na Tabela 3.

Tabela 3. Valores encontrados para as energias de iluminação que as amostras foram expostas.

$$
\text { potência ( } \mathrm{mW} \text { ) }
$$

10

20

50

100

\begin{tabular}{ccccc}
\hline tempo de iluminação $(\mathbf{s})$ & \multicolumn{4}{c}{ energia (J) } \\
$\mathbf{0}$ & 0 & 0 & 0 & 0 \\
$\mathbf{1 0}$ & $0,113(13)$ & $0,201(12)$ & $0,491(11)$ & $1,04(14)$ \\
$\mathbf{2 0}$ & $0,251(8)$ & $0,44(3)$ & $0,974(16)$ & $2,00(17)$ \\
$\mathbf{5 0}$ & $0,560(29)$ & $0,95(5)$ & $2,27(7)$ & $4,45(22)$ \\
$\mathbf{9 0}$ & $0,938(15)$ & $1,67(2)$ & $3,97(5)$ & $7,55(19)$ \\
$\mathbf{1 2 0}$ & $1,15(5)$ & $2,19(6)$ & $5,20(12)$ & $9,27(17)$ \\
\hline $\mathbf{1 8 0}$ & $1,74(6)$ & $3,26(4)$ & $7,63(5)$ & $13,2(6)$ \\
\hline
\end{tabular}




\subsection{Estudo da Variação do Sinal OSL em função da Energia Luminosa incidente nos dosímetros}

O estudo consistiu na análise de como a energia luminosa (luz vermelha ou infravermelha) incidente em dosímetros de óxido de alumínio $\left(\mathrm{Al}_{2} \mathrm{O}_{3}: \mathrm{C}\right)$, óxido de berílio $(\mathrm{BeO})$ e fluorita $\left(\mathrm{CaF}_{2}: \mathrm{Na}_{2} \mathrm{SiO}_{3}\right)$, previamente irradiados, influencia no sinal OSL, inicial e integrado. Inicialmente serão apresentados os resultados e, em seguida, os mesmos serão discutidos.

\subsubsection{Estudo da influência da lluminação com laser vermelho (658nm) e LED infravermelho (870nm) no Sinal OSL para dosímetros de Óxido de Alumínio}

Para a verificação da influência da energia luminosa incidente em dosímetros de óxido de alumínio no sinal inicial OSL as amostras foram iluminadas por laser de comprimento de onda no vermelho $(658 \mathrm{~nm})$ de potências de 10, 2050 e $100 \mathrm{~mW}$.

Nos experimentos com o laser de $658 \mathrm{~nm}$ os resultados obtidos para a análise do sinal inicial OSL são mostrados nas Figura 23, Figura 24 e Figura 25; para o sinal integrado os resultados encontrados são mostrados na Figura 26, Figura 27 e Figura 28.

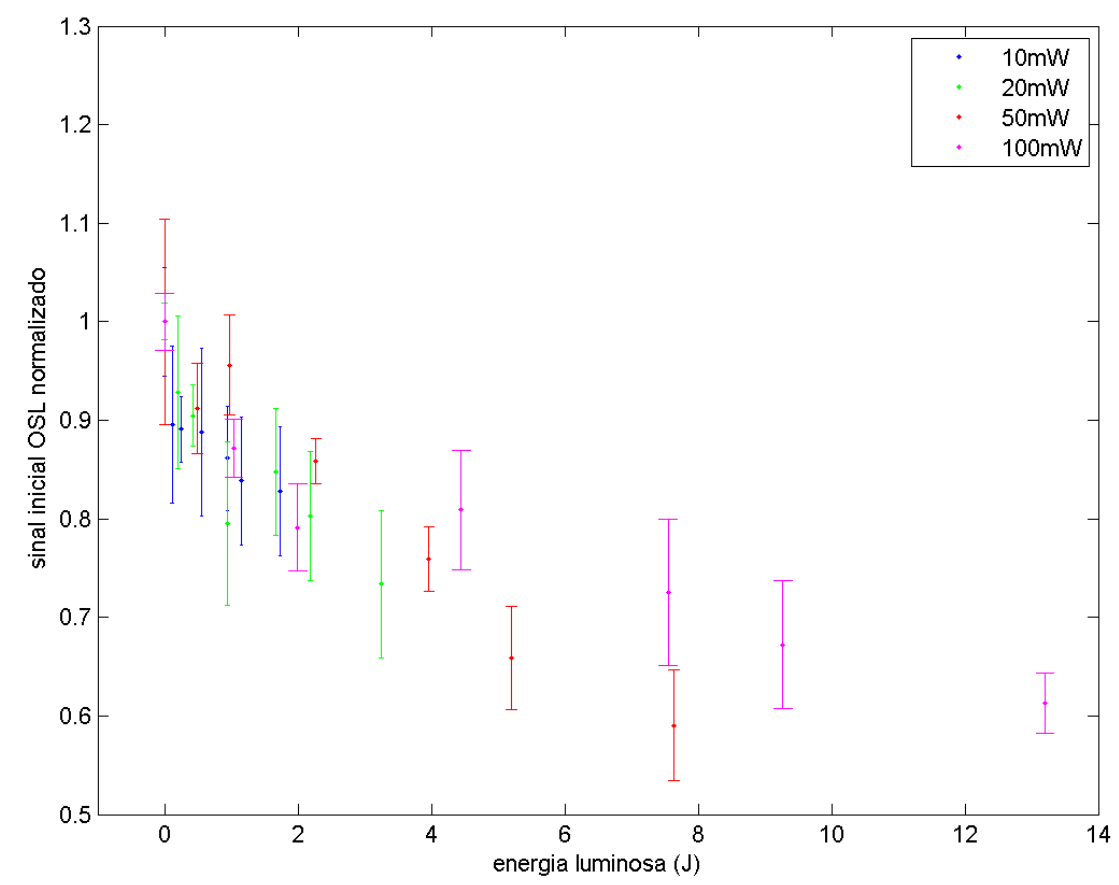

Figura 23. Variação do sinal inicial OSL normalizado ao primeiro ponto para os experimentos de iluminação das amostras de óxido de alumínio com laser de $658 \mathrm{~nm}$ e potências de 10, 20, 50 e $100 \mathrm{~mW}$ em função da energia luminosa incidente nos dosímetros. 


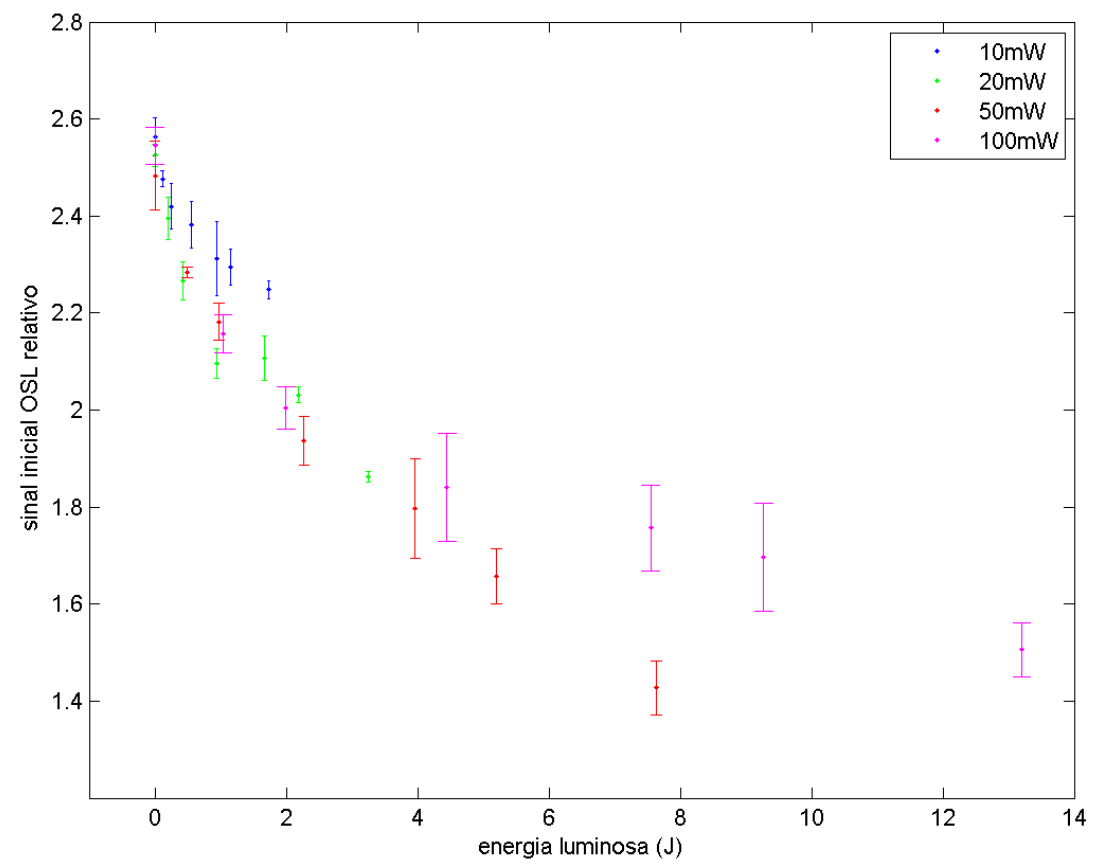

Figura 24: Variação do sinal inicial OSL relativo para os experimentos de iluminação das amostras de óxido de alumínio com laser de $658 \mathrm{~nm}$ e potências de 10, 20, 50 e $100 \mathrm{~mW}$ em função da energia luminosa incidente nos dosímetros.

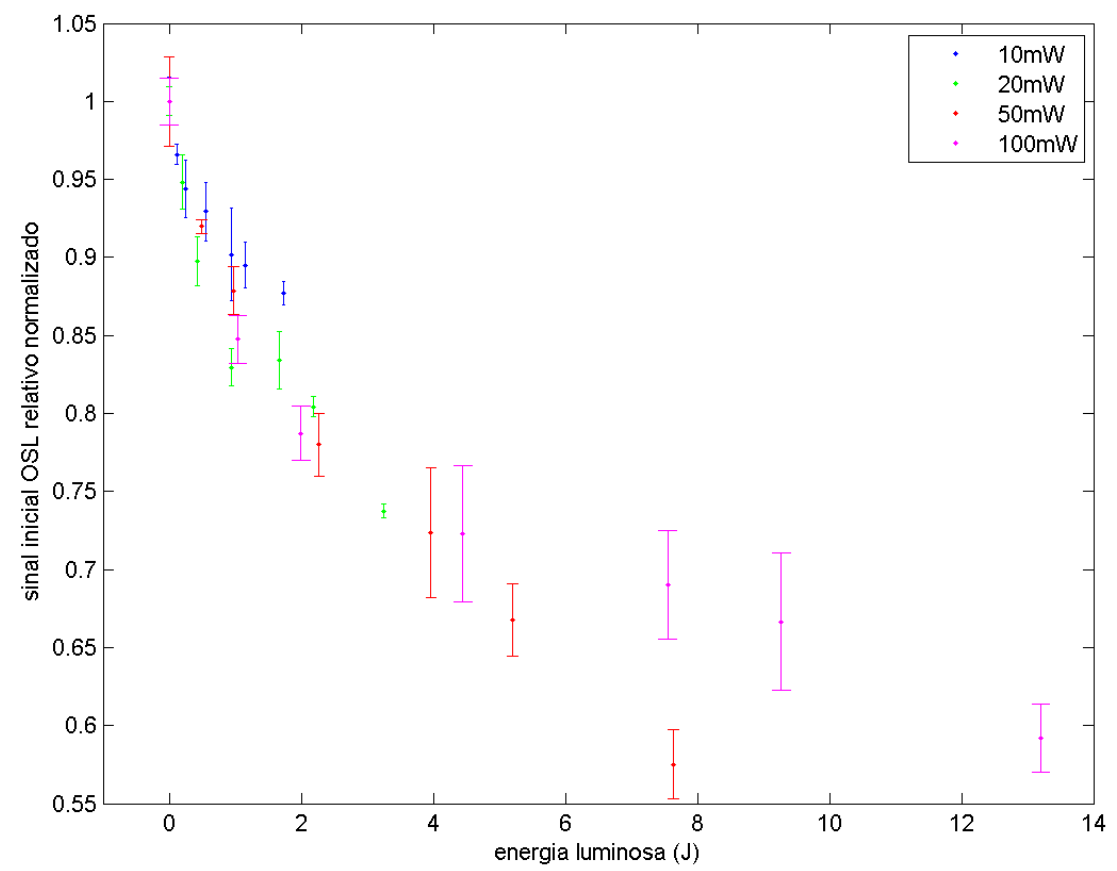

Figura 25 Variação do sinal inicial OSL relativo normalizado para os experimentos de iluminação das amostras de óxido de alumínio com laser de $658 \mathrm{~nm}$ e potências de 10,20, 50 e $100 \mathrm{~mW}$ em função da energia luminosa incidente nos dosímetros. 


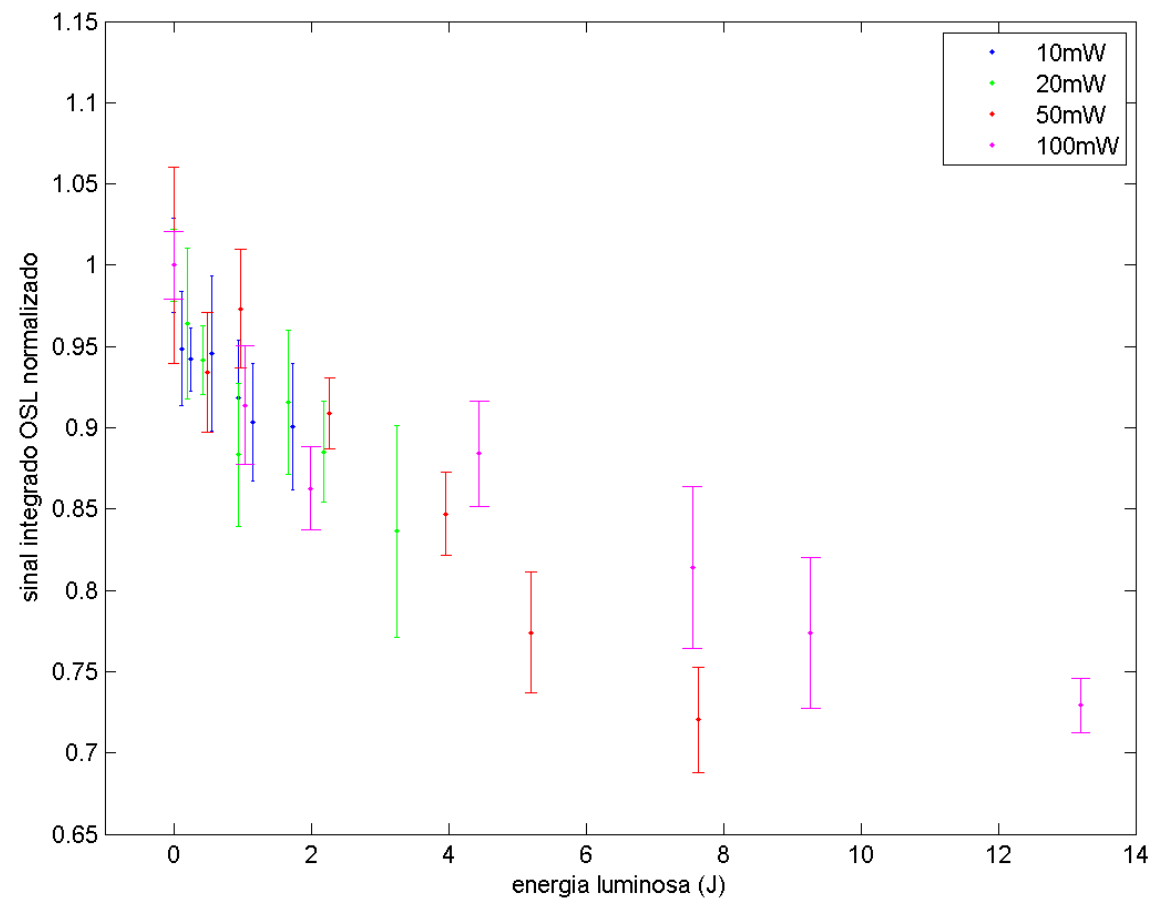

Figura 26. Variação do sinal integrado OSL normalizado ao primeiro ponto das amostras de óxido de alumínio iluminadas por laser de $658 \mathrm{~nm}$ e potências de 10, 20, 50 e $100 \mathrm{~mW}$ em função da energia luminosa incidente nas mesmas.

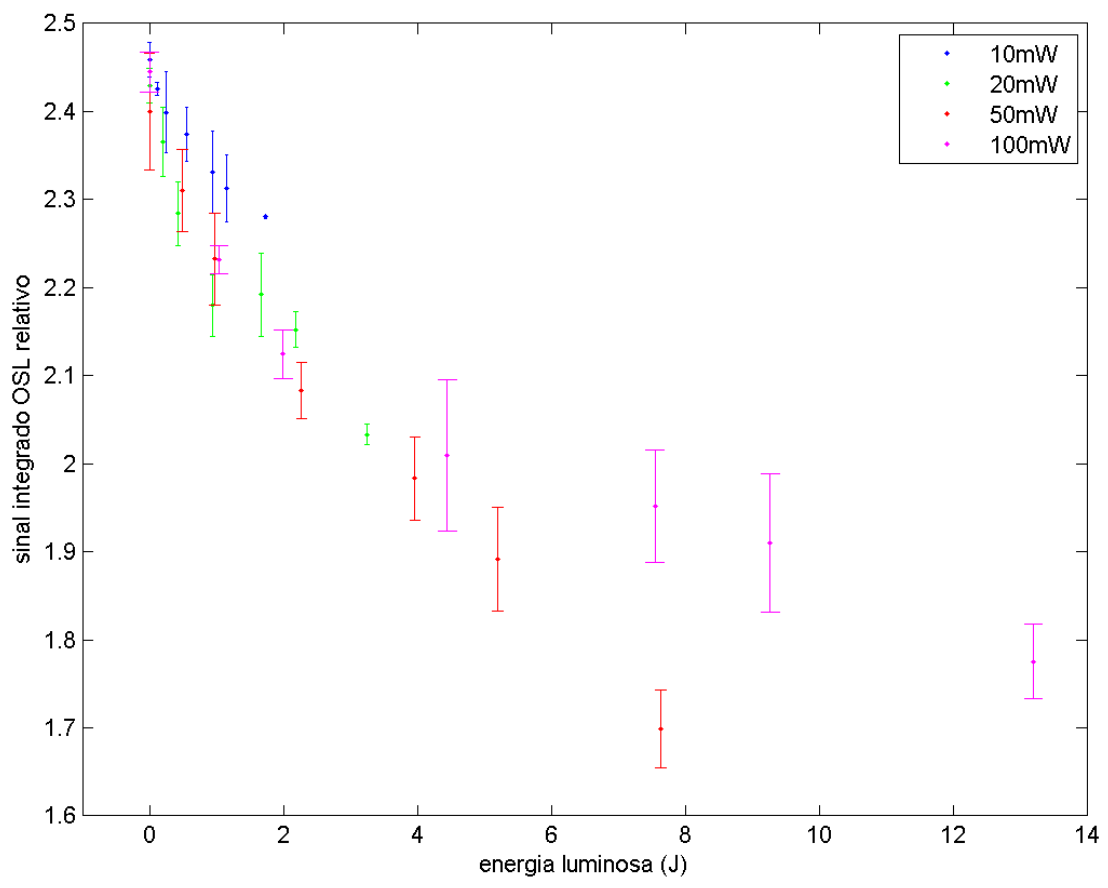

Figura 27 Variação do sinal integrado OSL relativo das amostras de óxido de alumínio iluminadas por laser de $658 \mathrm{~nm}$ e potências de 10, 20, 50 e $100 \mathrm{~mW}$ em função da energia luminosa incidente nos dosímetros. 


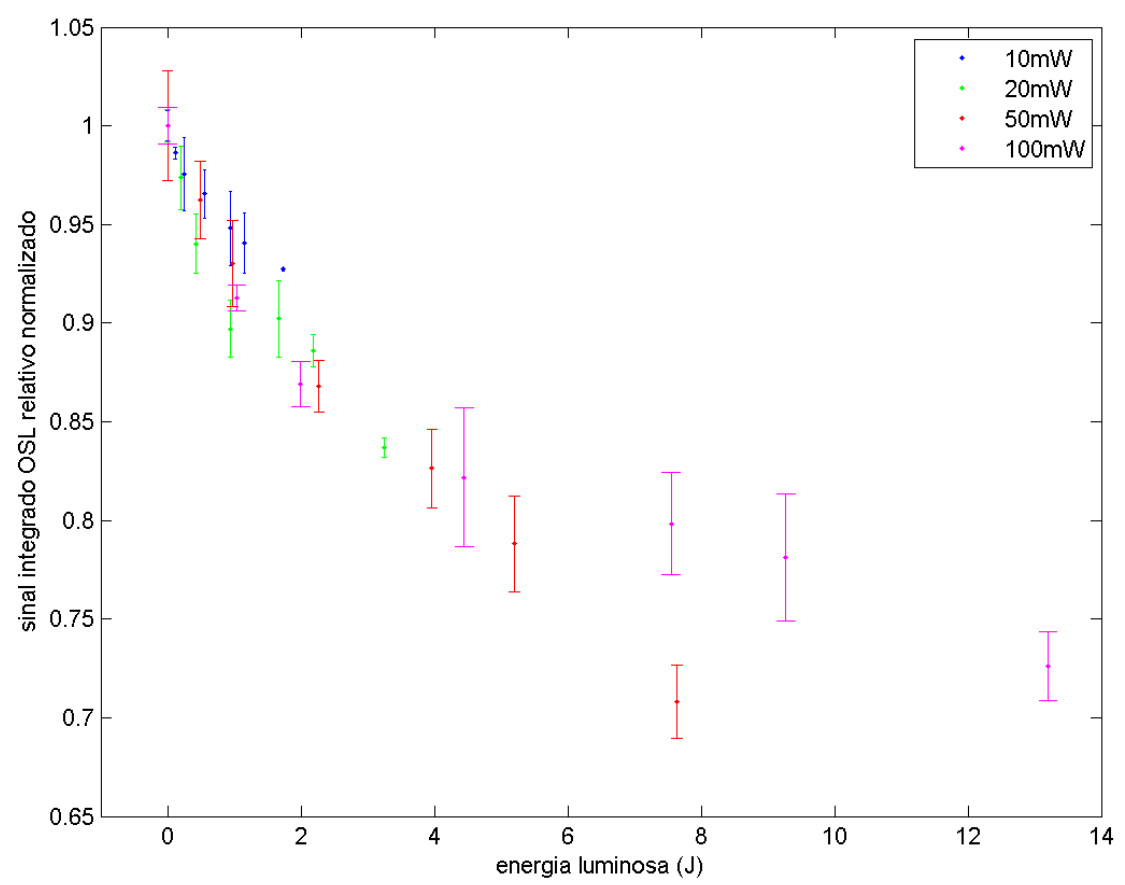

Figura 28 Variação do sinal integrado OSL relativo normalizado ao primeiro ponto das amostras de óxido de alumínio iluminadas por laser de $658 \mathrm{~nm}$ e potências de 10,20,50 e $100 \mathrm{~mW}$ em função da energia luminosa incidente nos dosímetros.

Os resultados evidenciaram que a iluminação com laser de $658 \mathrm{~nm}$ influencia o sinal OSL nas amostras de óxido de alumínio. O decaimento do sinal inicial OSL é de aproximadamente $40 \%$ no intervalo de energia luminosa de cerca de $13 \mathrm{~J}$ (Figura 23 e Figura 25). Para o sinal integrado OSL a tendência do decaimento é de aproximadamente $28 \%$ para o mesmo intervalo de energias luminosas incidente na amostra (Figura 26 e Figura 28). Os resultados também mostraram que o sinal OSL relativo, padronizado pelo sinal da segunda leitura OSL, apresenta uma incerteza menor quando comparado com o sinal OSL sem padronizar

Foi feita também a verificação da influência da energia luminosa incidente em dosímetros de óxido de alumínio no sinal OSL por LED de comprimento de onda no infravermelho ( $870 \mathrm{~nm}$ ) com $90 \%$ da potência do equipamento TL/OSL Ris $\varnothing(130,5 \mathrm{~mW})$. A análise foi feita através da observação da variação do sinal inicial e integrado OSL devido a iluminação das amostras.

Os resultados obtidos para o sinal inicial OSL das amostras de óxido de alumínio são mostradas na Figura 29, Figura 30 e Figura 31, e os resultados para o sinal integrado são mostrados na Figura 32, Figura 33 e Figura 34. 


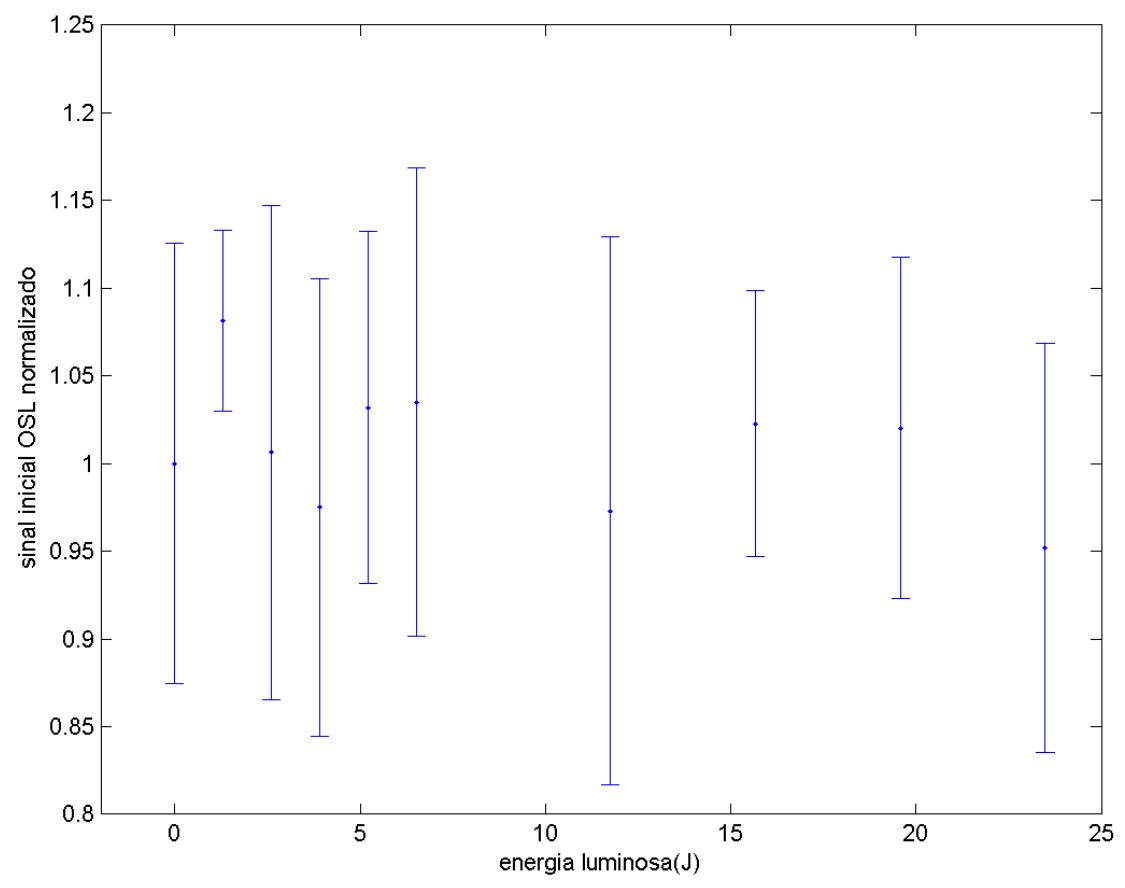

Figura 29. Variação do sinal inicial OSL normalizado para o primeiro ponto dos experimentos com iluminação das amostras de óxido de alumínio com LED de $870 \mathrm{~nm}$ e potências de 130,5 $\mathrm{mW}$ em função da energia luminosa incidente nos dosímetros.

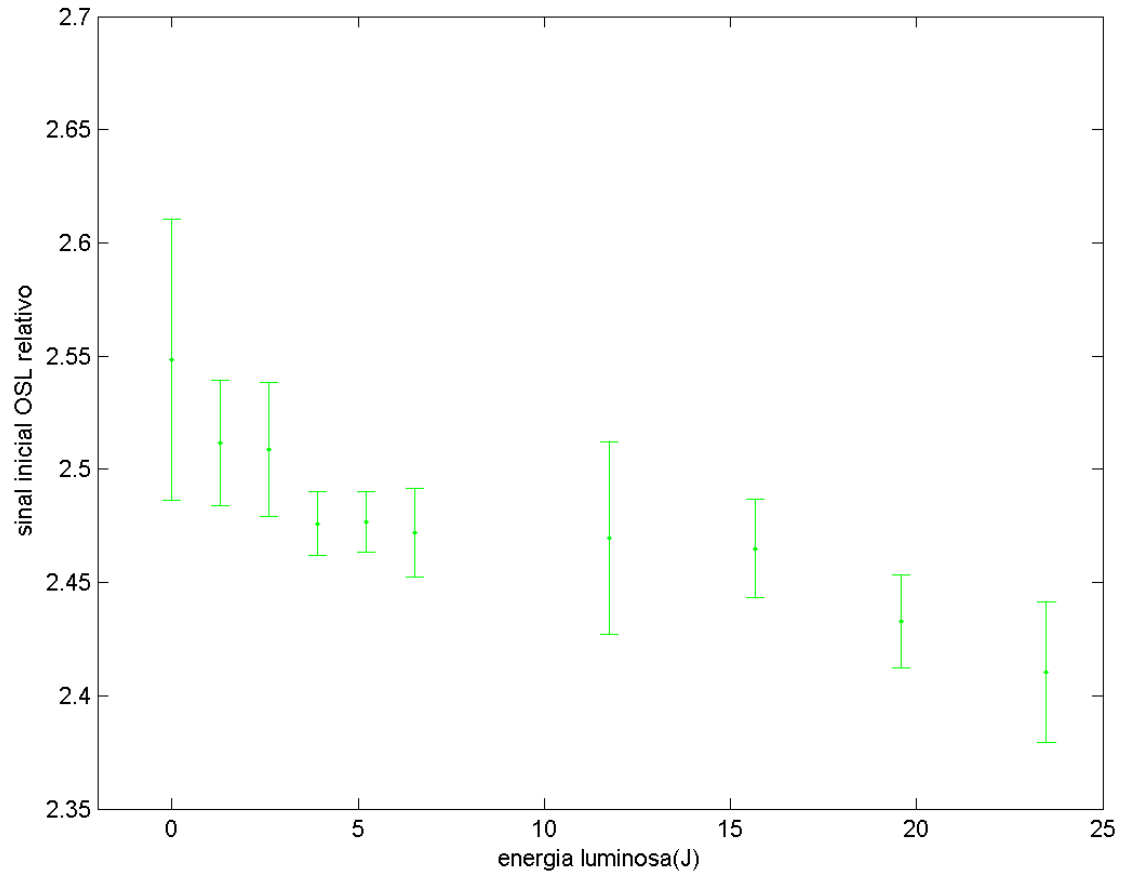

Figura 30. Variação do sinal inicial OSL relativo para os experimentos de iluminação das amostras de óxido de alumínio com LED de $870 \mathrm{~nm}$ e potências de 130,5 mW em função da energia luminosa incidente nos dosímetros. 


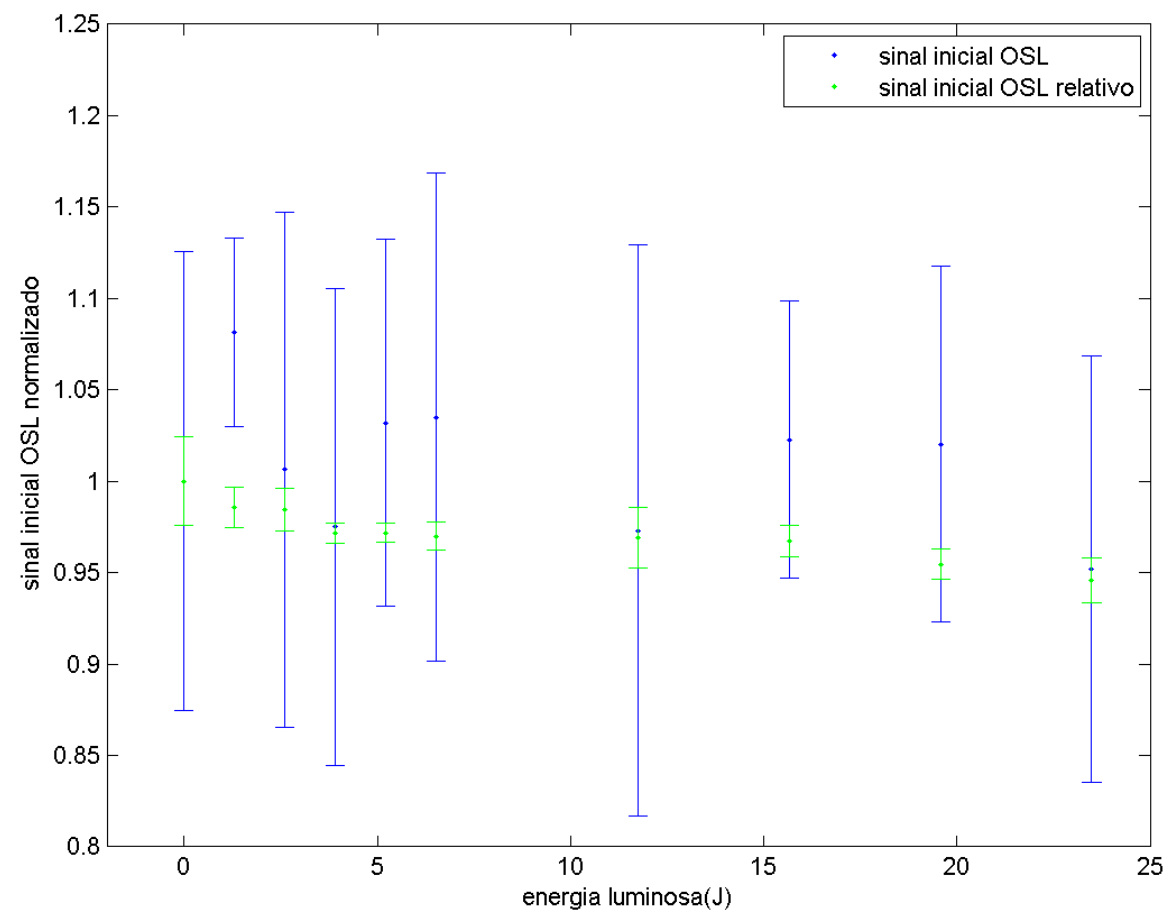

Figura 31. Comparação da variação do sinal inicial OSL e do sinal relativo normalizados ambos ao respectivo primeiro ponto para os experimentos de iluminação das amostras de óxido de alumínio com LED de $870 \mathrm{~nm}$ e potências de 130,5 mW em função da energia luminosa incidente nos dosímetros.

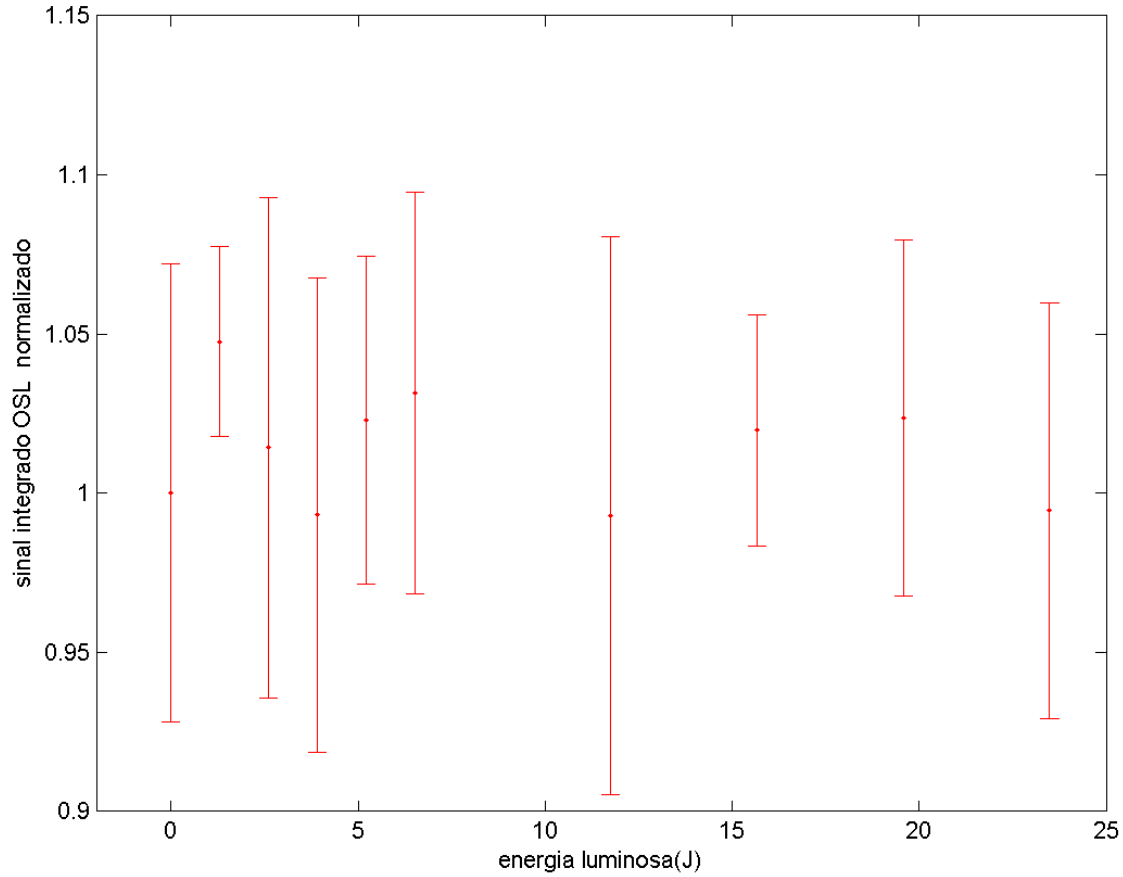

Figura 32. Variação do sinal integrado OSL para os experimentos de iluminação das amostras de óxido de alumínio com LED de $870 \mathrm{~nm}$ e potências de 130,5 mW em função da energia luminosa incidente nos dosímetros. 


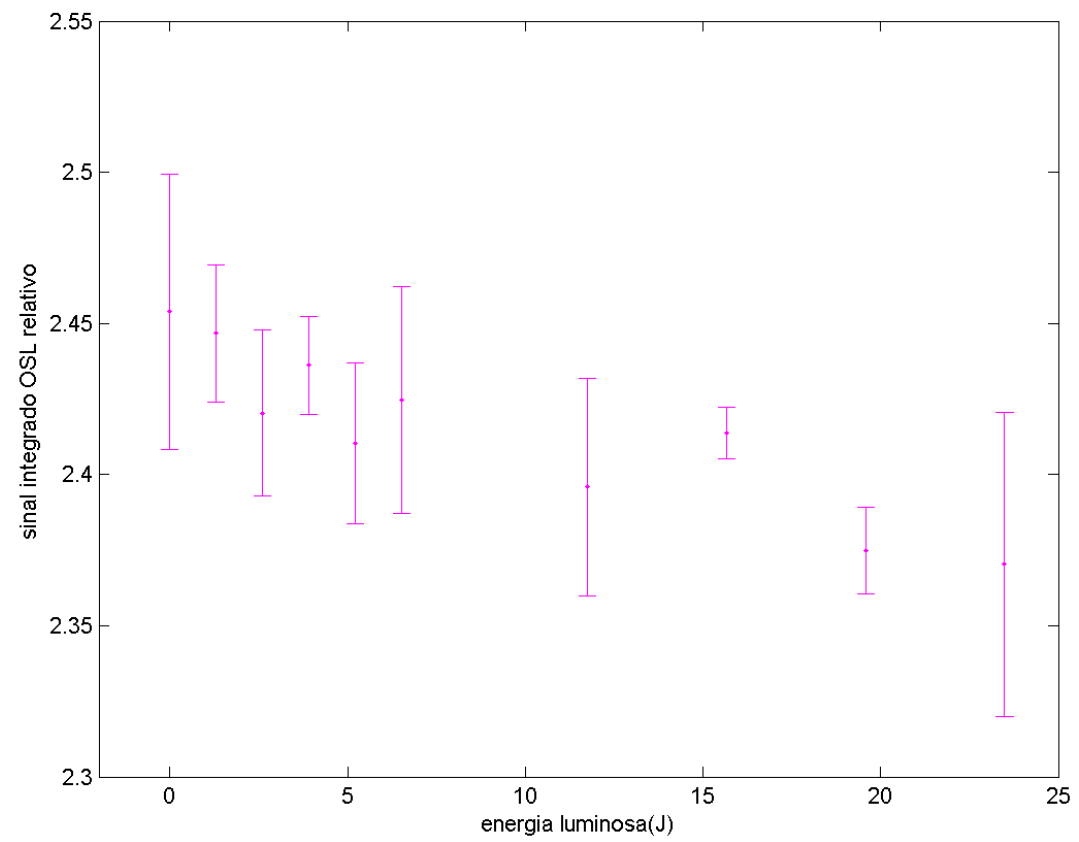

Figura 33. Variação do sinal integrado OSL relativo para os experimentos de iluminação das amostras de óxido de alumínio com LED de $870 \mathrm{~nm}$ e potências de 130,5 $\mathrm{mW}$ em função da energia luminosa incidente nos dosímetros.

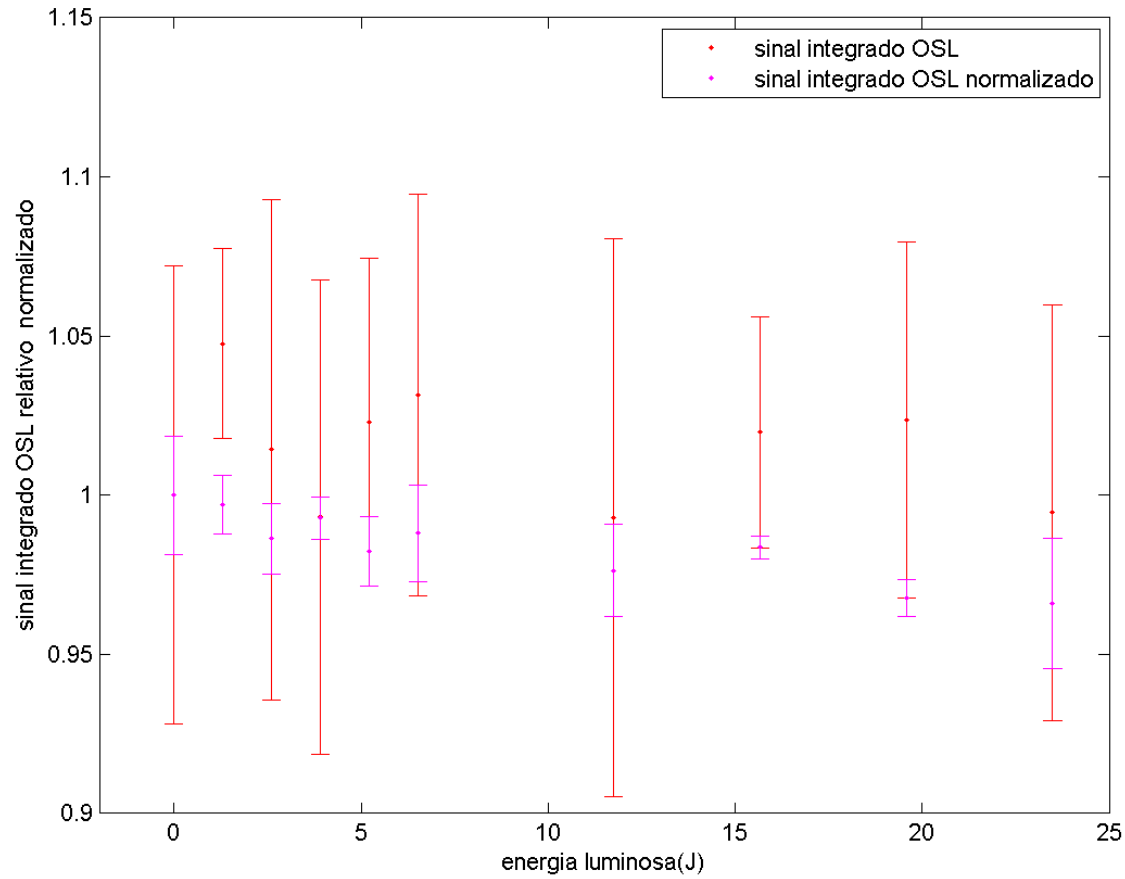

Figura 34. Comparação da variação do sinal integrado OSL e sinal relativo normalizado ambos ao respectivo primeiro ponto para os experimentos de iluminação das amostras de óxido de alumínio com LED de $870 \mathrm{~nm}$ e potências de 130,5 mW em função da energia luminosa incidente nos dosímetros. 
Os resultados obtidos para a iluminação das amostras com LED de $870 \mathrm{~nm}$ não mostraram nenhuma tendência de decaimento do sinal OSL em função da energia luminosa incidente. Estes resultados também mostraram que a incerteza do sinal OSL relativo é menor quando comparada com o sinal OSL sem padronizar.

4.2.2 Estudo da influência da lluminação no Sinal OSL para dosímetros de Óxido de Berílio

Os resultados mostrados nesta seção correspondem aos experimentos que iluminavam amostras de óxido de berílio previamente irradiadas com o laser de $658 \mathrm{~nm}$. Na análise do sinal inicial OSL, o resultados obtidos são mostrados nas Figura 35 e Figura 36; para o sinal integrado OSL obtivemos os resultados das Figura 37 e Figura 38.

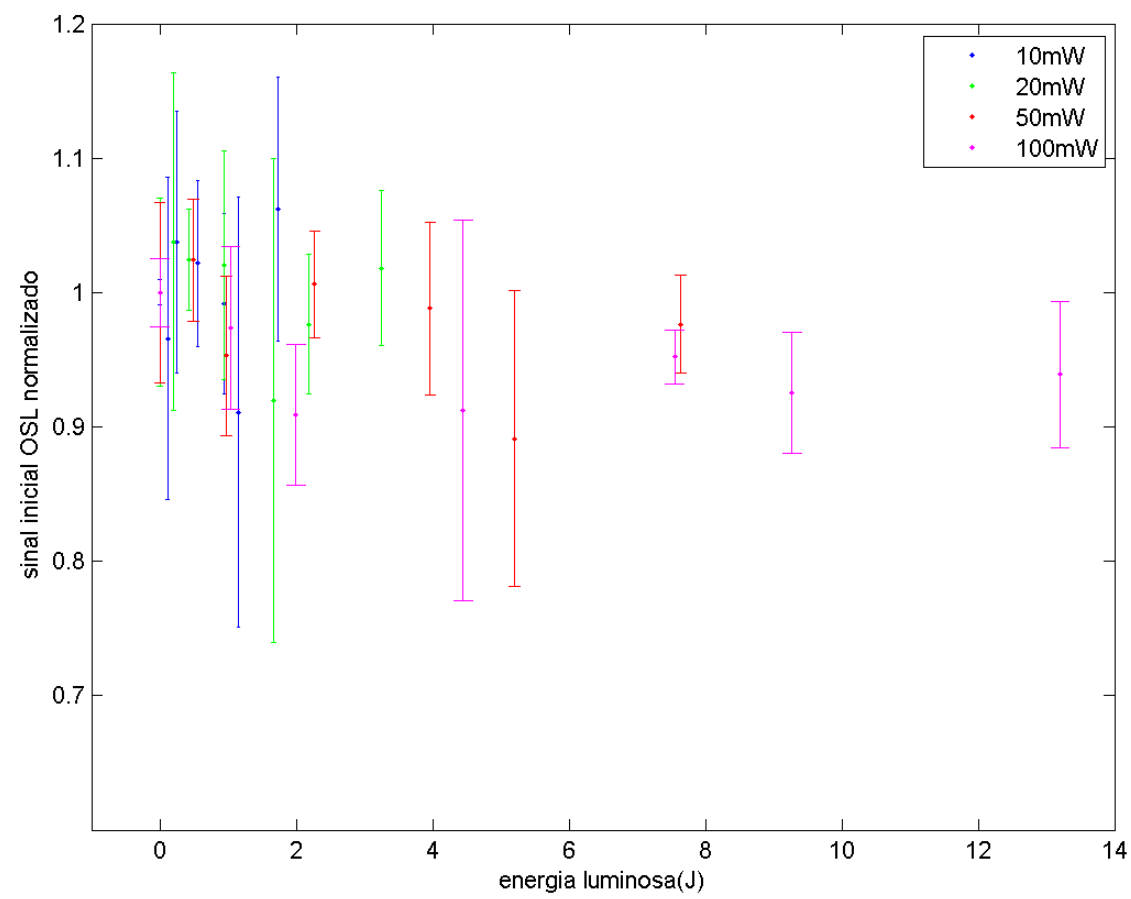

Figura 35 Variação do sinal inicial OSL das amostras de óxido de berílio iluminadas por laser de 658 nm e potências de 10, 20, 50 e $100 \mathrm{~mW}$ em função da energia luminosa incidente nas mesmas. 


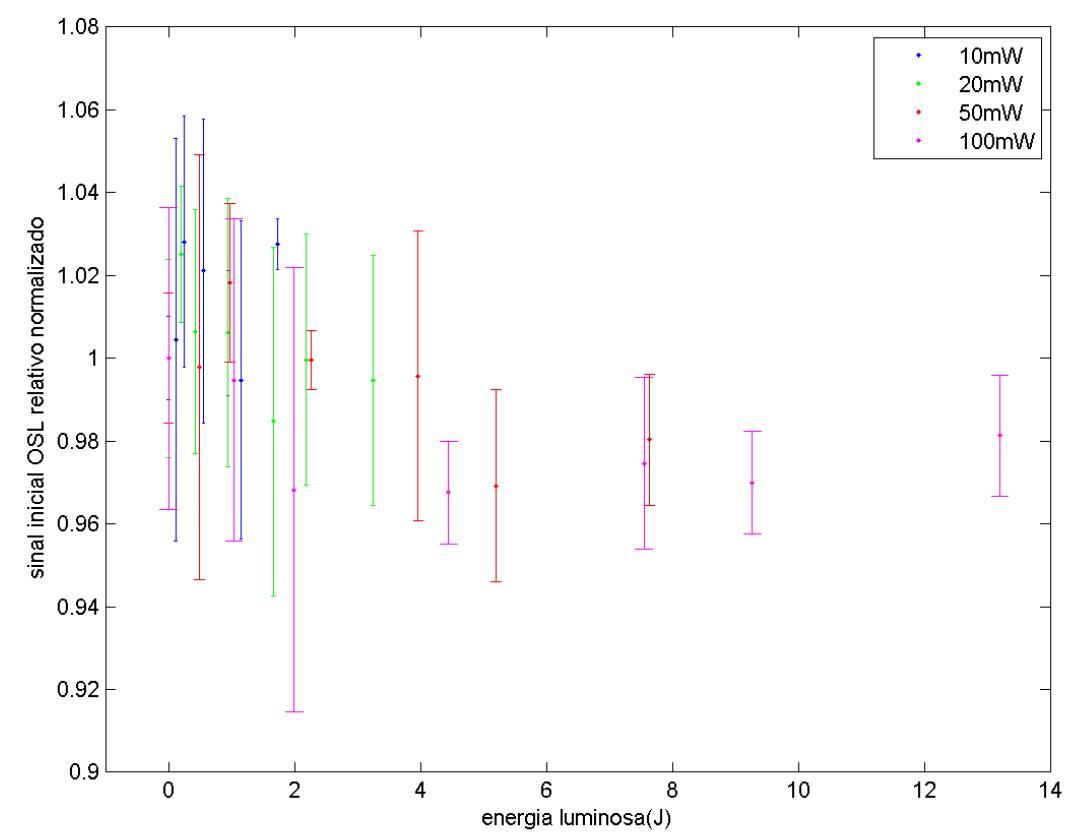

Figura 36. Variação do sinal integrado OSL relativo normalizado ao primeiro ponto das amostras de óxido de berílio iluminadas por laser de $658 \mathrm{~nm}$ e potências de 10,20,50 e $100 \mathrm{~mW}$ em função da energia luminosa incidente nos dosímetros.

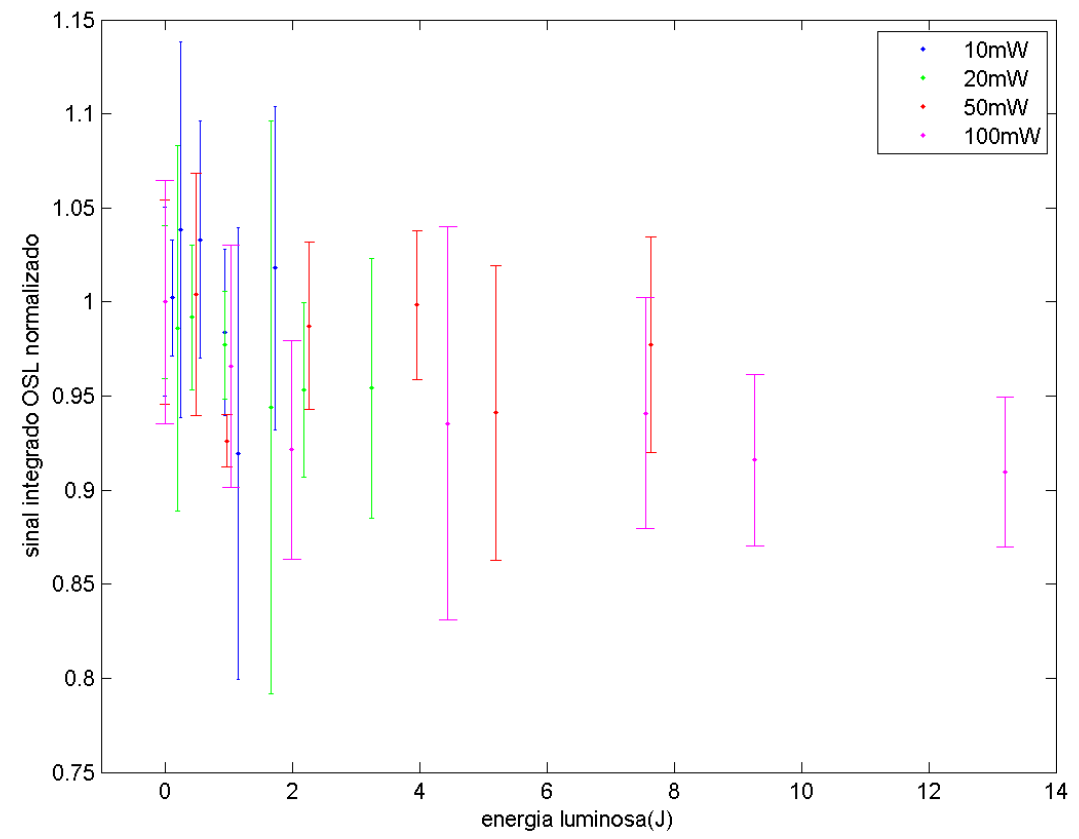

Figura 37. Variação do sinal integrado OSL normalizado ao primeiro ponto das amostras de óxido de berílio iluminadas por laser de $658 \mathrm{~nm}$ e potência de 10, 20, 50 e $100 \mathrm{~mW}$ em função da energia luminosa incidente nas mesmas. 


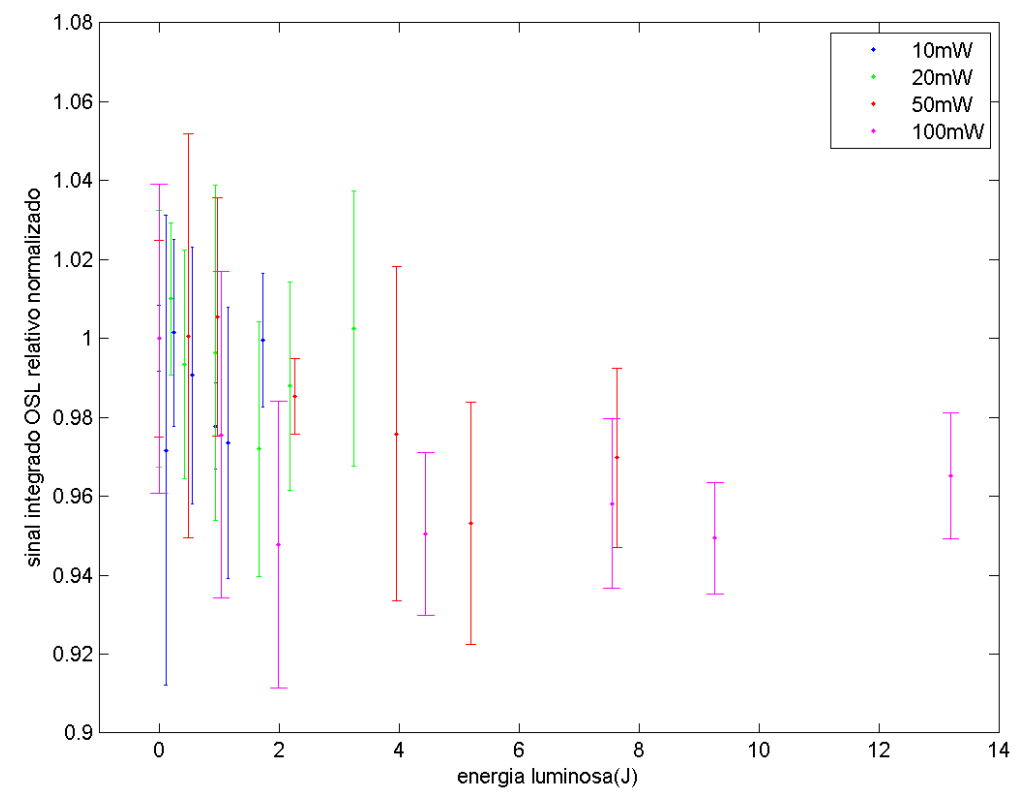

Figura 38. Variação do sinal integrado OSL relativo normalizado ao primeiro ponto das amostras de óxido de berílio iluminadas por laser de $658 \mathrm{~nm}$ e potência de 10, 20, 50 e $100 \mathrm{~mW}$ em função da energia luminosa incidente nas mesmas.

Os resultados obtidos para o óxido de berílio não mostraram influência da iluminação com laser de $658 \mathrm{~nm}$, no intervalo de energias luminosas de 0 a aproximadamente $13 \mathrm{~J}$, no sinal OSL das mesmas.

Para a variação do sinal inicial OSL em função da energia luminosa incidente de LED de $870 \mathrm{~nm}$ para o óxido de berílio os resultados são mostrados nas Figura 39 e Figura 40; para o sinal integrado os resultados obtidos são mostrados nas Figura 41 e Figura 42. 


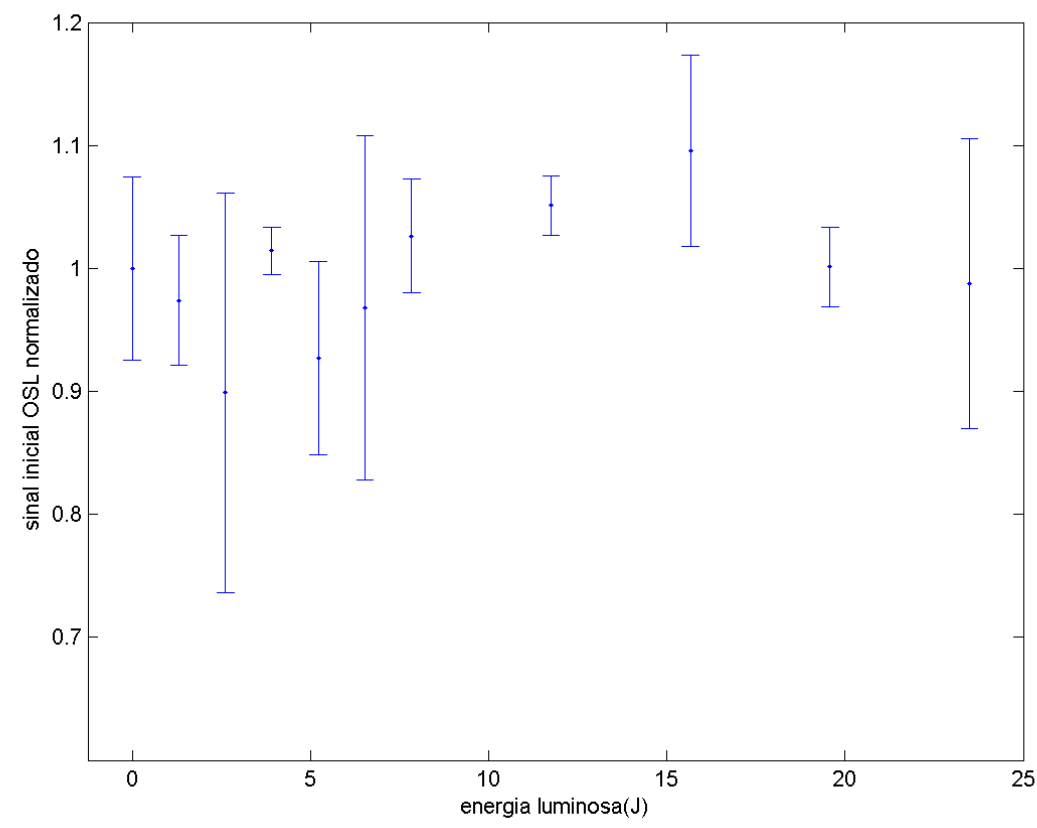

Figura 39. Variação do sinal inicial OSL normalizado para o primeiro ponto dos experimentos com iluminação das amostras de óxido de berílio com LED de $870 \mathrm{~nm}$ e potências de 130,5 mW em função da energia luminosa incidente nos dosímetros.

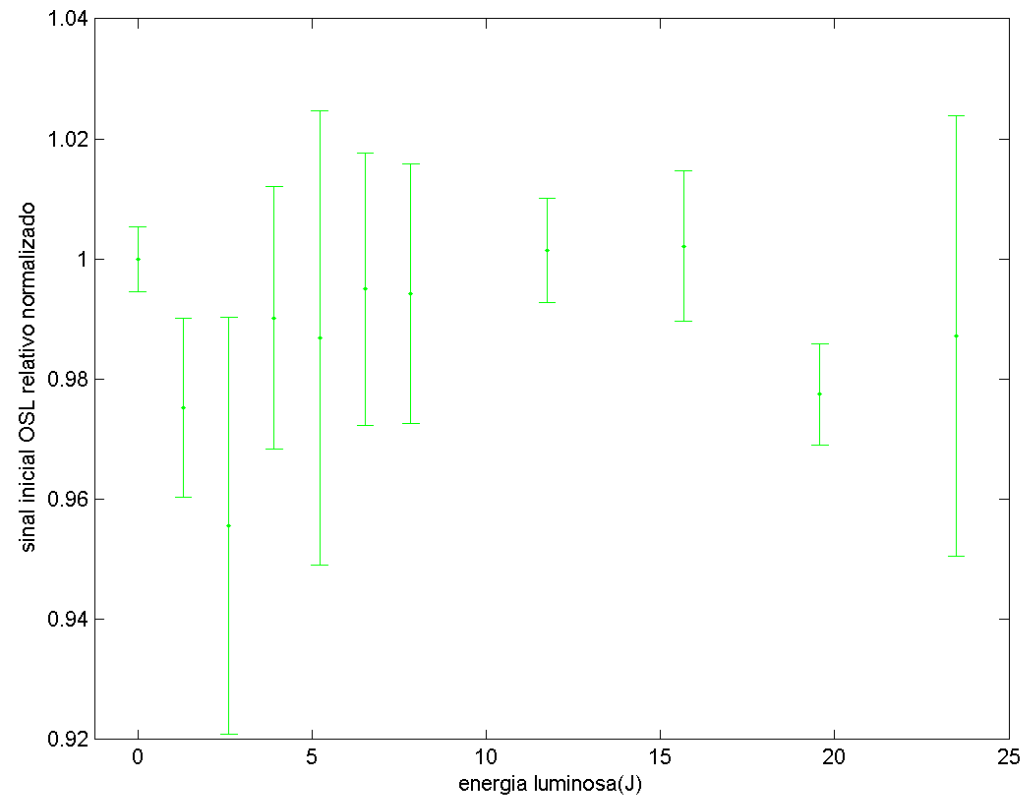

Figura 40. Variação do sinal inicial OSL relativo normalizado para o primeiro ponto dos experimentos com iluminação das amostras de óxido de berílio com LED de $870 \mathrm{~nm}$ e potências de 130,5 $\mathrm{mW}$ em função da energia luminosa incidente nos dosímetros. 


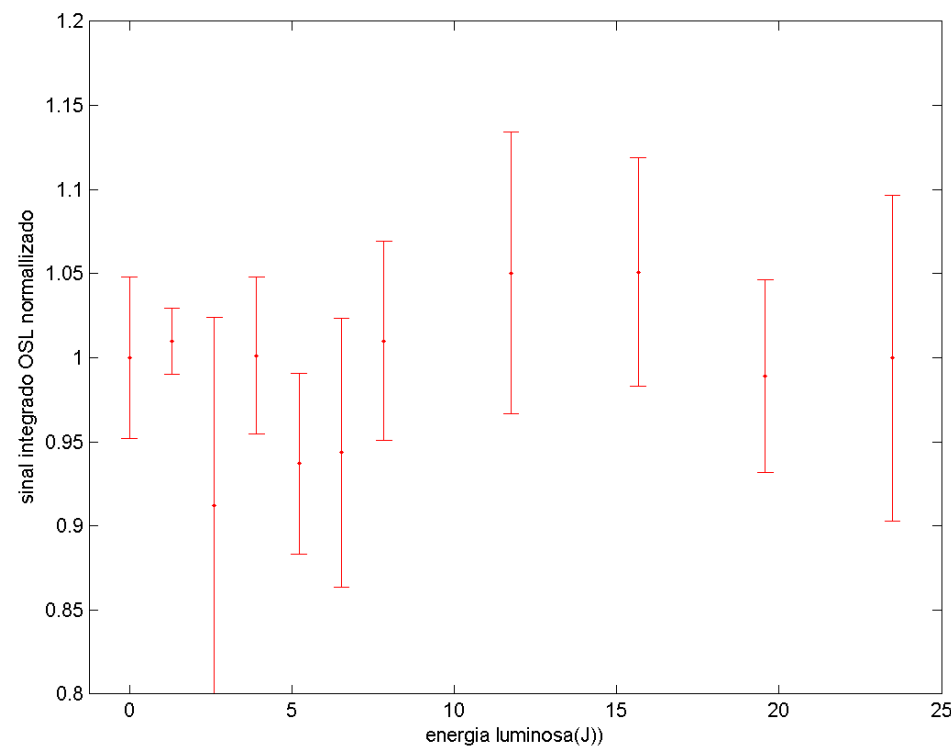

Figura 41. Variação do sinal integrado OSL normalizado para o primeiro ponto dos experimentos com iluminação das amostras de óxido de berílio com LED de $870 \mathrm{~nm}$ e potências de 130,5 mW em função da energia luminosa incidente nos dosímetros.

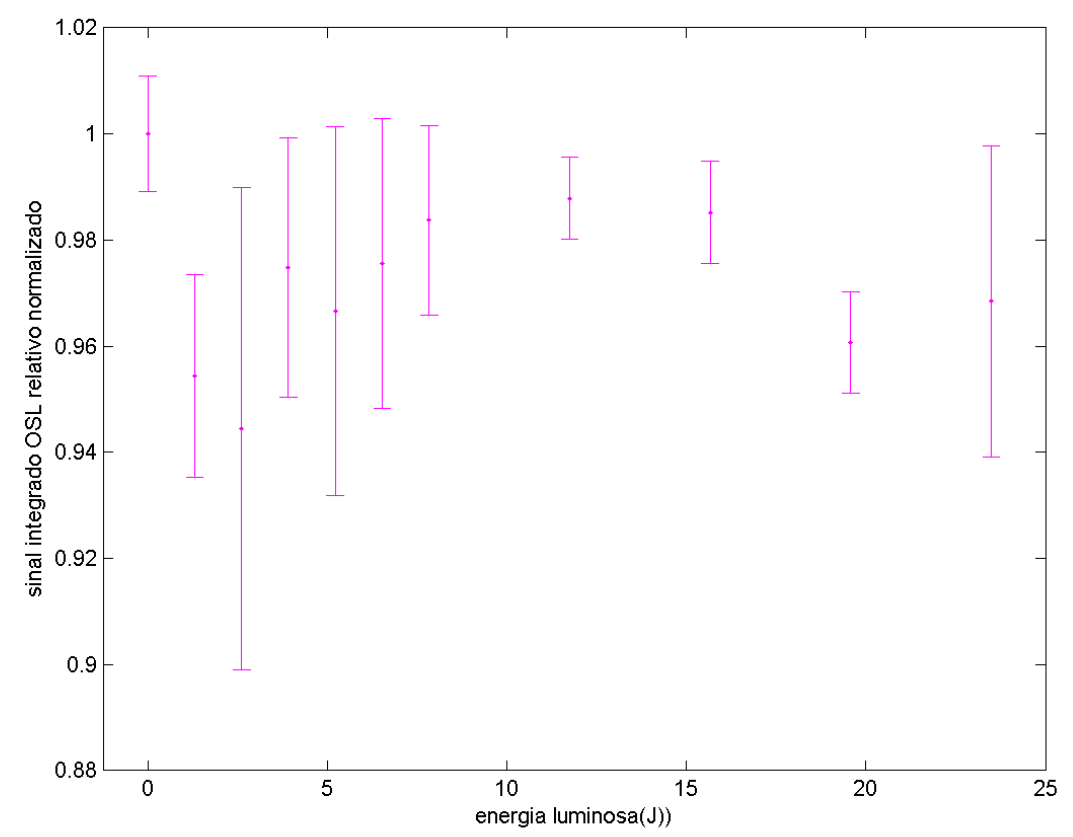

Figura 42. Variação do sinal integrado OSL relativo normalizado para o primeiro ponto dos experimentos com iluminação das amostras de óxido de berílio com LED de $870 \mathrm{~nm}$ e potências de 130,5 mW em função da energia luminosa incidente nos dosímetros.

Os resultados para a iluminação das amostras de óxido de berílio com LED de $870 \mathrm{~nm}$ para o intervalo de energias luminosas de 0 a aproximadamente $24 \mathrm{~J}$ não mostraram influência no sinal OSL das mesmas, similarmente ao que ocorreu com o laser de $658 \mathrm{~nm}$. 


\subsubsection{Estudo da influência da Energia Luminosa em dosímetros de Fluorita $\left(\mathrm{CaF}_{2}\right)$}

A análise da influência da iluminação no sinal OSL de amostras de fluorita previamente irradiada se diferencia das amostras de óxido de alumínio e berílio pelo fato de que o sinal OSL pode sofrer influência do fading. Isso faz com que os resultados contenham a variação do sinal OSL devido a iluminação adicionado ao fading delas. Considerando este efeito, foi feito um experimento, relatado na seção 3.3.3, que visava medir está variação de sinal OSL devido ao fading para acrescentá-la ao sinal OSL com a finalidade de isolar somente o efeito da iluminação. Os resultados encontrados para os experimentos de fading da fluorita são mostrados nas Figura 43, Figura 44 e Figura 45.

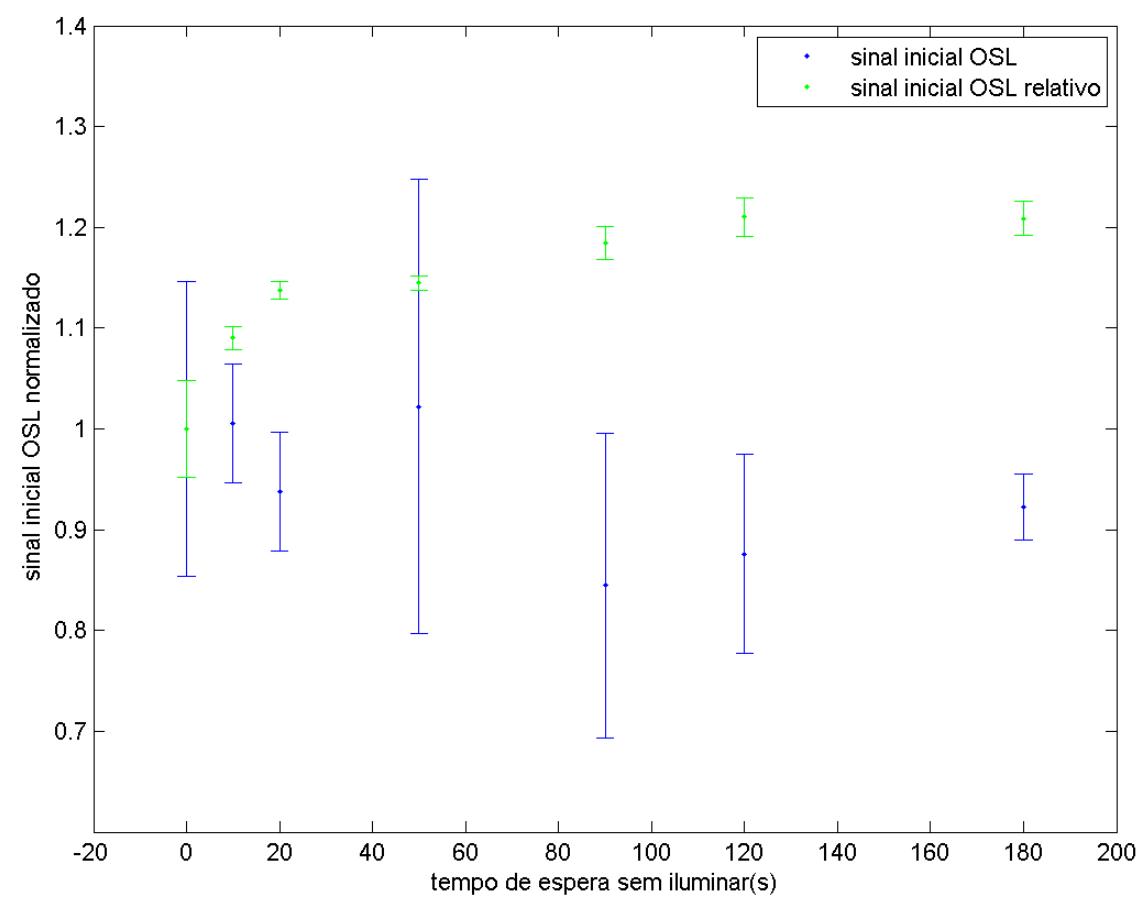

Figura 43. Variação do sinal inicial OSL normal e relativo normalizado de amostras de fluorita em função do tempo de espera sem iluminar 

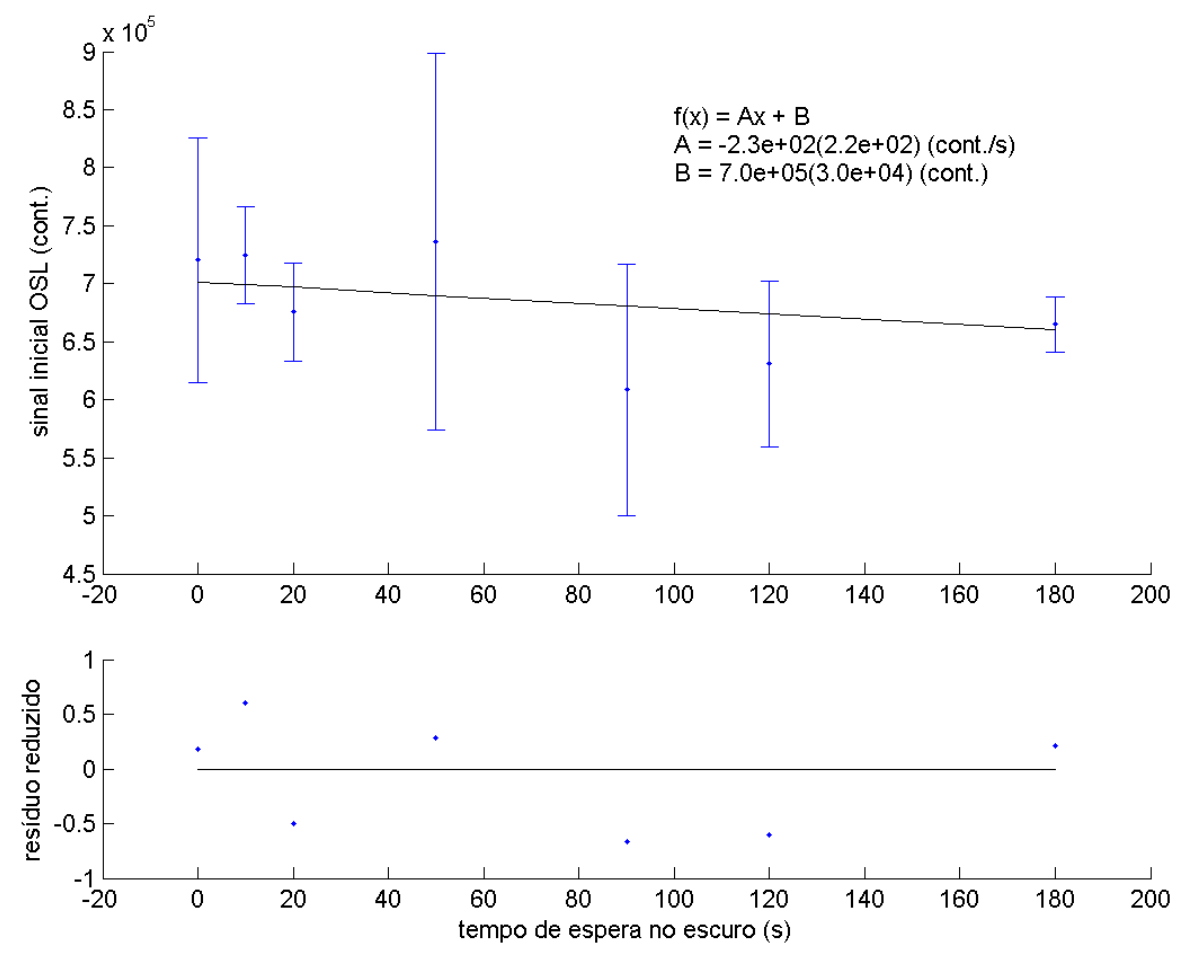

Figura 44. Variação do sinal inicial OSL de amostras de fluorita em função do tempo de espera sem iluminar. Uma reta $f(x)$ foi ajustada aos dados experimentais e os parâmetros ajustados foram colocados em destaque.
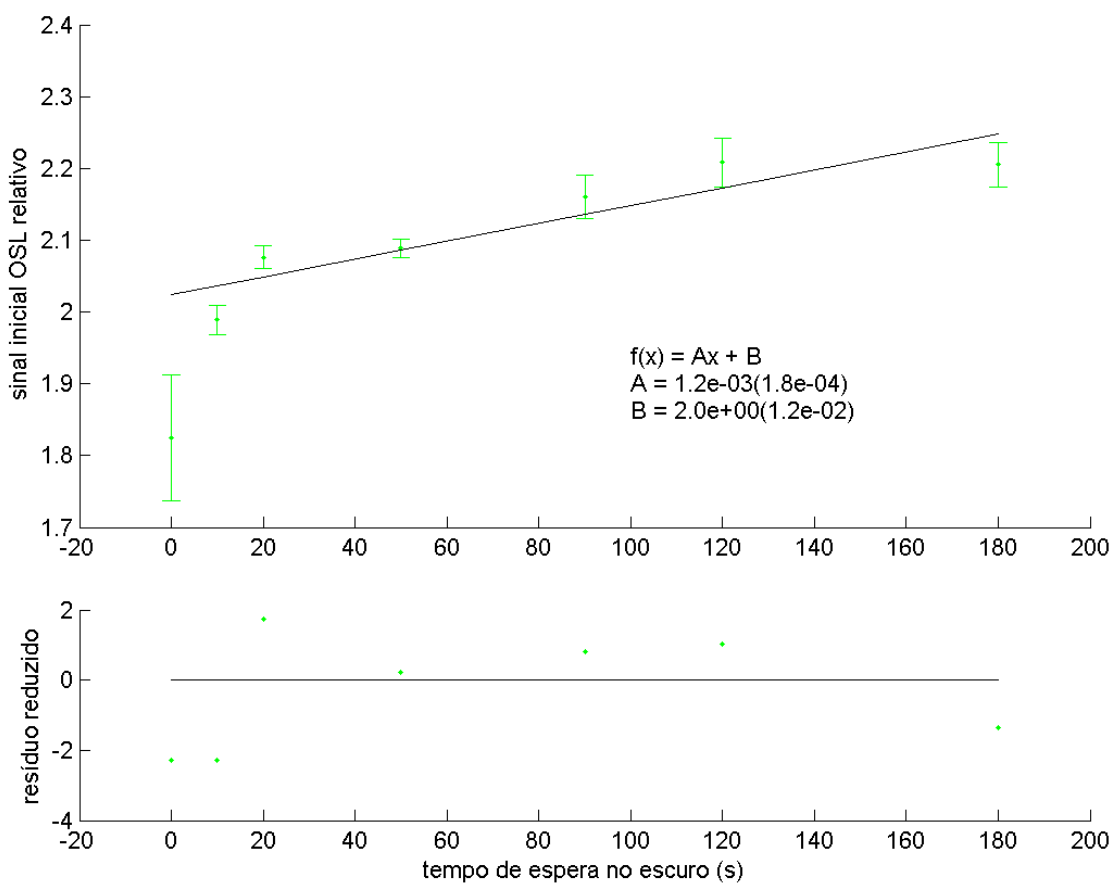

Figura 45. Variação do sinal inicial OSL relativo de amostras de fluorita em função do tempo de espera sem iluminar. Uma reta $f(x)$ foi ajustada aos dados experimentais e os parâmetros ajustados foram colocados em destaque. 
Foi avaliada a diferença de tempo de espera entre as irradiações e as leituras OSL nos experimentos. Os resultados foram colocados na Tabela 4. Na Figura 46 segue um gráfico com a razão entre os tempos de espera para a leitura OSL antes da segunda irradiação comparado com a primeira irradiação. Neste experimento, o grupo de dosímetros foi lido na mesma ordem tanto na primeira como na segunda leitura OSL.

Tabela 4. Tempos de espera para a leitura OSL das amostras no experimento de fading da fluorita e tempo total de espera das amostras

\section{Ordem de leitura OSL no TL/OSL Ris $\varnothing$

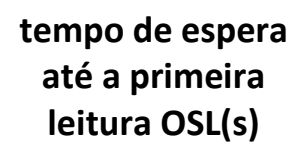

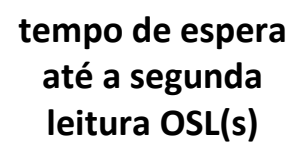

\section{diferença de tempo \\ nas duas \\ situações(s)}

\begin{tabular}{|c|c|c|c|}
\hline 1 & 135 & 54 & 81 \\
\hline 2 & 230 & 152 & 78 \\
\hline 3 & 325 & 250 & 75 \\
\hline 4 & 420 & 348 & 72 \\
\hline 5 & 515 & 446 & 69 \\
\hline 6 & 620 & 544 & 76 \\
\hline 7 & 725 & 642 & 83 \\
\hline 8 & 830 & 740 & 90 \\
\hline 9 & 935 & 838 & 97 \\
\hline 10 & 1050 & 936 & 114 \\
\hline 11 & 1165 & 1034 & 131 \\
\hline 12 & 1280 & 1132 & 148 \\
\hline 13 & 1395 & 1230 & 165 \\
\hline 14 & 1540 & 1328 & 212 \\
\hline 15 & 1685 & 1426 & 259 \\
\hline 16 & 1830 & 1524 & 306 \\
\hline 17 & 1975 & 1622 & 353 \\
\hline 18 & 2160 & 1720 & 440 \\
\hline 19 & 2345 & 1818 & 527 \\
\hline 20 & 2530 & 1916 & 614 \\
\hline 21 & 2715 & 2014 & 701 \\
\hline 22 & 2930 & 2112 & 818 \\
\hline 23 & 3145 & 2210 & 935 \\
\hline 24 & 3360 & 2308 & 1052 \\
\hline 25 & 3575 & 2406 & 1169 \\
\hline 26 & 3850 & 2504 & 1346 \\
\hline 27 & 4125 & 2602 & 1523 \\
\hline 28 & 4400 & 2700 & 1700 \\
\hline
\end{tabular}




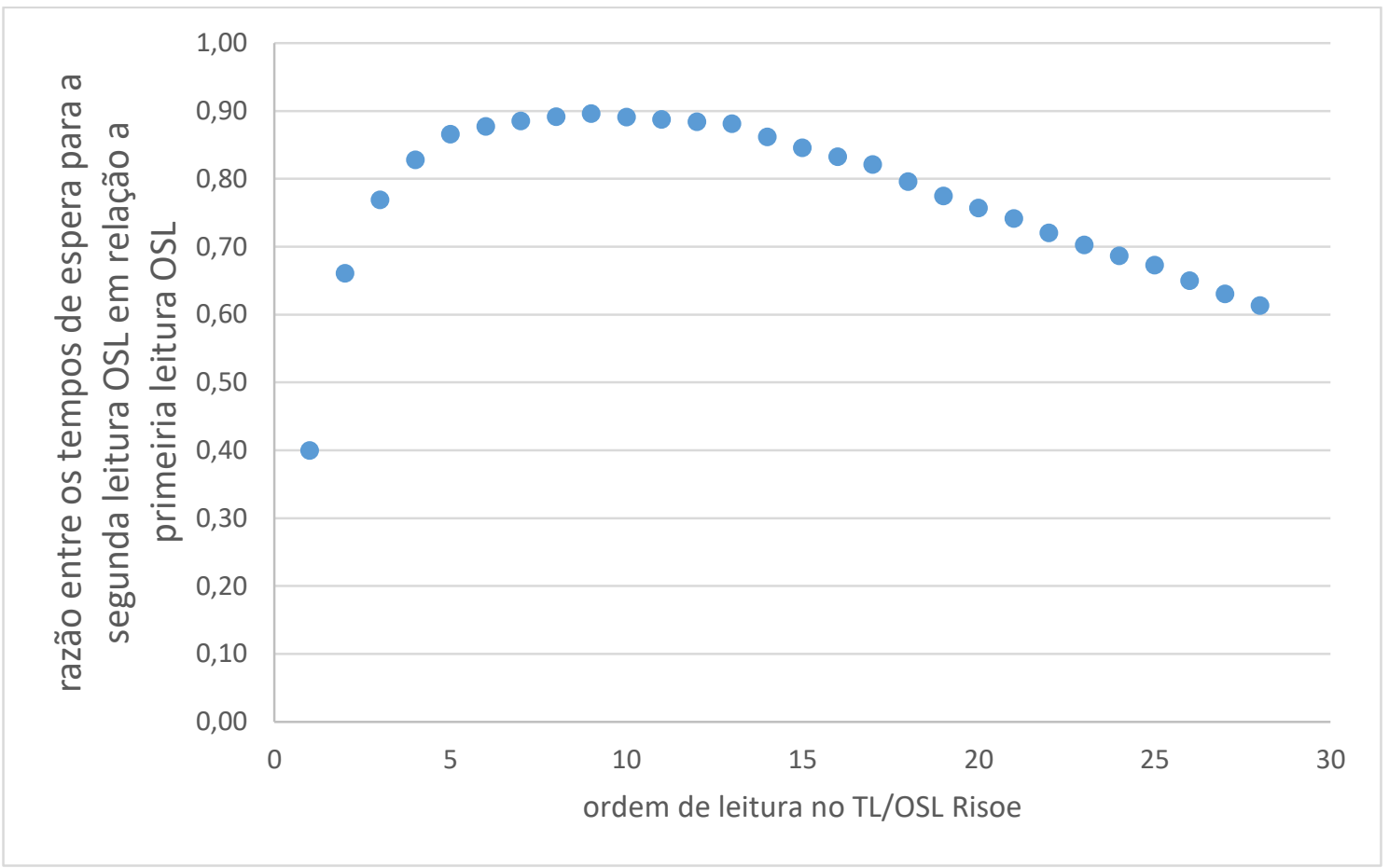

Figura 46. Variação da fração de tempo de espera antes da segunda irradiação comparado com o tempo de espera antes da primeira irradiação em função da ordem de leitura OSL dos dosímetros.

Para o sinal integrado OSL da fluorita, tivemos os resultados das Figura 47, Figura 48 e Figura 49.

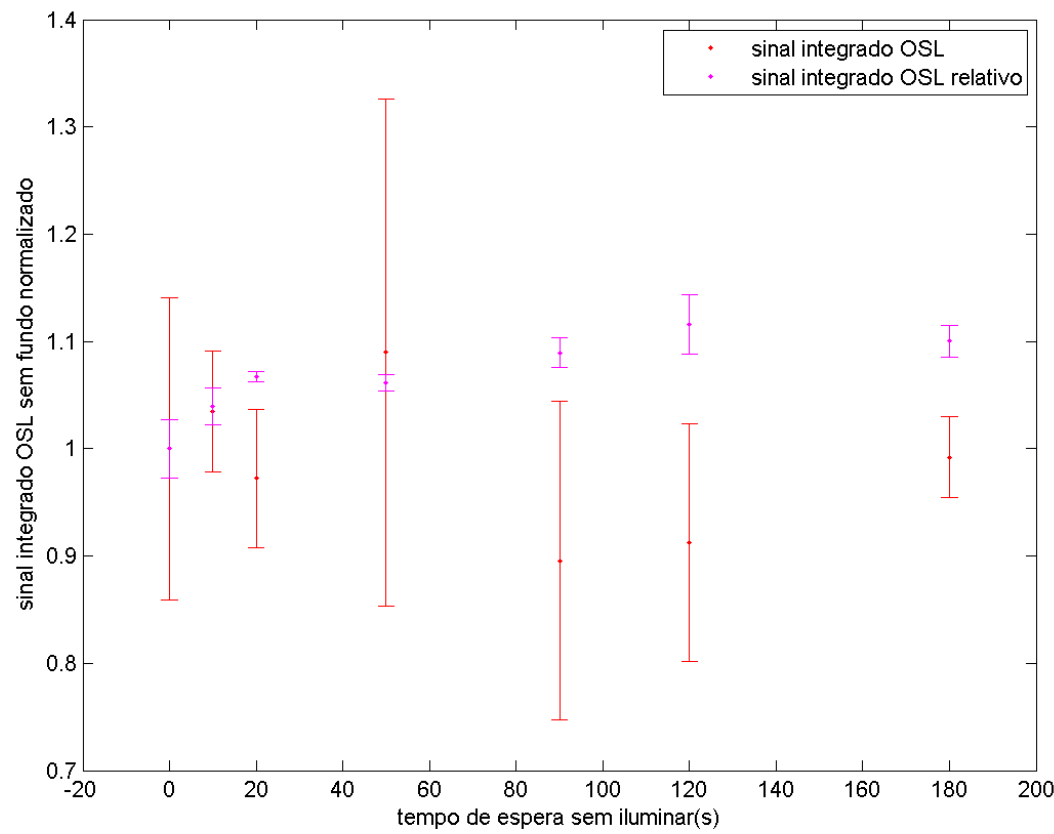

Figura 47. Variação do sinal integrado OSL normal e relativo normalizado de amostras de fluorita em função do tempo de espera sem iluminar 

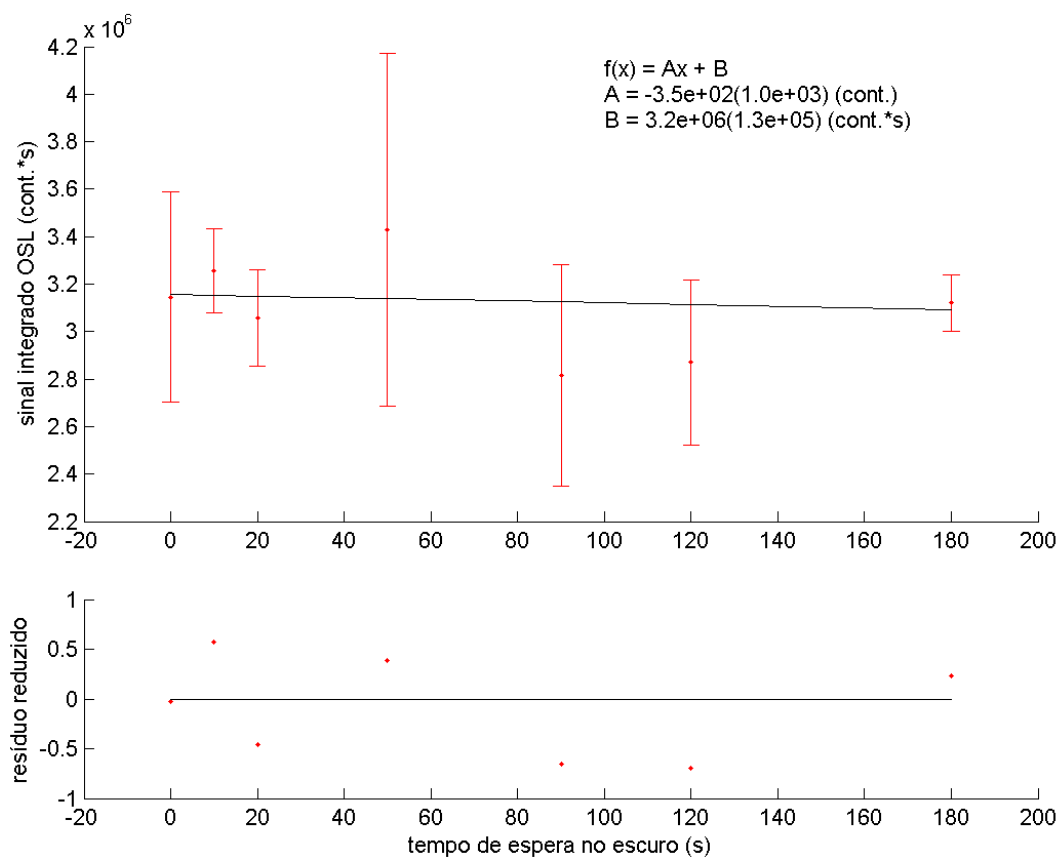

Figura 48. Variação do sinal integrado OSL de amostras de fluorita em função do tempo de espera sem iluminar. Uma reta $f(x)$ foi ajustada aos dados experimentais e os parâmetros ajustados foram colocados em destaque.
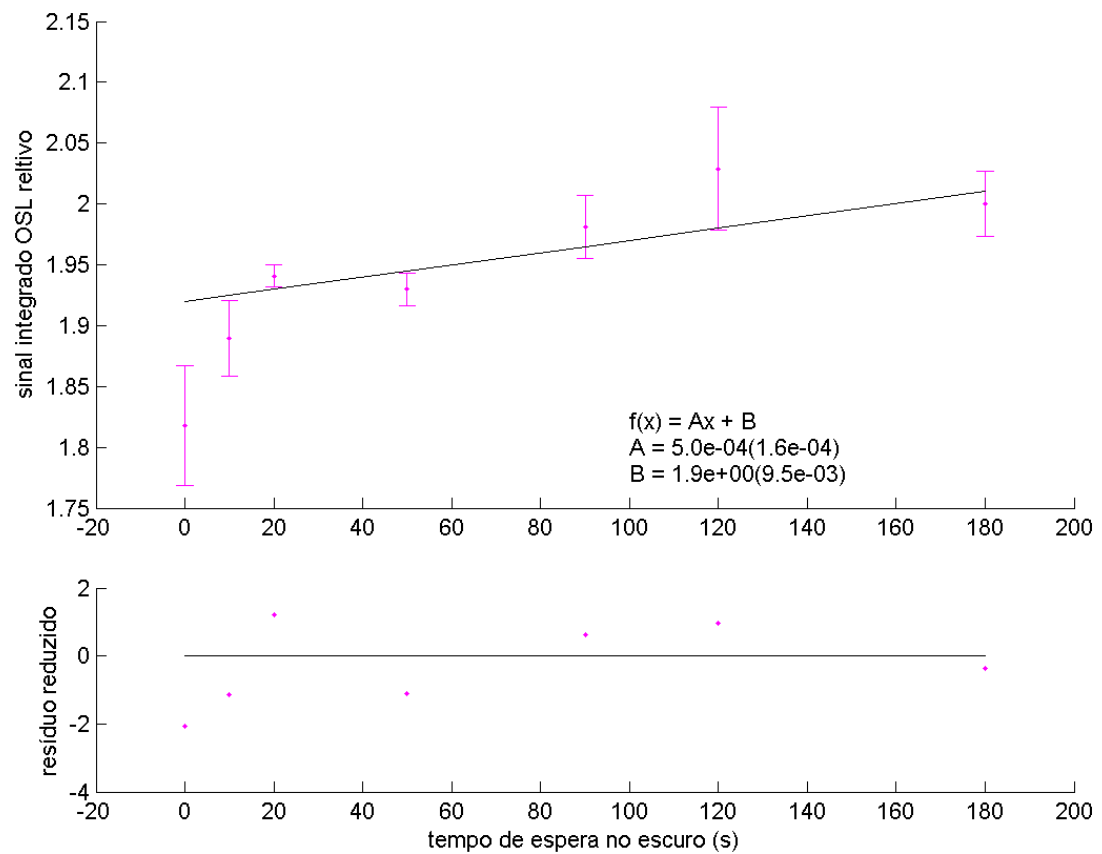

Figura 49. Variação do sinal integrado OSL relativo de amostras de fluorita em função do tempo de espera sem iluminar. Uma reta $f(x)$ foi ajustada aos dados experimentais e os parâmetros ajustados foram colocados em destaque. 
Estes resultados evidenciam que o sinal OSL não apresenta uma tendência de decaimento, ao contrário do sinal OSL relativo. Os ajustes lineares nas Figura 44, Figura 45, Figura 48 e Figura 49 evidenciam esta conclusão.

Em seguida, foram feitos os experimentos com amostras de fluorita iluminadas pelo laser de $658 \mathrm{~nm}$. Em todas as análises para as amostras de Fluorita foram feitos os descontos da variação do sinal OSL devido ao fading, como relatado na seção 3.3.3. Os resultados encontrados são mostrados nas Figura 50 e Figura 51 para a análise do sinal inicial e nas Figura 52 e Figura 53 para o sinal integrado.

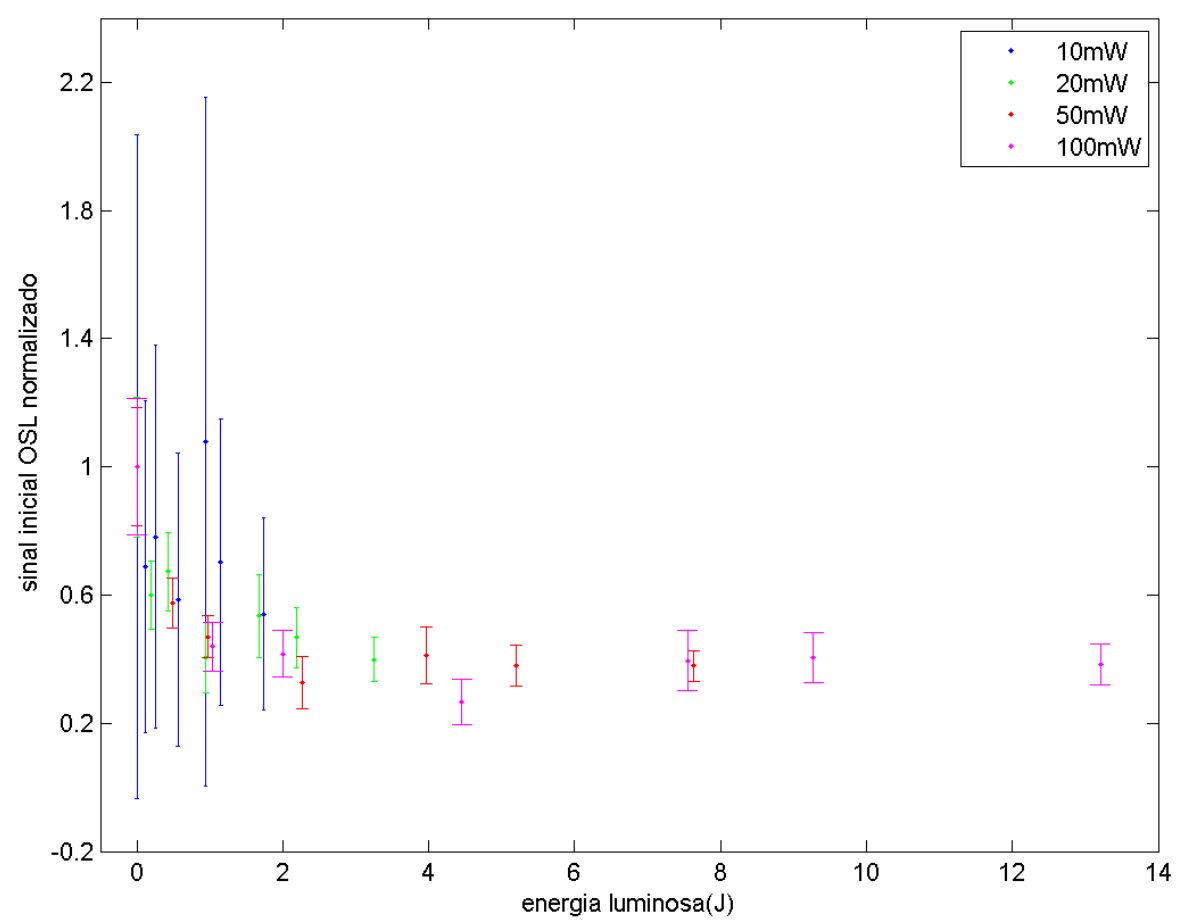

Figura 50. Variação do sinal inicial OSL normalizado para o primeiro ponto das amostras de fluorita iluminadas por laser de $658 \mathrm{~nm}$ e potências de 10, 20, 50 e $100 \mathrm{~mW}$ em função da energia luminosa incidente nas mesmas. 


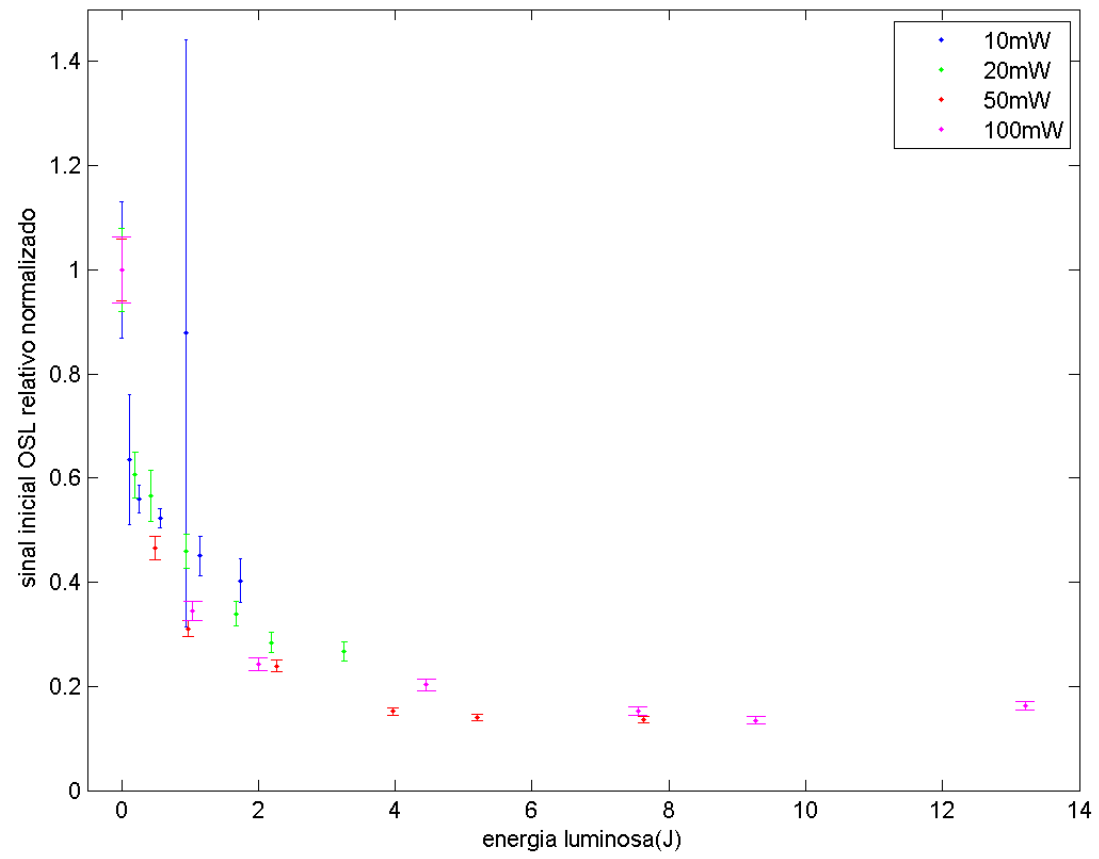

Figura 51. Variação do sinal inicial OSL relativo normalizado para o primeiro ponto das amostras de fluorita iluminadas por laser de $658 \mathrm{~nm}$ e potências de 10, 20, 50 e $100 \mathrm{~mW}$ em função da energia luminosa incidente nos dosímetros.

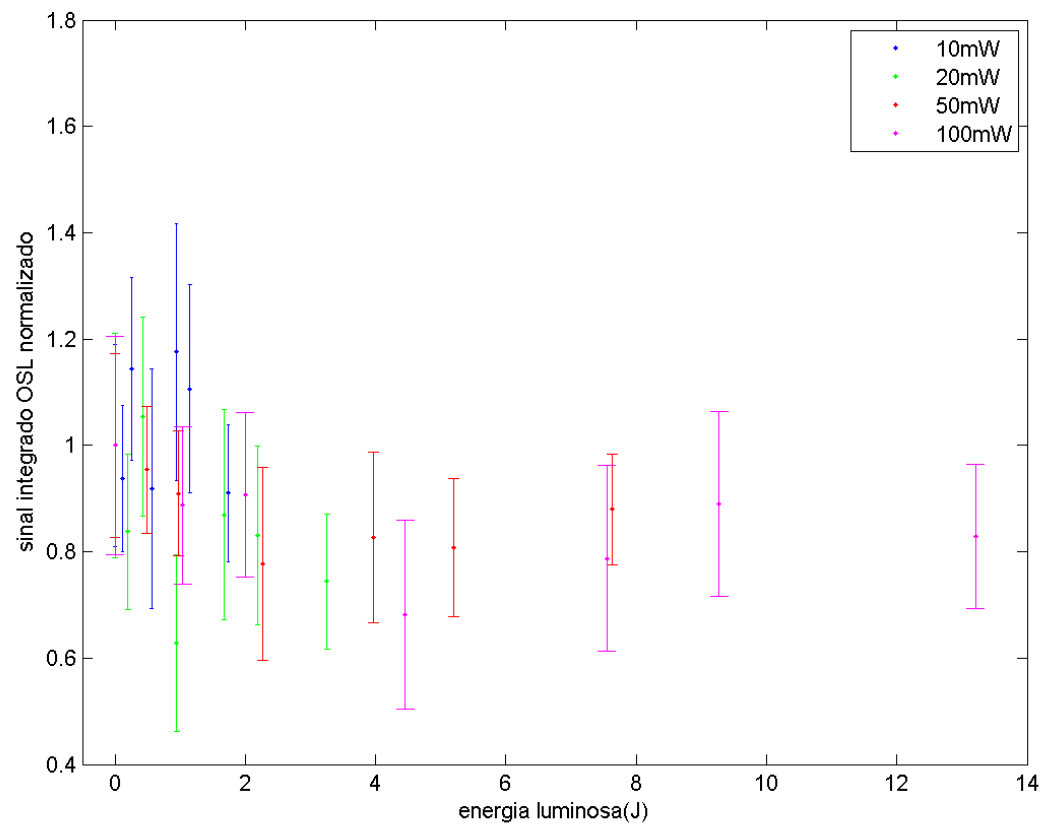

Figura 52. Variação do sinal integrado OSL normalizado par o primeiro ponto das amostras de fluorita iluminadas por laser de $658 \mathrm{~nm}$ e potência de 10, 20, 50 e $100 \mathrm{~mW}$ em função da energia luminosa incidente nas mesmas. 


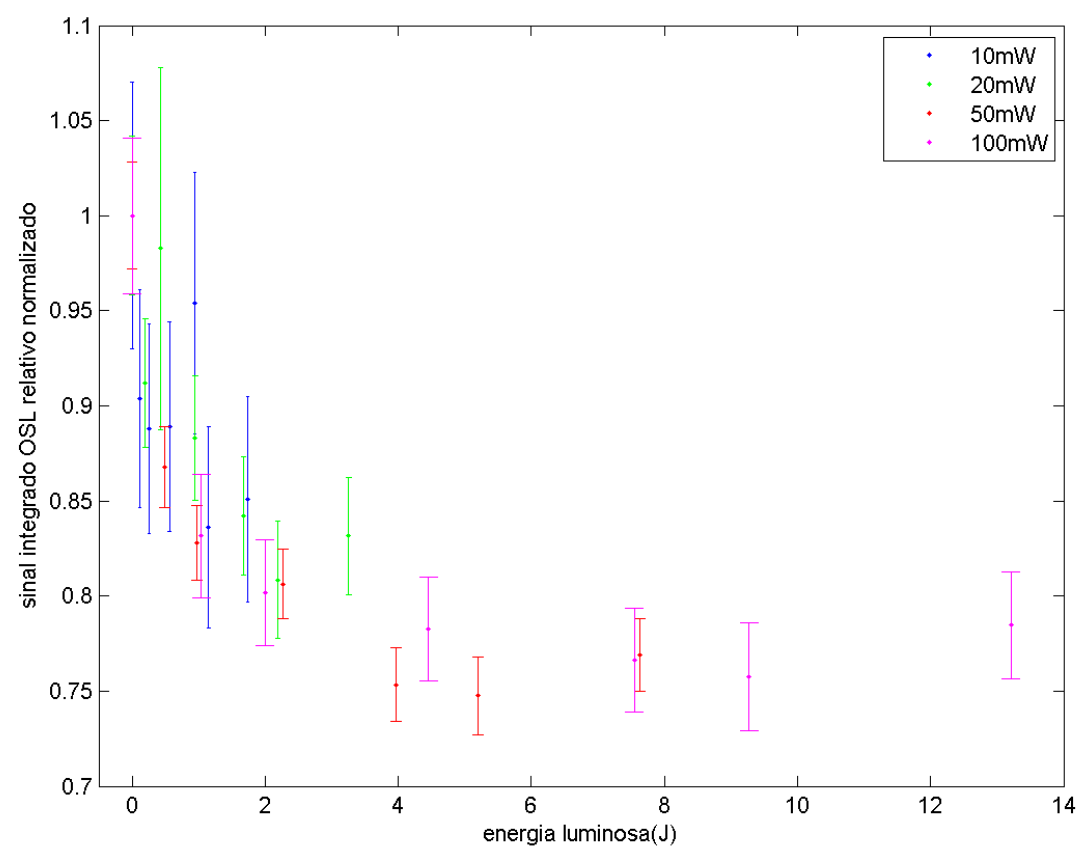

Figura 53. Variação do sinal integrado OSL relativo normalizado para o primeiro ponto das amostras de fluorita iluminadas por laser de $658 \mathrm{~nm}$ e potências de 10, 20, 50 e $100 \mathrm{~mW}$ em função da energia luminosa incidente nos dosímetros.

De acordo com os resultados verificou-se que a iluminação influencia o sinal OSL das amostras de fluorita. $\mathrm{O}$ sinal inicial OSL decai 60\% para as energias até aproximadamente $2 \mathrm{~J} \mathrm{e}$ permanece o mesmo para as energias maiores (Figura 50). O sinal inicial OSL relativo decai mais fortemente, aproximadamente $85 \%$ do sinal do primeiro ponto, para uma energia luminosa até $4 \mathrm{~J}$ (Figura 51). O sinal integrado OSL não mostrou tendência de decaimento, de acordo com as incertezas obtidas (Figura 52). O sinal integrado OSL relativo mostrou uma queda de $25 \%$ para energia luminosa de aproximadamente $4 \mathrm{~J}$ (Figura 53).

Também foram feitos experimentos para a verificação da influência da iluminação com LED de $870 \mathrm{~nm}$ no sinal OSL de amostras de fluorita. Este estudo também foi feito se analisando a influência da iluminação no sinal inicial e integrado OSL das amostras. As potências utilizadas foram de 14,5; 58 e 130,5 mW (respectivamente 10, 40 e 90\% da potência máxima do equipamento TL/OSL Ris $\emptyset$ ). Os resultados obtidos para a variação do sinal inicial OSL em função da iluminação das amostras de Fluorita são mostrados nas Figura 54, Figura 55 e Figura 56 e para a variação do sinal integrado são mostrados nas Figura 57, Figura 58 e Figura 59. 


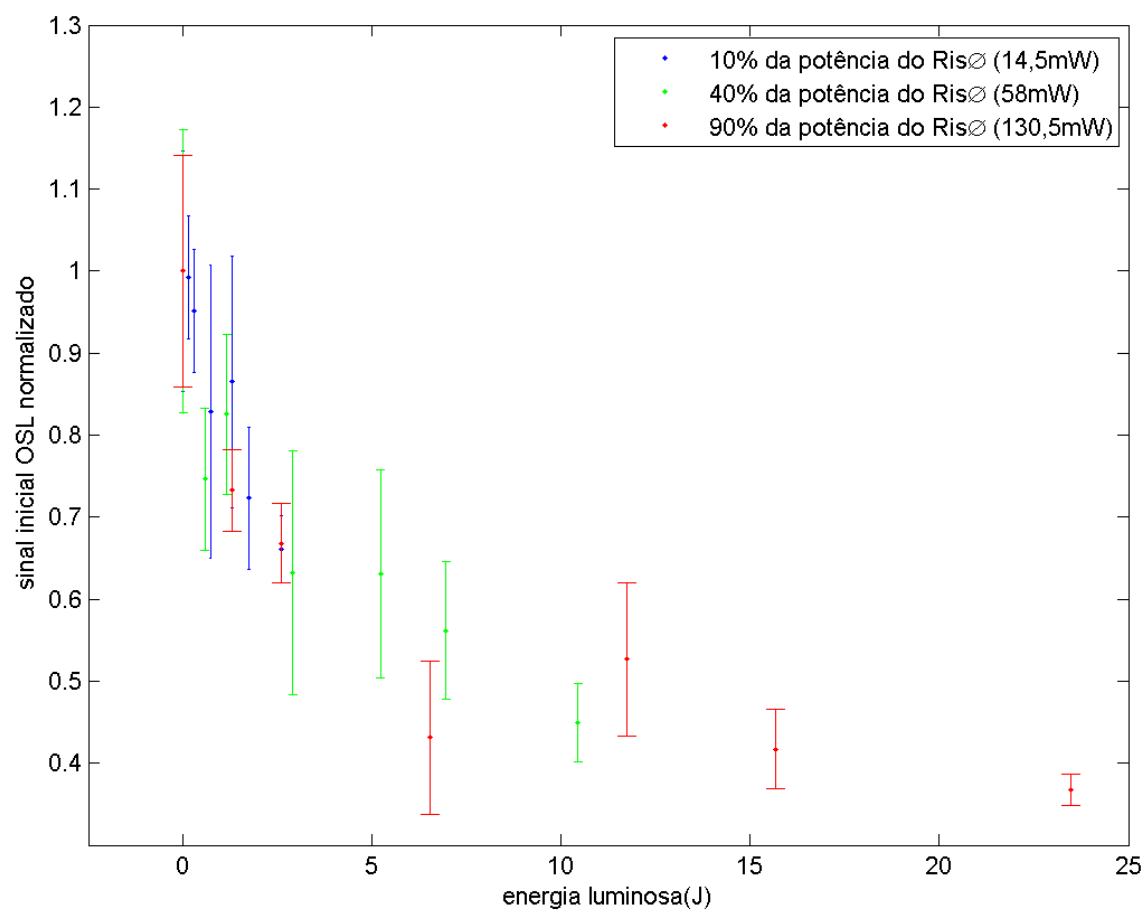

Figura 54 .Variação do sinal inicial OSL das amostras de fluorita iluminadas por LED de $870 \mathrm{~nm}$ e potências de 14,5; 58 e 130,5 mW em função da energia luminosa incidente nas mesmas.

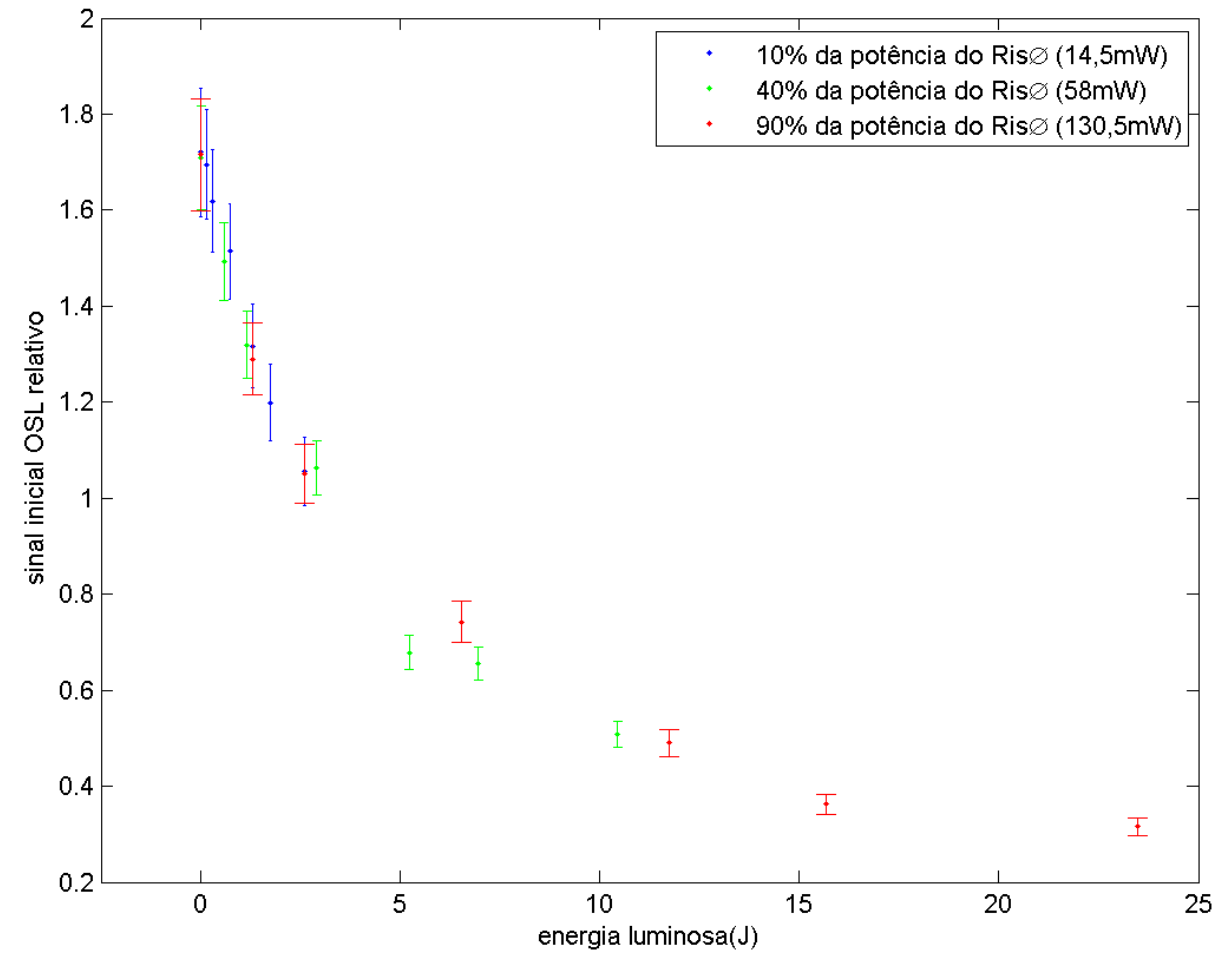

Figura 55 Variação do sinal inicial OSL relativo das amostras de fluorita iluminadas por LED de $870 \mathrm{~nm}$ e potências de 14,5; 58 e 130,5 mW em função da energia luminosa incidente nas mesmas. 


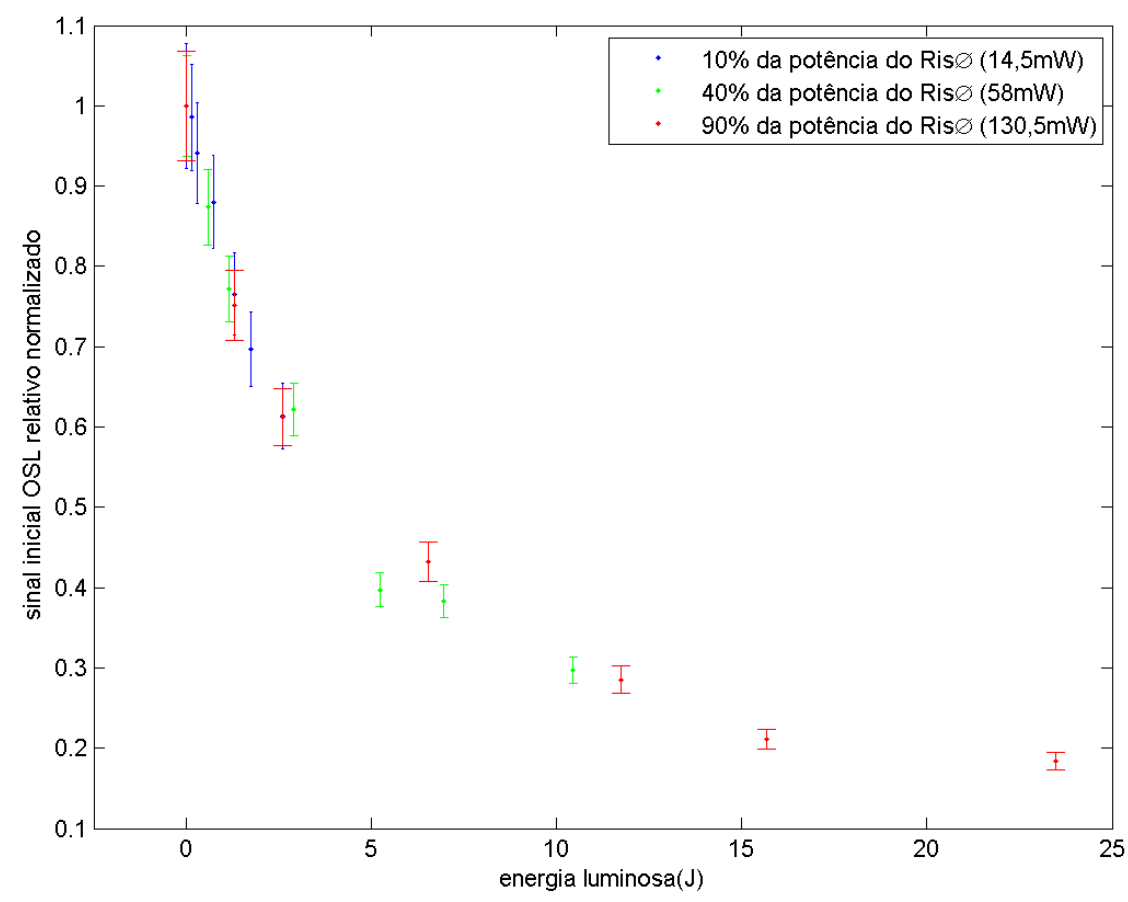

Figura 56. Variação do sinal inicial OSL relativo normalizado ao primeiro ponto das amostras de fluorita iluminadas por LED de $870 \mathrm{~nm}$ e potências de 14,5; 58 e 130,5 mW em função da energia luminosa incidente nas mesmas.

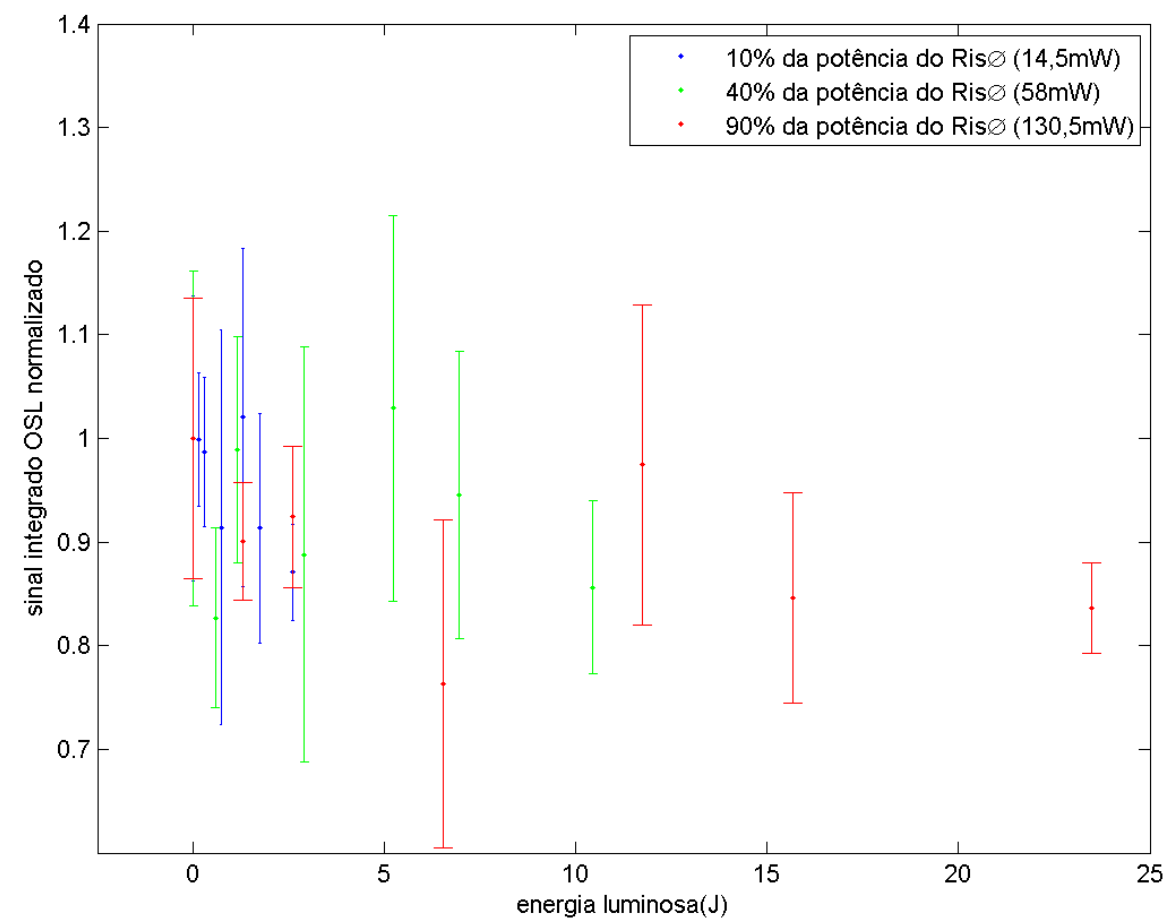

Figura 57. Variação do sinal integrado OSL das amostras de fluorita iluminadas por LED de $870 \mathrm{~nm}$ e potências de 14,5; 58 e 130,5 mW em função da energia luminosa incidente nas mesmas. 


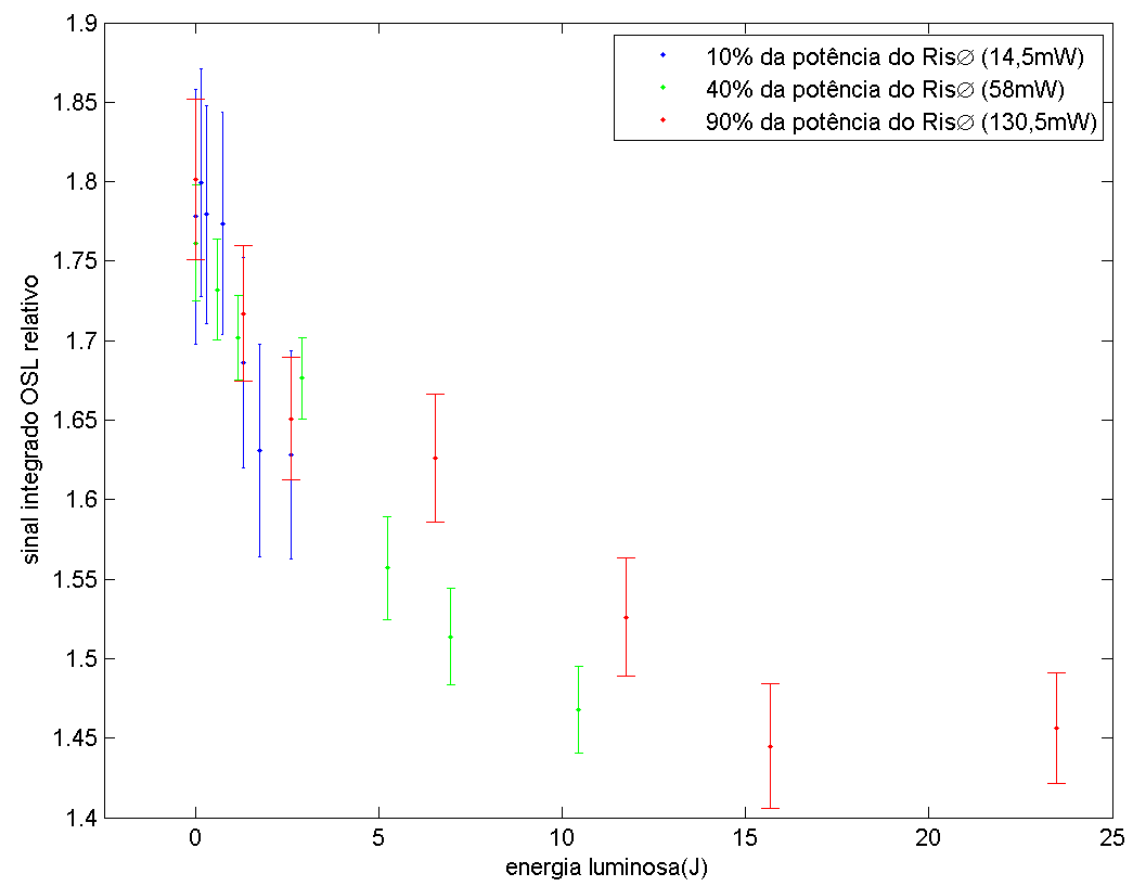

Figura 58. Variação do sinal integrado OSL relativo das amostras de fluorita iluminadas por LED de 870 nm e potências de 14,5; 58 e 130,5 mW em função da energia luminosa incidente nas mesmas.

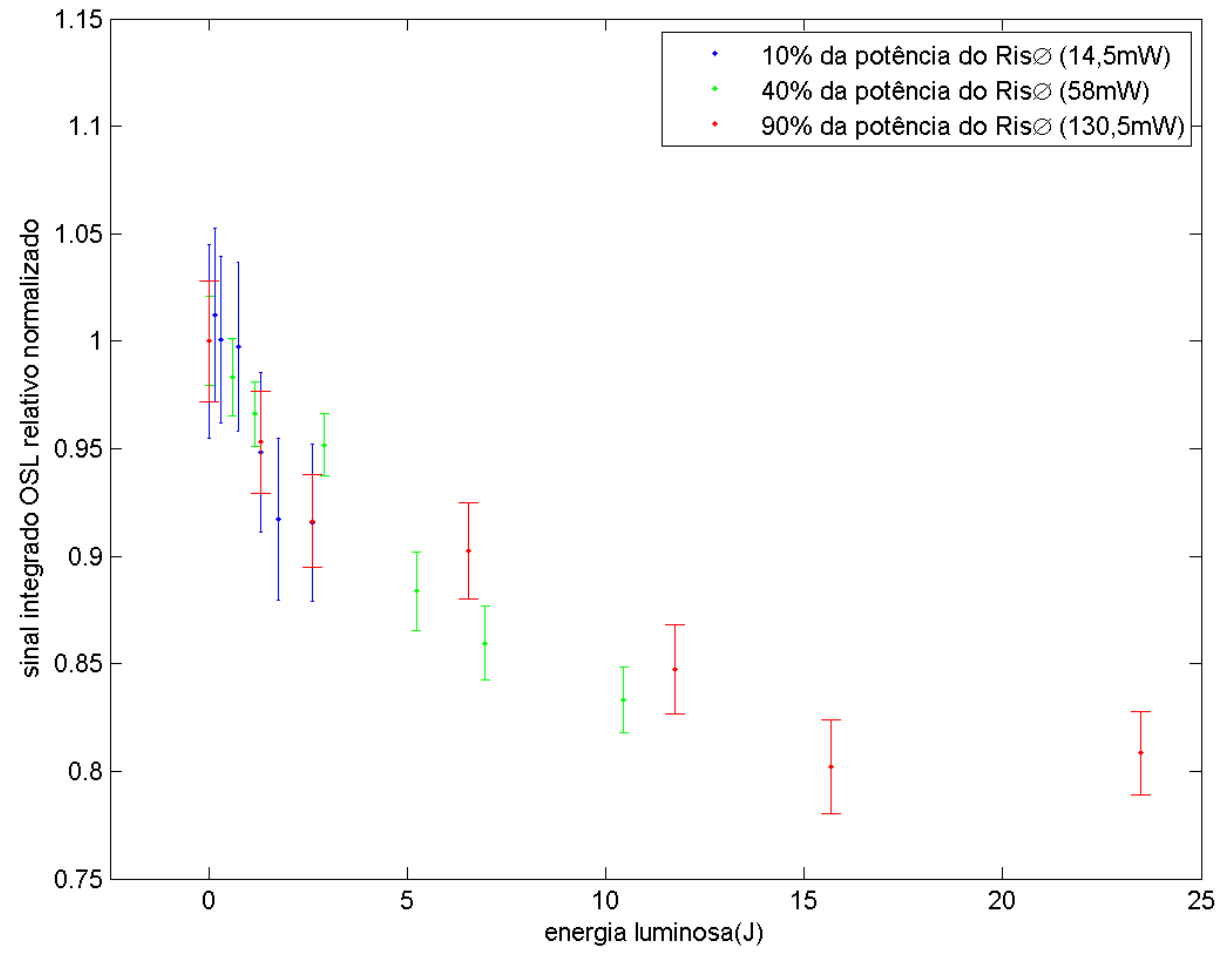

Figura 59. Variação do sinal integrado OSL relativo normalizado ao primeiro ponto das amostras de fluorita iluminadas por LED de $870 \mathrm{~nm}$ e potências de 14,5; 58 e 130,5 mW em função da energia luminosa incidente nas mesmas. 
Os resultados demonstram que, em alguns casos, o sinal OSL das amostras de fluorita é modificado pela iluminação das amostras com LED de $870 \mathrm{~nm}$. O sinal inicial OSL decai 70\% para energia luminosa incidente de até $24 \mathrm{~J}$ (Figura 54). O sinal inicial OSL relativo decai $80 \%$ para energia luminosa de até $24 \mathrm{~J}$ (Figura 56). $O$ sinal integrado OSL não demonstrou tendência de decaimento, de acordo com a faixa de incertezas obtidas (Figura 57). O sinal integrado OSL relativo apresentou uma queda de $20 \%$ para energias luminosas de até 24 J (Figura 59).

\subsubsection{Estudo do formato das curvas de emissão OSL para as amostras de Óxido de Alumínio e Fluorita}

Foi feito um estudo sobre a influência da iluminação no formato das curvas de emissão OSL das amostras de óxido de alumínio e fluorita. O óxido de alumínio era iluminado com laser de 658 nm e os resultados estão nas Figura 60, Figura 61, Figura 62 e Figura 63

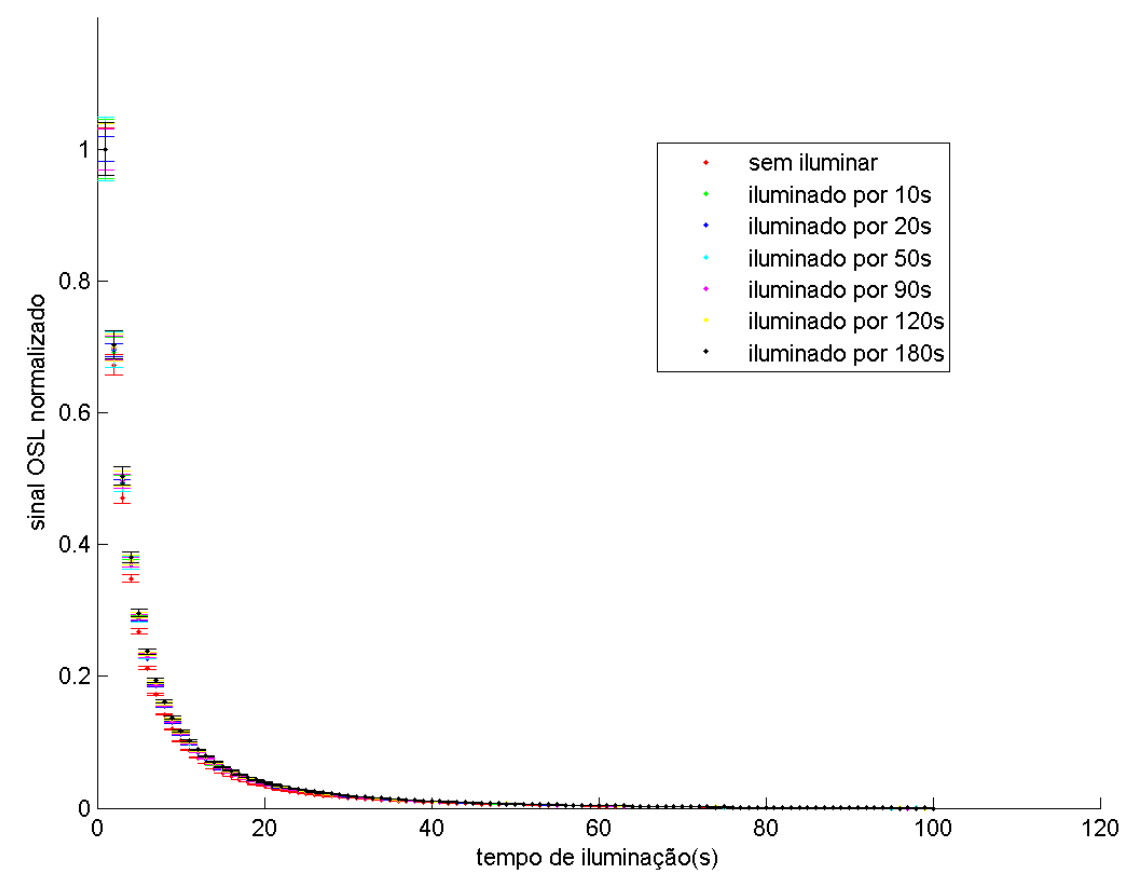

Figura 60. Curvas OSL das amostras de óxido de alumínio iluminadas previamente por laser de 658nm e potência de $10 \mathrm{~mW}$ com os tempos descritos na legenda. 


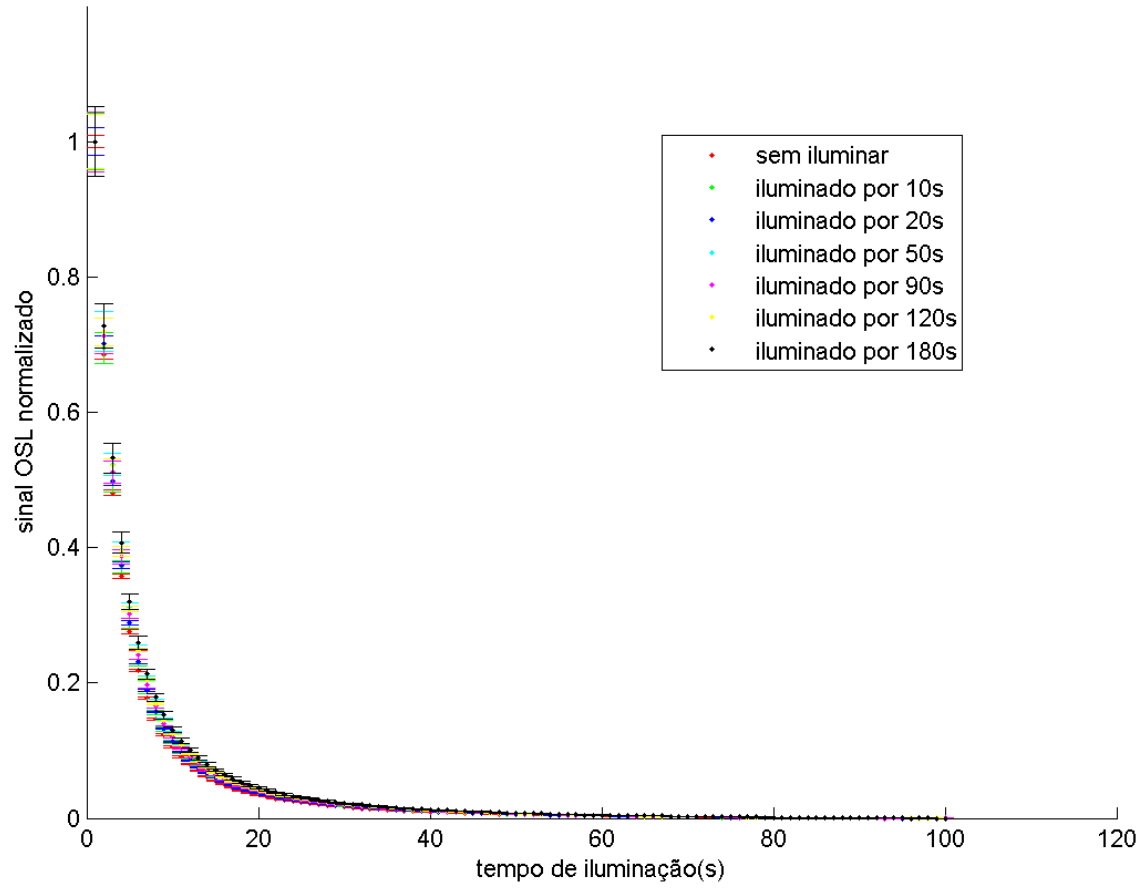

Figura 61. Curvas OSL das amostras de óxido de alumínio iluminadas previamente por laser de 658nm e potência de $20 m W$.

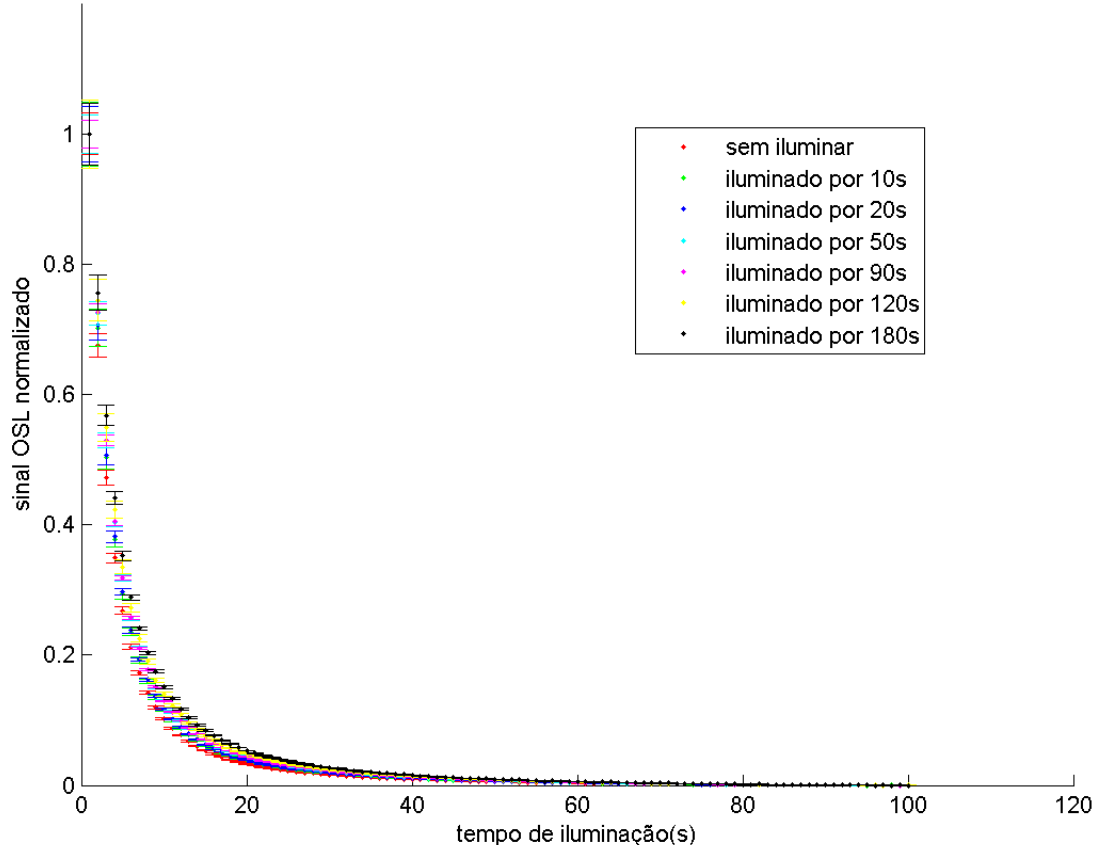

Figura 62. Curvas OSL das amostras de óxido de alumínio iluminadas previamente por laser de 658nm e potência de $50 \mathrm{~mW}$ 


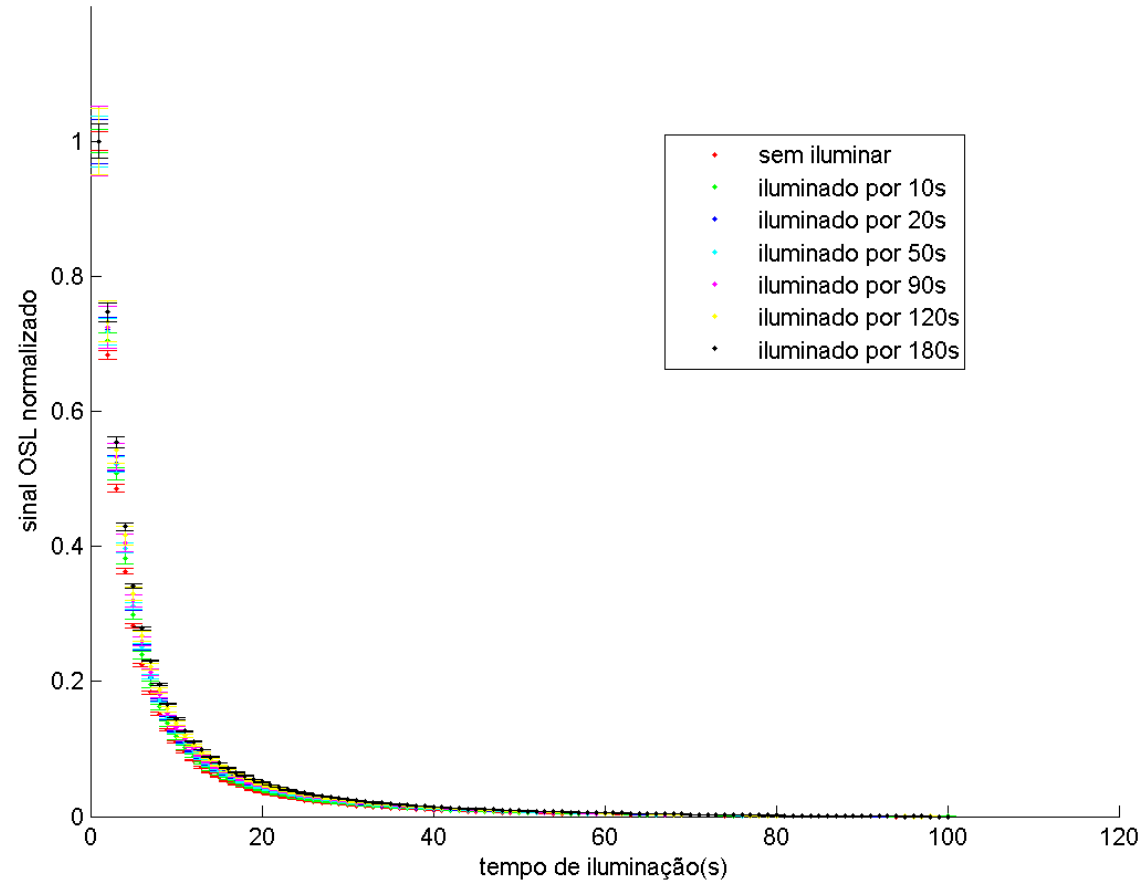

Figura 63.. Curvas OSL das amostras de óxido de alumínio iluminadas previamente por laser de 658nm e potência de $100 \mathrm{~mW}$.

Com estes resultados não se verificou uma mudança no formato da curva OSL das amostras de óxido de alumínio iluminadas com laser de $658 \mathrm{~nm}$, dentro das incertezas do experimento.

As amostras de fluorita foram iluminadas com LED de $870 \mathrm{~nm}$ e os resultados encontrados são mostrados nas Figura 64, Figura 65 e Figura 66. 


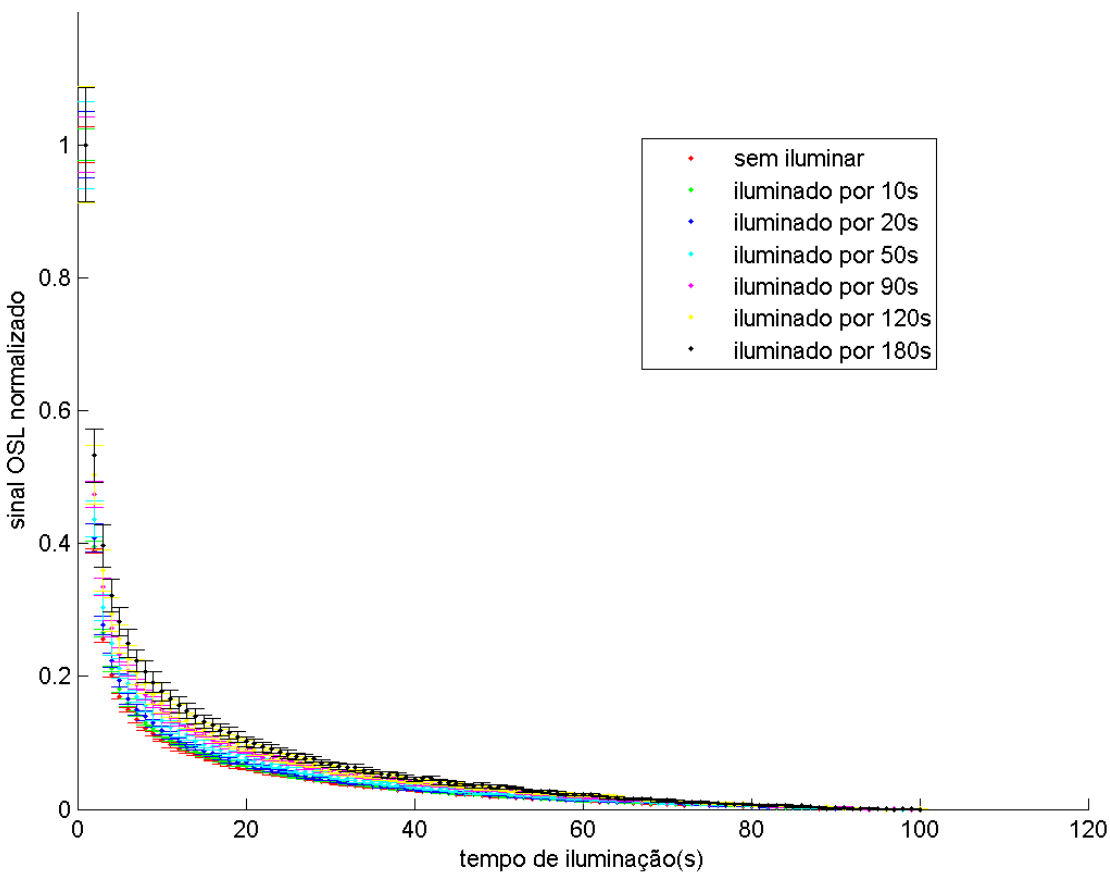

Figura 64. Curvas OSL das amostras de fluorita iluminadas previamente por LED $870 \mathrm{~nm}$ e potência de $14,5 \mathrm{~mW}$.

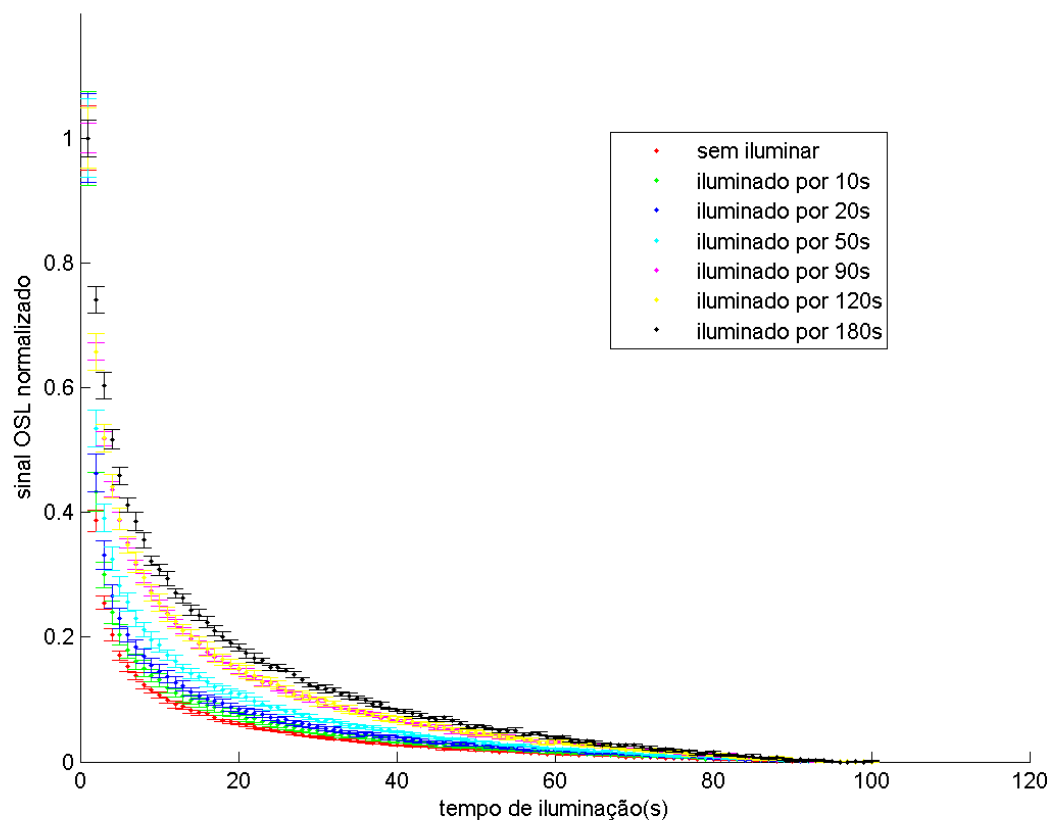

Figura 65. Curvas OSL das amostras de fluorita iluminadas previamente por LED $870 \mathrm{~nm}$ e potência de $58 \mathrm{~mW}$. 


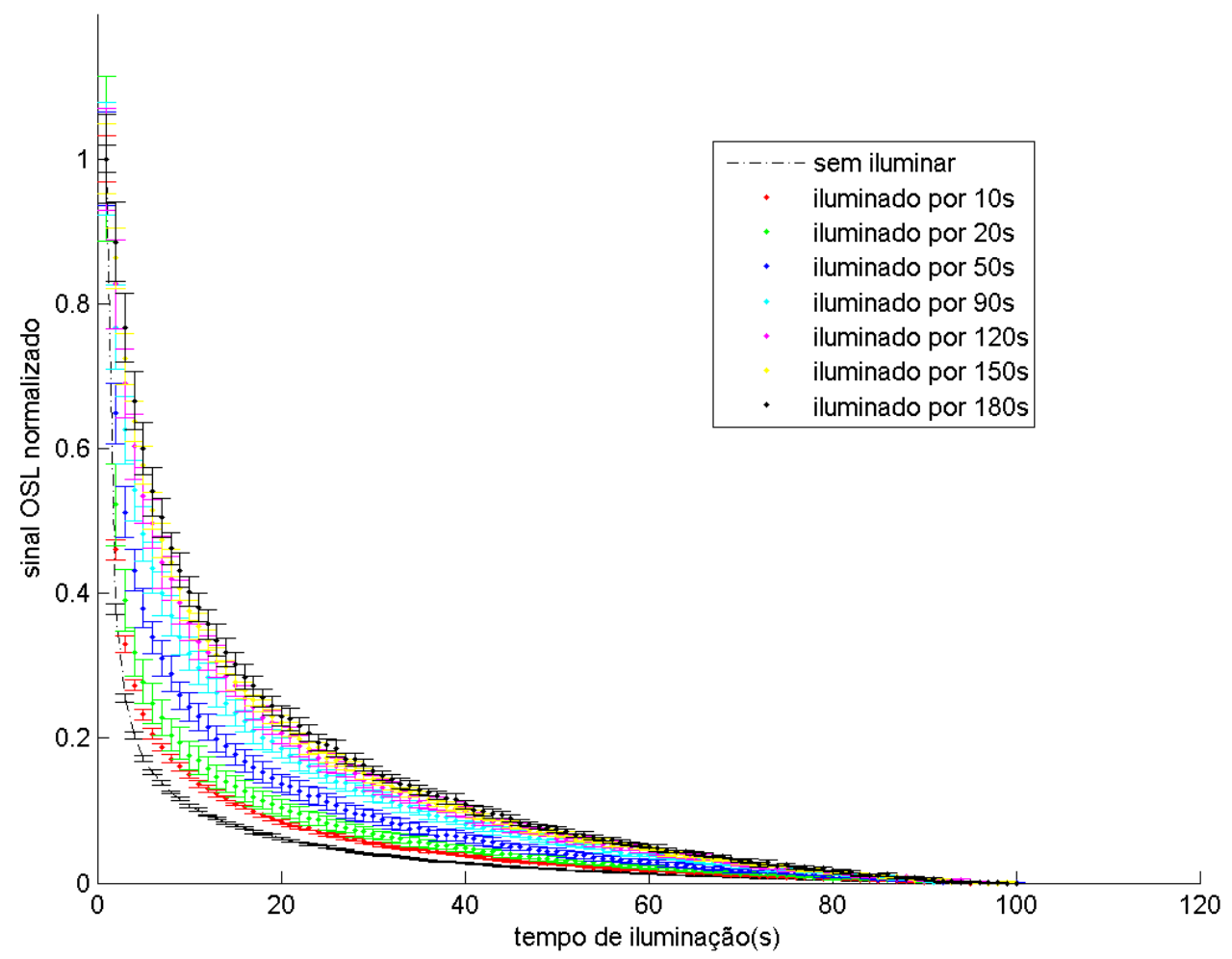

Figura 66. Curvas OSL de amostras de fluorita iluminadas previamente por LED $870 \mathrm{~nm}$ e potência de 130,5 mW.

Para a fluorita iluminada com LED de 870 nm observou-se uma influência da iluminação no formato das curvas OSL.

Complementamos esses resultados comparando as curvas OSL de dosímetros que foram iluminadas e receberam a mesma energia luminosa, mas com potências luminosas diferentes. $O$ intuito é verificar se a incidência de uma mesma energia luminosa nas amostras, variando os parâmetros de potência e tempo de iluminação alterariam o formato das curvas OSL das amostras. Isto foi feito para o óxido de alumínio iluminado com laser de $658 \mathrm{~nm}$ e para a fluorita iluminada com LED de 870 nm e parte dos resultados são mostrados nas Figura 67 e Figura 68. 


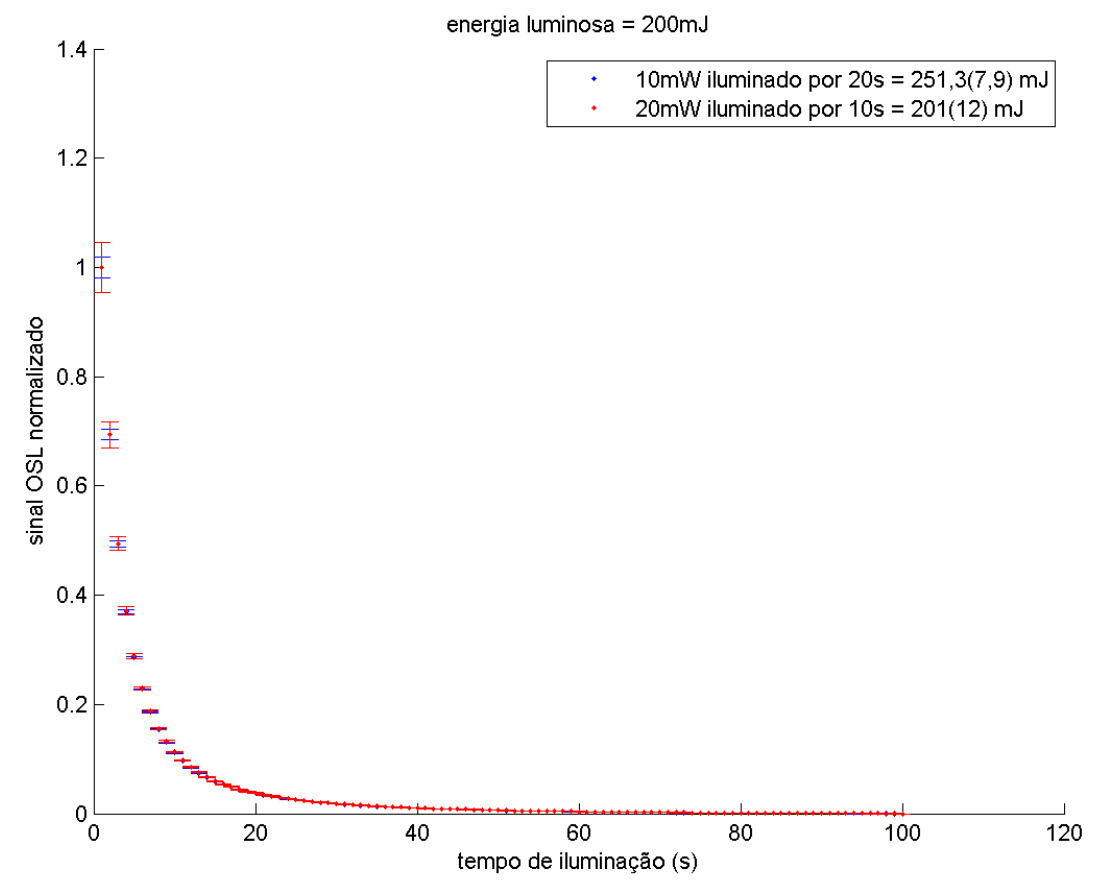

Figura 67. Curva OSL das amostras de óxido de alumínio iluminadas com mesma energia, mas potências e tempos de iluminação diferentes.

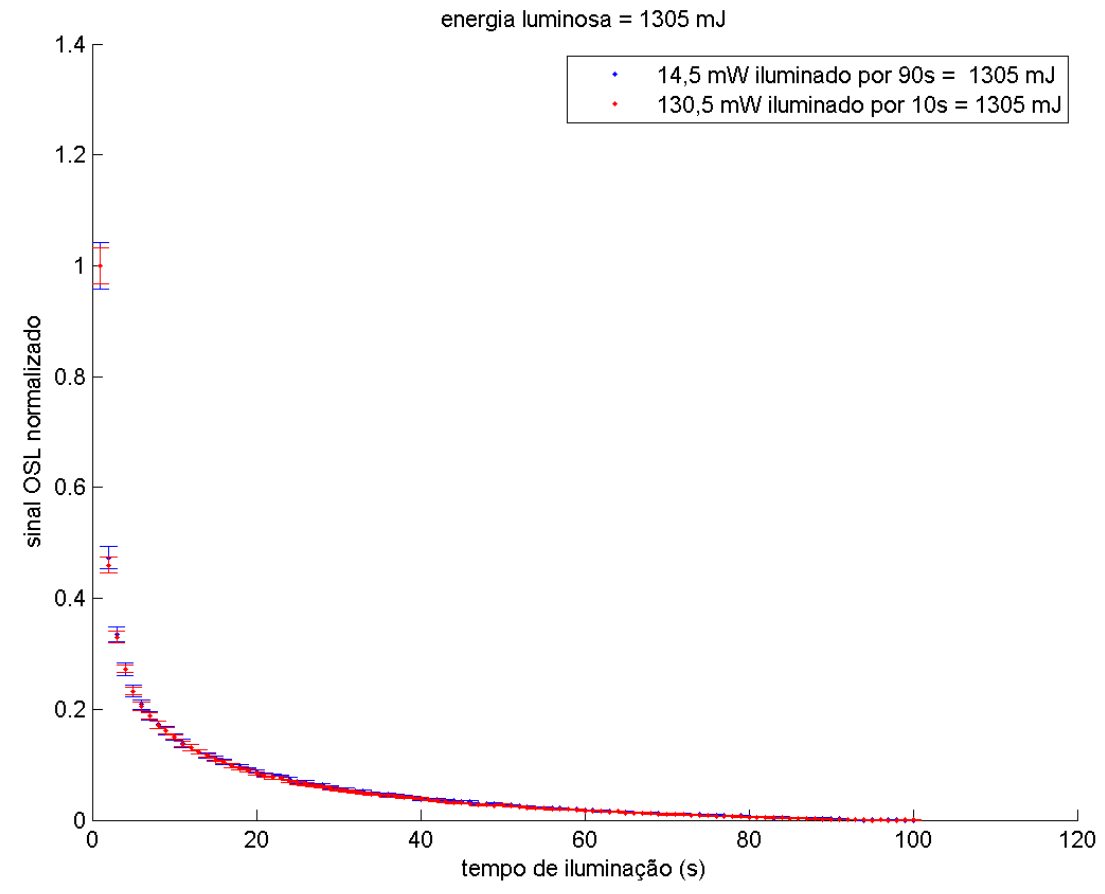

Figura 68. Curva OSL das amostras de fluorita iluminadas com mesma energia, mas potências e tempos de iluminação diferentes 
Os resultados mostram que o mesmo formato da curva de emissão é obtido para as diversas iluminações com mesma energia luminosa, independente da potência. Este fato foi verificado para as amostras de óxido de alumínio e fluorita. 


\section{DISCUSSÃO DOS RESULTADOS E CONCLUSÕES}

\section{1 Óxido de alumínio}

Segundo os resultados observados nas Figura 23, Figura 24, Figura 25, Figura 26, Figura 27 e Figura 28, os sinais OSL inicial e integrado do óxido de alumínio são influenciados pela iluminação com laser de $658 \mathrm{~nm}$. Comparando as duas formas de análise dos sinais OSL verificamos que para o sinal inicial o decaimento é mais proeminente, variando $40 \%$ do sinal devido ao primeiro ponto, enquanto o sinal integrado varia cerca de $28 \%$ para a energia luminosa incidente de aproximadamente $13 \mathrm{~J}$. Estes resultados mostram que o óxido de alumínio pode ser um promissor material para a identificação da energia luminosa devido a laser de $658 \mathrm{~nm}$ incidente no mesmo.

Para a iluminação com LED de $870 \mathrm{~nm}$ não é possível observar mudanças nos sinais OSL, inicial e integrado, do óxido de alumínio. Segundo os resultados das Figura 29 a Figura 34 e, apesar de uma aparente queda para o sinal OSL relativo (Figura 30, Figura 31, Figura 33 e Figura 34) as incertezas são grandes o suficiente para que não se consiga concluir precisamente se o sinal OSL é realmente influenciado pela iluminação da amostra. Não foram feitos experimentos com outras potências luminosas pois a potência utilizada neste experimento $(130,5 \mathrm{~mW})$ era a mais alta fornecida pelo equipamento. Com isso, não era possível se obter energias luminosas maiores devido a mudança da potência e, com o resultado encontrado, energias luminosas mais baixas não afetariam o material.

\section{2 Óxido de berílio}

Para o óxido de berílio tanto o sinal OSL, inicial e integrado, não mostraram influência alguma da iluminação com laser de $658 \mathrm{~nm}$ e com LED de $870 \mathrm{~nm}$. Estes resultados mostram que o sinal OSL de amostras de óxido de berílio não é influenciado pela iluminação com laser de $658 \mathrm{~nm}$ e LED de $870 \mathrm{~nm}$. É possível que o mesmo seja influenciado por luz de outros comprimentos de onda, no entanto, por causa destes resultados, o mesmo não seria uma alternativa para a medição de energia luminosa com estas fontes. Os resultados estão expostos na Figura 35 a Figura 42.

\subsection{Fluorita}


Inicialmente, com os resultados encontrados para a fluorita verificamos que o fading dela pode influenciar de forma relevante os resultados de medidas de sinal OSL. Como pode ser notado nos gráficos das Figura 43 a Figura 45, o sinal inicial OSL não varia significativamente com o tempo de espera no escuro (no ajuste, o coeficiente angular é compatível com zero). No entanto, o sinal inicial OSL relativo varia de maneira considerável com o tempo de espera, crescendo para os instantes de iluminação até aproximadamente $20 \mathrm{~s}$. Isso se deve ao fato do sinal OSL relativo ser a divisão dos sinais iniciais OSL depois da primeira irradiação (de $5 \mathrm{~s}$ ) e depois da segunda irradiação (de $2 \mathrm{~s}$ ) e, os tempos de espera da irradiação até o sinal OSL da amostra ser lido não são os mesmos nas duas situações. A Tabela 4 e a Figura 46 evidenciam esta diferença. Essa diferença explica o fato do sinal OSL relativo aumentar nos instantes iniciais. Para melhorar a precisão em medidas com a amostras de fluorita é necessário se avaliar o efeito do fading, e descontar ele do sinal OSL da amostra ou esperar para se realizar as leituras OSL depois que o sinal OSL se estabilize e o fading da amostra não for relevante. $O$ mesmo ocorre para o sinal integrado OSL, como é mostrado na Figura 47 a Figura 49.

Para as amostras de fluorita iluminadas com laser de $658 \mathrm{~nm}$ o sinal OSL mostrou uma tendência de decaimento (resultado nas Figura 50 a Figura 53). O sinal inicial OSL chega a decair cerca de $60 \%$ do primeiro ponto para energias de aproximadamente $2 \mathrm{~J}$ e $85 \%$ para o sinal inicial OSL relativo no mesmo intervalo de energia. No entanto, ele decai fortemente para as energias luminosas mais baixas. Para uma energia incidente maior do que aproximadamente $4 \mathrm{~J}$, o sinal OSL aparenta não ser mais influenciado pela iluminação. Estes resultados mostram que as amostras de fluorita não são um bom material para a medição da energia luminosa incidente nelas proveniente de laser de $658 \mathrm{~nm}$. Isto é devido a queda abrupta do sinal OSL para as energias luminosas mais baixas (até $2 \mathrm{~J}$ ) e a constância do sinal OSL para as energias maiores. Um sinal com decaimento mais comportado é melhor para a estimativa das energias em função da diminuição do sinal OSL.

Os resultados para os experimentos com as amostras de fluorita iluminadas com LED de $870 \mathrm{~nm}$ mostraram que o sinal OSL é modificado pela iluminação. Para o sinal inicial OSL (nas Figura 54 a Figura 56) há uma variação de cerca de $70 \%$ para uma iluminação com aproximadamente $25 \mathrm{~J}$ de energia. Para o sinal inicial OSL relativo a variação é de $80 \%$ no mesmo intervalo de energia. No entanto, o sinal integrado OSL (Figura 57) aparentemente não é afetado pela iluminação. $O$ sinal integrado OSL relativo mostra uma tendência maior de queda com a iluminação (Figura 58 e Figura 59) quando comparado com a curva anterior. Estes resultados mostram que a fluorita pode ser um promissor material para a medição da energia luminosa proveniente de LED de $870 \mathrm{~nm}$ com intervalo de energia luminosa de 0 a $24 \mathrm{~J}$.

\subsection{Modificação nas curvas OSL}

Com os resultados anteriores, observou-se que as amostras mais promissoras para a análise de uma iluminação com laser de $658 \mathrm{~nm}$ e LED de $870 \mathrm{~nm}$ eram o óxido de alumínio e a fluorita, respectivamente. A Figura 60 a Figura 63 mostram a curva OSL do óxido de alumínio normalizada ao primeiro ponto, lida após a iluminação das amostras com o laser de $658 \mathrm{~nm}$ por diversas potências. Não podemos concluir que ocorre uma mudança no formato da curva OSL, dentro das incertezas do experimento. No entanto, para a fluorita (Figura 64 a Figura 66) é possível se 
notar uma mudança no formato da curva OSL. Nesse caso, as amostras iluminadas por mais tempo apresentavam uma curva OSL que decai mais lentamente, quando comparada com as outras.

A hipótese para estes resultados é que as amostras de fluorita apresentam um conjunto de estados armadilhados previamente cheios e na iluminação ocorre um esvaziamento parcial das armadilhas, somente as relacionadas com a energia luminosa dos fótons do LED de $870 \mathrm{~nm}$. Este esvaziamento esgota parte do sinal da amostra, a parte relacionada as armadilhas com a energia de ativação do LED de $870 \mathrm{~nm}$, e, na leitura OSL posterior, o sinal OSL decai mais lentamente do que quando ele não foi iluminado. No caso da fluorita, o sinal inicial OSL é mais influenciado pela iluminação com $870 \mathrm{~nm}$ que o sinal integrado: somente a parte inicial do sinal de emissão OSL é fortemente afetada por essa iluminação. Isto pode ser devido ao número de elétrons armadilhados nos estados afetados pela iluminação ser bem menor do que os nos outros estados. As amostras de óxido de alumínio provavelmente não apresentam um conjunto de armadilhas rasas e a iluminação com $658 \mathrm{~nm}$ não esvazia as armadilhas distintas de forma diferente.

Com uma iluminação das amostras com mesma energia luminosa (Figura 67 e Figura 68) não foi observada nenhuma alteração na sua curva OSL, quando se variou a potência com a qual as iluminações foram feitas. Isso evidencia que o desarmardilhamento dos estados aparenta estar relacionada com a energia luminosa incidente neles.

\subsection{Conclusões Finais:}

Verificamos que a técnica OSL poderia, conceitualmente, ser empregada para avaliar energias luminosas empregadas na Terapia com Laser de Baixa Intensidade. Dosímetros OSL irradiados com radiação beta tem o seu sinal OSL diminuído de maneira sistemática por terem sido iluminados com laser de $658 \mathrm{~nm}$ ou com LED de $870 \mathrm{~nm}$. A variação do sinal permite a quantificação da energia luminosa incidente.

Especificamente, pudemos observar que 0 dosímetro composto por $\mathrm{Al}_{2} \mathrm{O}_{3}: \mathrm{C}$ (comercialmente conhecido como Luxel) permitiria a avaliação de energias luminosas entre $\sim 0,1$ e $12 \mathrm{~J}$ para luz laser de $658 \mathrm{~nm}$, empregando tanto o sinal inicial como o sinal integrado. Outro material OSL, a fluorita natural, permite avaliar energias luminosas entre $\sim 0,1 \mathrm{e} \sim 15 \mathrm{~J}$ para luz de $870 \mathrm{~nm}$.

Além disso, a curva de emissão OSL da fluorita é modificada em sua forma, pela iluminação com luz de 658 ou $870 \mathrm{~nm}$. Possivelmente uma quantificação dessas mudanças de formato pode complementar a determinação de energias luminosas com esse material.

Estudos complementares podem modificar as faixas de energia aqui apresentadas, com mudanças, por exemplo, na dose de radiação beta empregada para irradiar os materiais. 


\section{OBRAS CITADAS}

Akselrod, M. S., Kortov, V. S., \& Gorelova, E. A. (1993). Preparation and properties of alphaAl2O3:C. Radiation Protection Dosimetry, 47, pp. 159-164.

Bibiano, J. A. (2015). Estudo das Propriedades Luminescentes da Fluorita. Dissertação (Mestrado em Física). 113 f - Universidade Federal de Pernambuco, Recife, PE.

Bos, A. J. (2001). High sensitivity thermoluminescence dosimetry. Nuclear Instruments and Methods in Physics Research B, 184, pp. 3-28.

Botter-Jensen, L., McKeever, S. W., \& Wintle, A. G. (2003). Optically Stimulated Luminescence Dosimetry (Vol. 1). Amsterdam, Holanda: Elsevier Science.

Bulur, E., \& Göksu, H. Y. (1998). OSL From BeO Ceramics: New Observations From An Old Material. Radiation Measurements, 29(6), 639-650.

Bulur, E., \& Yeltik, A. (2010). Optically stimulated luminescence from BeO ceramics: An LM-OSL study. Radiation Measurements, 45, pp. 29-34.

Chavantes, M. C. (2009). Laser em Bio-Medicina: Princípios e Prática - Guia para Iniciante, Pesquisadores e Discentes na Área de Saúde e Exatas. São Paulo: Atheneu.

Chougaonkar, M. P., \& Bhatt, B. C. (2004). Blue Light Stimulated Luminescence in Calcium Fluoride, Its Characteristics and Implications in Ratiation Dosimetry. Radiation Protection Dosimetry, 112, pp. 311-321.

Chung, H., Dai, T., Sharma, S. K., Huang, Y., Carroll, J. D., \& Hamblin, M. R. (2012). The Nuts and Bolts of Low-level Laser (Light) Therapy. BMES - Biomedical Engineering Society, 40(2), 516-533.

Grimadova, T. I., Bessonova, T. S., Tale, I. A., Avvakumova, L. A., \& Bodyachevsky, S. V. (1990). On the thermoluminescence mechanism of non-doped corundum monocrystals with defect structure. Radiation Protection Dosimetry, 33, pp. 47-50.

Huang, Y. Y., Chen, A. C.-H., Carrol, J. D., \& Hamblin, M. R. (2009). Biphasic Dose Response In Low Level Light Therapy. Dose Response. 7:358-383.

Huang, Y., Chen, A. C.-H., \& Hamblin, M. (2009). Low-level laser therapy: an emerging clinical paradigm. SPIE. DOI: 10.1117/2.1200906.1669

Kittel, C. (2006). Introdução a Física do Estado Sólido. (R. S. Biasi, Trad.) Rio de Janeiro: LTC.

Malthez, A. L. (2015). Desenvolvimento e caracterização de dosímetros ara monitoramento individual de trabalhadores ocupacionalmente expostos à radiação combinando as técnicas de termoluminescência (TL) e luminescência opticamente estimulada (OSL). Tese (Doutorado em Física) - UNICAMP. Campinas, SP.

McKeever, S. M. (2001). Optically stimulated luminescence dosimetry. Nuclear Instruments and Method in Physics Research B, 184, pp. 29-54. 
McKeever, S. W., Moscovitch, M., \& Townsend, P. D. (1996). Thermoluminescence Dosymetry Materials: Properties and Uses. Radiation Protection Dosimetry, 65, pp. 267-272.

Niemz, M. H. (2004). Laser-Tissue Interactions: Fundamentals and Applications. Heidelberg: Springer.

Okuno, E., \& Watanabe, S. (1972). U. V. Induced Thermoluminescence on Natural Calcium Fluoride. Health Physics, 23, 377-382.

Okuno, E., Umisedo, N. K., Cancio, F. S., Aldred, M. A., \& Yoshimura, E. M. (2015). Thirty Five Years of Occupational Individual Monitoring at University of São Paulo. International Conference on Individual Monitoring of lonizing Radiation. Bruges.

Riso DTU. (2010). Guide to "The Riso TL/OSL Reader". Denmark.

Sommer, M., \& Henniger, J. (2006). Investigation of a BeO-based Optically Stimulated. Radiation Protection Dosimetry, 119(1-4), pp. 394-397.

Trzesniak, P., Yoshimura, E. M., Cruz, M. T., \& Okuno, E. (1990). Brazilian Fluorite-Based Dosimetric Pellets: History and Post-Use Review. Radiation Protection Dosimetry, 34(1/4), 167-170.

Whitley, V. H., \& McKeever, S. W. (1999). Photoionisation of deep center in $\mathrm{Al}_{2} \mathrm{O}_{3}$. Journal of Applied Physics, 87, pp. 249-256.

Yoshimura, E. M., \& Yukihara, E. G. (2006). Optically Stimulated Luminescence: Searching for New Dosimetric Materials. Nuclear Instruments and Methods in Physics Research B, 250, 337-341.

Yukihara, E. (2011). Luminescence properties of BeO optically stimulated luminescence (OSL). Radiation Measurements, 46, pp. 580-587.

Yukihara, E. G., \& McKeever, S. W. (2011). Optically Stimulated Luminescence. Oklahoma, USA: John Wiley \& Sons Ltd. 